\title{
International Student Retention and Recruitment: An Empirical Study in Denmark
}

\author{
by
}

Alexandra Dauncey-Elwood

A thesis submitted to the Faculty of Graduate and Postdoctoral Affairs in partial fulfillment of the requirements for the degree of

\author{
Master of Arts \\ in \\ Political Science
}

Carleton University

Ottawa, Ontario

(C) 2019

Alexandra Dauncey Elwood 


\begin{abstract}
Currently, there are pronounced knowledge gaps on how countries can effectively recruit and retain international students for domestic innovation and growth, and how policies, initiatives, and immigration programs can be designed to actively encourage and assist in the global race for talent. This research analyzes what factors influence international students' decision to remain in Denmark and how stakeholders (businesses, universities and government) are able to recruit and retain international students and international talents, more generally. Twelve weeks of field research was conducted in Denmark, which included thirty-one interviews. This research combines intersectional feminist institutionalism and actor-centered institutionalism to offer insights into how Danish institutions currently support and/or hinder the ability for stakeholders to recruit and retain international students. Four main themes emerge as specific avenues for Denmark to focus their future policies and initiatives on to best recruit and retain international students and top talent.
\end{abstract}




\title{
Acknowledgements
}

\author{
"Sometimes I will start a sentence and don't even know where it is going, I just \\ hope to find it along the way" \\ - Michael Scott, The Office
}

\author{
"It is handled" \\ - Olivia Pope, Scandal
}

Thank you to all the wonderful people who have supported me throughout this process. I am especially grateful to my supervisor, Professor Martin Geiger, for the opportunity to research such an innovative topic and for the insightful feedback. Thank you to my hosts at Roskilde University in Denmark, Professor Shahamak Rezaei and Birte Hansen. Further, thank you to all interview participants for allowing me the chance to hear your insights and experiences. I would also like to thank Carleton University's Political Science department, especially Brookes Fee, and all my committee members for their immense efforts. I am grateful for financial support from Mitacs, Centre for European Studies, and the Ontario Early Researcher Award.

This thesis could not have been possible without the ongoing support and encouragement from my friends and family in Ottawa and in B.C. Thank you to my parents and sister who have always supported me, your work effort and passion constantly inspires me. I would also like to thank the staff at the B.C. Ministry of Education for fostering my passion for international education. 


\section{Table of Contents}

Abstract $\quad$ i

Acknowledgments $\quad$ ii

Table of Contents $\quad$ iii

Introduction 1

Section One: Mobility for Innovation - International Student Mobility 5

Section Two: Intersectional Feminist and Actor-Centered Institutionalist 36

Perspective of International Student Mobility

Section Three: Qualitative Research Methods $\quad 47$

Section Four: Context - Denmark’s Institutional Environment 59

Section Five: Stakeholder and International Student Findings $\quad 78$

Section Six: Analysis of Interviews and Four Main Themes 102

$\begin{array}{ll}\text { Conclusion } & 127\end{array}$

Works Cited $i$

Annex 1: List of Interviews $\quad$ XX

Annex 2: Interview Guide: Stakeholder xxi

Annex 3: Interview Guide: International Student xxiii

Annex 4: International Student Questionnaire xxiv 


\section{Introduction}

International student mobility has been significantly increasing for the past twenty years, with now more than 5 million students studying outside their home country (IIE 2018). In Denmark, between 2007 and 2012, the number of international students studying at a Danish university doubled to 22,000 (Study in Denmark 2018b). International student mobility is expanding beyond the traditional dominance of a few host countries, such as the United States or the United Kingdom (Altbach and Knight 2007; Bhandari and Blumenthal 2011). More countries than ever before are involved in sending and hosting a greater diversity of students. The skills and knowledge students learn through international education are no longer luxuries but vital to students' future career, state economic competition, and global innovation (Bergerhoff et al 2013; Uof T and Uof O 2018). There are emerging links between the migration of people, perspectives, and knowledge, and the increase of innovative products, solutions, and initiatives (Porter 1998; Shachar 2013; Czaika and Parsons, 2016). However, there is limited research on the challenges and hurdles international students' encounter transitioning to post-graduate work in host countries. There is also a knowledge gap in how stakeholders - government, businesses, organizations, and universities - are able to develop effective and inclusive strategies and initiatives to retain innovative and highly mobile students once they complete their studies. Furthermore, current literature overlooks how international students and stakeholders are shaped by institutions and how they, as actors, also posses significant agency to influence those institutions.

This research aims to address the initial questions of (1) whether international students studying science and technology are choosing to pursue post-graduate work in Denmark and (2) how stakeholders can, through inclusive strategies, recruit and retain 
these international students upon graduation to foster innovation. Science and technology are increasingly important in the global economic competitiveness and innovative growth, therefore more attention is being paid to these industries, especially when domestic talent is no longer sufficient (Bilimora et al 3). However, the literature relating to innovation, migration, and science and technology often overlook intersectional biases that are often reproduced. By drawing on intersectional feminist institutionalism and actor-centered institutionalism, this research will offer insights into (3) what barriers and challenges international students encounter when transitioning into post-graduate work in Denmark. Interviewing international students is intended to answer specific questions regarding what factors international students consider when choosing where to study, what challenges they face, and where current initiatives have been successful in their own recruitment and retention. Furthermore, elite stakeholder interviews will develop insights into what successful policies and initiatives stakeholders - government, businesses, organizations, and universities - have in recruiting highly skilled international talent and what hurdles still remain.

Additionally, this research will contribute to the academic and policy literature on innovation and migration by developing an empirical study in an under-researched area of international student mobility (Bhandari and Blumenthal 2010; Wildasky 2010). This research is also significant as it utilizes intersectional feminist institutionalism (Mackay and Waylen 2009; Waylen 2009; Krook and Mackay 2011) and actor-centered institutionalism (Scharpf 1997). The joining of these two theories allows for critical engagement on how institutions and the actors within them are shaped by and can perpetuate biases. This is especially important as the science and technology fields greatly underrepresent women, and international student mobility is imbedded with racial, cultural, 
and class power dynamics. While the empirical research focuses on Denmark, the findings are intended to apply, in part, to a larger audience of international actors, including states, businesses, and universities.

Denmark, a country of 5.6 million people, hosts around 22,000 international students annually (Statistics Denmark 2018a). This is about twice the Organisation for Economic Cooperation and Development (OECD) average and two percent higher than the European Union (EU) average (11\% and 9\% respectively) (OECD 2018). Denmark is an EU Innovation Leader and is excelling in areas of research and development funding and support for entrepreneurship (European Commission 2015; Woodside et al 2016). Recently though, the Danish government announced the reduction of international students by 1,000, bringing the debate of international education to the forefront of society (Gadd 2018b). Overall, Denmark is a tolerant and accepting society particularly in areas of gender equality and LGBTQ rights, however through the rise of the Danish People's Party - a far right, Eurosceptic party - immigration policies and processes have been increasingly restrictive, making Denmark a juxtaposing case study.

The thesis provides the (1) theoretical and conceptual background to understanding the interplay between innovation, mobility, and international student mobility, while highlighting where the discrepancies in each theoretical concept are. Next, this thesis develops (2) intersectional feminist and actor-centered institutionalism as the theoretical framework to critically engage with the recruitment and retention strategies of institutions and actors. After (3) methodology of the empirical study is developed, (4) Danish institutions and relevant background will be contextualized. Then (5) findings from stakeholder interviews, and international student interviews will be descripted. Lastly, (6) the four main themes that developed will be analyzed. This includes insights into initial 
recruitment and retention strategies Danish institutions and actors can employ to best transition international students into post-graduate work. In conclusion, future areas of research are explored. 


\section{Section One: Mobility for Innovation - Increasing International Student Mobility}

\subsection{Significance of Increasing Mobility and Innovation}

Domestic talent, due to the changing needs of global economy, is no longer sufficient to meet labour market demands, nor support growing innovation, which is fueling what governments, industry, and academics are increasingly calling the global race for talent (Shachar 2006; Geddie 2015; Docquier and Machado 2016). Increased efforts are required to attract the best and brightest international talent to states, cities, organizations, and universities. Specifically, there is a now a growing global competition to recruit and retain international students, due to their education, language skills, and, at times, affluence (Bhandari and Blumenthal 2010; Wildasky 2010). International students are also regarded as 'attractive migrants' and typically fall under highly skilled categories, which can facilitate simpler transitions through an immigration system (Arthur and Flynn 223; Scott et al 2015). International education is developing, as Knight (2011) predicts, for three reasons (1) increasing demand for skills supportive of a knowledge-based economy, (2) growing orientation to commodification of education, and (3) increased numbers of students wanting to participate in international education and potential gain international credentials (211). However, there is limited attention given to how stakeholders such as government, businesses, organizations, universities, and public institutions are able to recruit and retain innovative talent, particularly international students (Hemsey-Brown and Oplakta 2006).

Currently, it is difficult to develop inclusive and effective recruitment and retention strategies when data, such as international students' retention rates or what post-graduate pathways international students pursue, are sparse and incomplete (Weisser 28). Countries 
use different statistical methodologies, leading to a lack of comparable data. Briefly, there are a few predicted factors and motivations for indicating if an international student will stay after graduation. In Denmark's largest survey of international students, the government found that the longer international students studied in Denmark the more likely they were to remain upon graduation (Damvad 2013). Other factors influencing students' decisions to remain in Denmark included; satisfaction of education, knowledge of job market, network, and country of origin (Damvad 2013). More recently, Weisser (2016) notes that $\mathrm{PhD}$ students from lower socio-economic classes are more likely to stay upon graduation (31). Female students more often opt to remain in the host country (Vasiljeva, 2014; Weisser 2016). And it is overall predicted that international students in the natural and technical sciences remain more frequently than international students in social sciences (Weisser 31). However, these studies are very broad and simply focus on student motives without offering insights on how to strengthen stakeholders' recruitment and retention practices. Therefore, it is timely to conduct an empirical study into how the factors international students cite for remaining or leaving Denmark can be utilized by stakeholders to strengthen recruitment and retention initiatives.

Additionally, it is essential to conduct research with an intersectional lens as the areas of science and technology, along with migration and student mobility, often overlook the intersection of oppressions such as race, sexuality, gender, class, or age. While this research, at times, focuses more on gendered biases within institutions and actors, racial, class, and other biases are inherent in all institutions and actors. These intersecting identities can significantly influence international students' decisions after graduation. World-wide women only represent $26 \%$ of employees in the STEM fields (World Economic Forum 2018). Currently, more women (50\%) than men (38\%) aged 25-38 are 
university educated, however this does not translate into labour market participation as women are employed $10 \%$ less than men with an income gap of over $26 \%$ percent, despite the same education (OECD 2018). For example, women compromise $20 \%$ of graduates in engineering but only 10\% are working as engineers (World Economic Forum 2018). Only $12 \%$ of female undergraduates are in STEM and only one third find employment within the STEM fields (World Economic Forum 2018). There is a growing base of research on the factors that are constraining women's participation in science and technology industries (Cheryan et al 2011; Bilimora et al 2014; Reilly et al 2017; Wynn and Corell 2018). While this research is not going to offer overarching insights into how to get more women into science and technology, it is taking into account how institutions that often leave women's, and other groups' perspectives out can have significant influence over decisions in postgraduate work and life.

The next section will begin to develop an understanding of how migration can foster increased innovation. Specifically, the section will draw connections between international migration and mobility, and its ability to act as a catalyst for domestic and international innovation, despite an absence of literature. International student mobility is likely an important means of migration for increasing innovation. Furthermore, literature relating to migration, innovation, and international student mobility will be explored to highlight the overarching lack of attention given to the recruitment and retention of international students.

\subsection{Fostering Innovation}

Innovation thrives in creative and diverse settings that can lead to social, technological, political, and economic advances. However, what is innovation? The OECD defines innovation as the: 
"implementation of a new or significantly improved product (good or service), or process, a new marketing method, or a new organisational method in business practices, workplace organisation or external relations" (OECD 2005).

This can be technological advances, public or private policy approaches, or overall social developments, it simply includes a new approach. Take the example of Danish Carpenter, Ole Kirk Christiansen, who took the existing concept of a brick and utilized new resources and knowledge to create, arguably the most innovative toy, LEGO (Robertson, 17). Furthermore, innovation requires the ability to break out of the traditional path - which the Kirk Family did through the utilization of plastic at a time of only wooden toys. Innovation is also crucial for growth and development of a country's economy (Mihi-Ramírez et al 456). Therefore, countries are competing to attract talent to foster increased innovation. While innovation can arise with increased migration, innovation can also be highly attractive for international students and talent (Mihi-Ramírez et al 452). Institutions such as governments, universities, and organizations, can strengthen and hinder innovation. In other words, institutions and the actors within, are agents of innovation. Innovation cannot happen without a conducive institutional environment with effective actors.

\subsection{Innovation Theories}

The first iteration of innovation theory is attributed to Joseph Schumpeter (18831950) and by the 1970's his work on innovation, entrepreneurship, and economics became more widely cited with greater attention given to innovation and the entrepreneur's role in creating innovation, particularly in stimulating economic growth of a state (Sundbo 55). Later, Sweeney (1985) strengthened the support of innovation's role in economic development. However, relevant to the Danish context is Sundbo (1998), a Danish academic, who provides an analysis of innovation at the micro-level through individual 
companies, and at the macro-level decisions, usually made by the state (2). This analysis differs from previous innovation theories, which were often only at the macro-level and highly state centric. Sundbo argues that innovation theory must be understood in three different paradigms, spanning three different time periods, respectively, (1) the entrepreneur, (2) the technology-economic, and (3) the strategic paradigm (26). In other words, innovation theory originated from the individual, was accelerated by large scale industrialization which focused on technological advances, and now focuses on the companies' relationship between the consumer and market (Sundbo 1998). All of these periods are imbedded with various institutions and actors that cultivate innovation. Sundbo concludes his analysis by noting the end goal of innovation is economic and corporate growth.

Sundbo's understanding of innovation theory is highly rooted in the economic value and profits of innovation. In other words, institutions and actors only partake in innovation if there are tangible economic benefits. While innovation can very much still be associated with this today, such as Amazons' innovative business model that took the old mechanism (bookstore) and bridged it with new knowledge (online and underselling), to create an online bookstore with the aim of long-term profits and monopolization of the market. There can also be innovative practices where profit margins are not the end goal. Lifestraw, which filters water immediately through a straw, still makes a profit for their innovative product but the driving force was eradicating water-borne diseases. Therefore, the measures of innovation are not simply economic or profit driven. The changing goals of innovation matches the shift in innovation research. In the last twenty years, more and more literature has been published on innovation from a wider perspective such as, innovation's connection to research and development (Rodríguez-Pose and Crescenzi 
2008; Fagerberg and Srholec 2008), entrepreneurship (Anokhin and Schulze 2009; Dodgson 2011; Woodside et al 2016), innovation policy (Park 2014), management (Manso 2011) and as a apart of the knowledge-based economy (Howlett et al 2012). There is no specific literature relating to innovation that discusses how international human migration and mobility might foster or strengthen innovation.

\subsection{Knowledge-Based Economy}

In an effort to recognize the influence of innovation on the global structure, the term knowledge-based economy is often used. The OECD defines:

"the knowledge-based economy [as] an expression coined to describe trends in advanced economies towards greater dependence on knowledge, information and high skill levels, and the increasing need for ready access to all of these by the business and public sectors" (OECD 2005).

It recognizes the shift in the economy based on the skills and values required to encourage growth. Crucial to supporting the knowledge-based economy and increasing innovation is facilitating knowledge transfer. Neubauer et al (2012) argues that knowledge transfer is the "set of individual memory systems in combination with the communication that takes place between individuals" (39). Therefore, to increase knowledge transfer individuals must be interacting amongst new people with different perspectives, ideas, and information than to that of themselves. This can be stimulated by international mobility. In the process of mobility and knowledge transfer, innovative ideas and solutions can be created to overcome social, political, or economic challenges.

To support effective and efficient knowledge transfer, innovation clusters have developed. Ostergaard and Park (2015) describe clusters as:

"geographic concentrations of interconnected companies, specialized suppliers, service providers, firms in related industries, and associated 
institutions in a particular field, linked by commonalities and complementarities" (835).

What makes clusters important is the interconnected web of institutions reliant on each other that strengthen knowledge spill over, economies of specialization, and labour pooling (Ostergaard and Park 836). Cluster institutions are deeply influenced by the socio-political and economic environment in which they exist. Clusters transform according to the society and economic needs at the time, therefore the ability to maintain flexible and adaptable to the changing conditions is vital.

However, for countries to compete globally for talent specific knowledge and skills, predominately those of science and technology are increasingly required. With great advances in Artificial Intelligence (AI) and Machine Learning (ML) the knowledge-based economy is being conceptualized further (Huang 2019). Typical knowledge-based professions, such as lawyers or doctors, have had less disruption by automation advances than manufacturing (Pasquale 75). However, the current advances in AI and ML are challenging these knowledge-based professions through the ability to perform tasks more effective and cost efficient (Pasquale 80). For example, AI and ML can now diagnosing diseases or processing legal research faster than human ability. This simply highlights the ongoing innovative advances and the increasing focus on science and technology to support innovation.

\subsection{Conclusion: Innovation Through Increasing Diverse Perspectives}

Innovation requires diverse perspectives and ideas. This can be strengthened by mobility and migration. There is currently a knowledge gap in the development of the connections between migration and innovation (Brinley 1954; Porter 1998; Hunt and Marjolaine 2010; Shachar 2013 Bosetti et al 2015; Geiger and Bergmann 2017). However, 
developing more literature and knowledge around how mobility and migration can foster and strengthen migration is crucial. Migration is important because it facilitates the interactions between diverse individuals. If women, people of color, or people from different socio-economic classes are excluded through formal or informal institutional mechanism from participating in science and technology and therefore the innovation process, it hinders societal progress overall. For example, women can miss out on participating and benefitting from the personal and economic benefits of innovation, particularly because science and technology careers offer the highest paying salaries for women ${ }^{1}$ (World Economic Forum 2018). Additionally, society can overlook innovative ideas and solutions that women could have supported. This is equally true of people from different racial identities, classes, and sexualities. The current base of literature discussing women or a gendered analysis, which has only recently developed, is more focused on women's underrepresentation in STEM, rather than innovation more broadly (Cheryan 2011; Bilimora et al 2014; Chubin et al 2015; Reilly et al 2017; Wynn and Corell 2018). Furthermore, there is limited regarding the intersection of oppressions in increasing innovation (Kushnirovich and Heilbrunn 2013; Costa 2016). This begins to highlight that to increase innovation all members of society must be able to participate and benefit equally. Furthermore, research must move beyond only looking at gendered implications but to broader intersections. With increasing mobility and migration there should be a rise in more inclusive approaches to fostering and strengthening innovation.

\footnotetext{
${ }^{1}$ Women make 92 cents for every dollar a man makes in the STEM careers, which is the smallest gender pay gap of any career (World Economic Forum 2018).
} 


\subsection{International Migration and Human Mobility}

People have continually been participating in migration and mobility, whether out of choice, necessity, or force (Malkii 1992). The Vikings, an iconic Scandinavian seafarer, starting in the $8^{\text {th }}$ century, migrated throughout the North Atlantic to strengthen trading relationships and, for some Vikings, to find a better life (McEovy and Edwards 2005). They left a lasting impact throughout the region and remain an iconic image of Scandinavian migration (McEovy and Edwards 2005). However, while there is ongoing movement of people, the motives and methods have expanded, particularly based on increased globalization. More recently, Guigni and Passy (2006) divide post-WWII migration up into two periods, before and after the mid 1970s economic crisis, where people prior to the 1970 s migrated to Western Europe for work and more permanent migration to North America often following past colonial paths, and people migrated after the 1970s for family reunification, refugees, and high skilled migration (4). There is a significant body of research within the field of migration, covering issues of international governance (Barnett and Finnemore 1999; Geiger and Pecoud 2014), refugees (Watson 2007; Betts and Loescher 2011; Milner 2014), integration (Guiliherme Fernandes 2015; Gudrun Jensen et al 2017), border security (Hammerstad 2000; Geddes and Taylor 2013), development (Liversage 2009; Raghuram 2009; Boeri et al 2012), and much more. While there is extensive literature discussing a diverse range of important migration issues, there is limited information regarding the benefits of increased migration and mobility on innovation (Brinley 1954; Porter 1998; Hunt and Marjolaine 2010; Shachar 2013 Bosetti et al 2015; Geiger and Bergmann 2017). Migration's role in fostering innovation is under researched, especially when understanding international students' agency in strengthening innovation. 


\subsection{Migration Theories}

Early migration theories arose with work by Reclus and Ravenstein (1882). However, there was increasing attention given to migration theory correlating with the end of World War II, including why people migrate and the policies to control migration (Brinley 1954; Hannerberg 1957). Massey et al (1993) offers one of the most comprehensive summaries of migration theories. They state there is no single cohesive theory of migration but rather incomplete theories that developed in relative isolation from one another (Massey et al 432). Briefly the four main theories are; neo-classical economics $(\text { macro and micro level) })^{2}$, the new economics of migration ${ }^{3}$, dual labour economics ${ }^{4}$, and world systems theory ${ }^{5}$. These theories are critical to understanding migration, such as micro-level theory offers insights into actor's preferences, or the dual labour economics theory highlights immigrations' role in sustaining a country's economy. However, the migration of international students is not included within any of these theories. Stakeholders' roles in supporting migration and recruiting international talents and students is also overlooked.

Overall, Massey et al synthesizes the theories to conclude that acquisition of human capital is always linked to the likelihood of individuals being internationally mobile (456). In other words, attaining education or having the ability to work in an innovative

\footnotetext{
${ }^{2}$ The macro level theory understands migration as the results of low and high wage economics finding equilibrium through the movement of people from low to high wage economies (Massey et al 433). The micro level looks at the motivation for migration at the individual level by weighing the cost- benefit factors against each other, which then produces the decision to move (Massey et all 434).

3 The new economics of migration theory says that decisions to migrate are not made by isolated actors but rather "larger units of related people" which could include families or households, who aim to collectively increase income and mitigate economic risks (Massey et al 436)

4 The dual labour market theory is where migration is thought to originate from the ongoing need for developed states to have immigrant labour which creates two tracks of labour in a developed state - domestic and immigrant (Massey et al 440).

${ }^{5}$ The world systems theory links migration to the disruption caused by capitalist pursuits, usually linked to past colonial origins, as the cause of migration (Massey et al 445).
} 
environment and support the knowledge-based economy can fuel migration through peoples' desire to participate in this process. This is the only aspect of migration that the authors recognize as inherent, while other situations are subject to variables such as history, economics, and politics (Massey et al 456). However, migration theories, even while not elaborated on, presume the neutrality of migration institutions devoid of gender, race, or class-based understandings. Furthermore, the theories do not account for the inherent power hierarchies throughout every society that shape who is able to move, in what capacity, and to where. Although, world systems theory does offer a more critical understanding of the intersections of power and oppression, especially regarding racial identities (Mabogunje 1970). This is due to the theory's roots in colonial critiques. Furthermore, all theories focus on the economic side as the primary rationale in why people move, yet since migration continues to persist without equilibrium of the supply and demand, therefore the political environment must be a factor.

Denmark is recognized for being a social welfare state and it is a highly influential aspect of their migration policies. Epsing-Anderson, a Danish scholar, is well known for his typology and theoretical understanding of the welfare state (1990). As EpsingAnderson grapples with the notion that there is no one singular definition of the welfare state, therefore, he categorizes welfare states into three typologies: liberal regimes (AngloSaxon countries), conservative regimes (Germany and central Europe), and social democratic regimes, which is where Denmark and the other Nordic countries fall (EpsingAnderson 1990). The social democratic welfare model is premised on high decommodification, strong universalism, and increased role of government. Further, Epsing-Anderson is important as he points to the role institutions and actors have in creating certain types of the welfare state (23). More recently, Razin et al's (2011) adopts 
an additional method to explain how a country's welfare policies can act, at times, as a strong incentive for migration as state supports can mitigate some of the partial risks associated with migration (Razin et al 5). This can often lead to a greater number of unskilled workers believing they will benefit more from migration than it will cost them, therefore many welfare state countries employ fairly restrictive immigration policies to counteract migration (Razin et al 27). In this theory, countries take a more political economic perspective to develop effective policies which weigh the benefits and drains on the state's welfare systems. Additionally, there is a stronger focus on pleasing the welfare state voters. This is an argument currently being made in Denmark regarding offering free tuition for international students from within the EU. While this can incentivise students to study in Denmark, coupled with the SU payments (student stipend per month), it is a huge cost to the Danish welfare system, which resulted in the government reducing the number of international students admitted for $2019-2020^{6}$. Furthermore, this theory is reflective of Denmark's overall increasingly restrictive immigration, far stronger than its fellow Nordic welfare states.

\subsection{Migration Policy}

Governments have limited control on who leaves the country, but they can create policy that shapes who enters, therefore migration policy is crucial in discussing international student mobility and highlights the state centric nature (Ritzen and van Dalen 239). Giugni and Passy (2006) identify three main areas of policy coverage; regulation of immigration flows; the management of ethnic relations and integration; and antiracism and antidiscrimination policies (1). They further stress the role that non-state actors play in the

\footnotetext{
${ }^{6}$ The Danish government announced in November 2018, that they are reducing the number of international students, specifically targeted at EU students who do not pay a tuition, by 1,000 (Gadd 2018b).
} 
development of migration policies, which moves beyond the very traditional state and economic centric focus of migration policy. However, it is not inconceivable to think that states who are often the sole creators of migration policies due to authority over borders, would be central to migration policies. There is literature to support this (Favell 2006; Pattieu 2017). While EU member states have given up some sovereignty over borders, states still take steps to assert their ongoing authority over migration policies, whether that is through the temporary borders within the EU (Denmark and Sweden, Denmark and Germany, Austria and Hungary) or policies to restrict the number of refugees and their allocation throughout a country. Member states still have partial authority over the number of EU students entering the country (see The Lisbon Treaty Article 79(5)) ${ }^{7}$, as can be seen through Denmark's recently announced initiative reducing the number of EU students.

In a very specific example but relevant to the Danish context, Triadafilopoluos and Zaslove (2006) describe the typically unwritten connection between migration policies and political parties, which is often ignored due to centrist right- and left-wing parties preferring to deal with immigration concerns through consensus-based agreements outside the public eye (171). However, there is increasing attention due to the rise of right-wing parties focusing on restrictive immigration policies (Triadafilopoluos and Zaslove 171). Denmark's core Eurosceptic party, the Danish People's Party (DPP) has gained prominence since 2001 in national and EU level politics through their anti-immigration stance and support for increased border controls (Topaloff 177). Due to the DPP's representation in the Danish Parliament as the second largest party (21\% of the seats), they have influenced the restrictive direction of immigration policies. The interactions of the political system and partisanship have a significant influence over policies and should not

\footnotetext{
${ }^{7}$ Article 79 (5) of the Lisbon Treaty states that the EU and member states will share responsibilities of how many migrants are allowed to work in each member states (European Union, Lisbon Treaty, 2006).
} 
be underestimated (Triadafilopoluos and Zaslove 189). Overall, migration policy, despite having obvious international implications is predominantly left up to the state, especially regarding labour and high skilled migration.

\subsection{Reliance on High Skilled Migration}

Since domestic labour market demands are increasingly unmet by the national labour force, there is growing reliance on international talent, particularly high skilled. Thirty years ago, Ritzen and van Dalen noted the projected labour shortages facing Western Europe (232). Their proposed policy solutions to address this pressing issue included; increasing educational training and retraining; increase the labour force participation by supporting more women's participation, and most relevant to this research, instituting policies that best allow well trained young people to migrate to Europe (Ritzen and van Dalen 232). Furthermore, they noted the importance of young highly educated migrants due to their recent knowledge, especially in a time of rapidly changing innovation (Ritzen and van Dalen 233). The demand for this innovative high skilled group is ever increasing with the rise of global competition and international students are at the forefront.

Shachar (2006) and Shachar and Hirschel (2013) analyse how high skilled migration and competition was originally driven by migrants' desire to gain citizenship and now is also influenced by strengthening a country's national pride and international reputation. Shachar also offers early insights into the interconnection of immigration policies and recruitment policies. However, she overlooks that countries are likely engaging in the global race for talent to sustain their own economies and maintain growth through innovation, which can be attributed to the ongoing change in economic circumstances and globalization. There is no mention here or in other literature on the role international students have in high skilled migration or that high skilled migrants are often 
exceedingly educated. Furthermore, stakeholders and institutions, beyond the state, are not included as driving and supporting high skilled migration, despite their role in supplying high skilled employment.

Even when discussing the term 'high skilled' there are the inherent assumptions. The first being, that there is some common understanding of what high skilled means despite various interpretations world-wide. The term is rarely deconstructed to understand how institutions' - especially government immigration - and actors' interpretation of high skilled is influenced by social, economic, and political contexts. How does cultural interpretations change who is considered high skilled? Furthermore, society values certain skills as 'high skilled', which are inherently subjected to gendered, racialized, and classed dichotomization of high and low skilled labour (Boucher 28). There are certain rights and privileges attached to skills (Boucher 45). Are the skills of caring, educating, and healing, associated with high skills, even if there is formal education required? Why are those skills not as readily attached to the term high skilled, like management, finances or research skills are? Is there any link to what is considered high skilled and low skilled and how the labour force is inherently gendered, racialized, and classed? While this research is not going to deconstruct high skilled it is important to develop awareness of the connotations of the term.

\subsection{Conclusion: Furthering Migration Research}

Understanding how states are able to recruit and retain international talents is intricately embedded in international migration policies, which highlights the complexities between state sovereignty and state cooperation (Geiger and Pécoud 868). Migration and its interdisciplinary relations are often understudied, or when it is refugee policies and politics tends to take center stage, typically in a negative light. Furthermore, economics is 
central and the additional benefits, such as innovation, are missed. The lack of literature on high skilled workers limits the much-needed debate around the role high skilled migration has in state growth and innovation. There is limited literature on how states can better cooperate in recruitment and retention of migrants (Pemberton and Stevens 2010; Shachar and Hirschl 2013; Khoo 2014) and the effects of states' immigration policies on growth (Appleyard 1992; Kim and Kwon 2012; Geddie 2014). There is even less literature regarding the role of non-government institutions and actors have in the recruitment and retention of migrants (Manthorpe et al 2010; de Hoyos and Green 2011). This is particularly true when looking at the role of universities have in promoting international student mobility (Wildavsky 2010). All of these are crucial to better recruitment and retention of international talent, yet there is inadequate, theory on effective strategies of public and private stakeholders. Moreover, there is limited information how stakeholders, especially companies and start-ups benefit or are challenged by current government migration policies.

Migration and the link to gender or other intersecting identities often are not in forefront of immigration policy makers' minds, as displayed by the lack of research in migration focusing on gender (Raghuram 2009; Salisbury et al 2010; Holloway et al 2012; Siim 2013; Martin 2014). However, this connection is immensely relevant with increasing international focus on migration, whether that be refugees or in the global race for talent. Migration is inherently imbedded with gendered, racial, and classed biases, which are then perpetuated by institutions and actors. Just under half of the world's international migrants are women (48.4\%) (Migration Data Portal 2018). Despite a lack of comprehensive data on migration and gender, women are increasingly migrating as head of household or as independent workers, however just over $40 \%$ of labour migrants are women (Migration 
Data Portal 2018). Furthermore, when women are discussed in relation to migration it is usually in respect to traditionally female-dominated occupations (ie: domestic work, nursing) and the female migrants in science and technology, whether they fit in a feminized understanding or not, are often overlooked due to the gender-neutral perspective undertook by research (Raghuram 85). Overall, there is limited literature that discusses gender and migration, therefore an intersectional feminist analysis of migrations' connection with international student mobility and innovation is significant. It would also permit further analysis on the way race, class, and sexuality can have an influence on migration.

\subsection{Expansion of International Student Mobility}

One of the specific pathways countries engage in the global race for talent is through international education. International education is a "dynamic concept that involves a journey or movement of people, minds, or ideas across political and cultural frontiers" (Hansen 5). With a knowledge-based economy increasingly relying on international skills and experiences, international students are supporting the future economic system. The official definition of an international student was agreed upon by UNESCO, OECD, and EUROSTAT in 2015 to be:

"an individual who has physically crossed an international border between two countries with the objective to participate in educational activities in a destination country, where the destination country is different from his or her country of origin" (Migration Data Portal 2018).

International student mobility is not a new phenomenon, as students have always sought mobility to learn and expand their horizons, however it is the drivers that have changed and expanded (Bhandari and Blumenthal 1). Furthermore, there is an increase in students going abroad and expansion of who is able to study internationally. This is coupled with more governments creating policies to support their citizens to go abroad and universities 
marketing their programs. It is part of a larger process of globalization of education, where it is no longer just the countries in the global north attracting international students, but rather traditional 'sending' states actively seeking to recruit students to their educational institutions (Bhandari and Blumenthal 2). There is the move away from a one directional flow of students to interconnected mobility of international students as a whole. This is due, in part, to an overall recognition of the extensive economic, social, and political benefits international students create.

In 2018, more than five million students studied outside their home country; this number is expected to rise even further in the coming years (IIE 2018). The Asia-Pacific Region, which has the world's largest population, is continually the largest area for outbound mobility (IIE 2018). While, the host of the largest number of students is continually the United States, followed by the United Kingdom, and China - which saw a ten percent international student increase from 2017-2018 (IIE 2018). The increase in international students going to traditional 'sending countries' such as Malaysia or China is due to and simultaneously fuels the increasing number of universities in 'sending countries' (Bhandari and Blumenthal 2). Notably, Canada had the largest increase - eighteen percent - in international students in 2017-2018 (IIE 2018). Denmark, which will be elaborated on in Section Four, hosts upward of 22,000 international students annually, proportionately higher than the OECD and EU average (OECD 2018; Eurostat 2018). While specific and comparable data is difficult to find, it is clear there are growing benefits for students who go abroad, domestic students who interact with international students, states' economies and innovation, and labour market stakeholders (Munk 2009; Bhandari and Blumenthal 2011; Bergerhoff 2013). 
A testament to the increase attention given to international education is the expanding forms and methods of international education, such as the rise of online courses, summer schools abroad, and university partnerships. Universities are increasing partnering with other universities abroad to facilitate smoother and increased student mobility (Knight 212). In Dubai, there are over twenty-five international universities with branches located there, such as John Hopkins University (Knight 212). This is a trend that extends to China, Singapore, Qatar, and many more countries with regional 'education' clusters (Knight 215). This not only allows domestic students to receive an international education but international students to obtain a domestic education, internationally (Knight 215). This supports numerous economies in the process. Furthermore, high schools supported by another state's education curriculum, are opening up world-wide. The Canadian province of British Columbia has secondary schools in China, Egypt, France, Japan, and Colombia. Even if students are not moving, the process of education is becoming increasingly internationalized through domestic education by international entities. This research is solely focusing on international students in a host state as they, particularly those in a Master's or PhD programs, are in a pivotal point in their life where positive career prospects could entice a student to stay in their host country or continue their career paths outside their home country - it is about how to transition international students into the labour market rather than international education overall.

\subsection{Beyond Economic Benefits of International Student Mobility}

There are tangible and perceived benefits associated with international education for students and stakeholders, such as business, universities, and government. McHale (2011) identifies three main reasons why, in this case Canada, focuses on recruiting international students; revenue generation, knowledge production in higher education, and 
a more talented immigration pool (168). First, international education is one of the largest exports in countries, such as the United States and Canada (Bhandari and Blumenthal 1). It is difficult to predict exactly how much international education brings into an economy, however, it is estimated that the international education industry in British Columbia contributes over two billion to the provincial economy annually (BCCIE 2017). International students almost always pay higher tuition than domestic students, typically twice the amount, and support the economy through tourism and living costs. At times international students are perceived as displacing domestic students in universities, however international students actually bring in revenues which allows for an overall higher quality educational experience for all students (McHale 176). Furthermore, this does not even account for the benefits domestic students receive through interactions of knowledge and culture exchange with international students, supporting the broader process of interculturalization. Therefore, international education offers mutual migration benefits to states and students.

There is a momentum to understand international education's contribution beyond pure economics. However, there are significant economic benefits to local economies, educational institutions, and domestic students. International education is also highly beneficial for the receiving state, as due to international students' potential education, language skills and, at times affluence, they are considered relatively attractive migrants which can facilitate simpler transitions through an immigration system (Arthur and Flynn 223; Scott et al 2015). Additionally, with increased migration restrictions, especially in a state like Denmark, international students are one of the few legitimate options for mobility (Wilken and Ginnerkov Dhalberg 1348). The diversity that international students bring into the education environment is understood as a positive outcome for supporting the 
broadening of perspectives, ideas, and understandings of knowledge (McHale 180). Viewing international mobility as crucial for knowledge sharing helps build stronger cultural understandings and increase international cooperation amongst the generation of future leaders (Bhandari and Blumenthal 2). In other words, domestic and international students gain significant experiences through exchange of ideas, perspectives, and cultures. This strengthens the knowledge-based economy and in turn can foster innovation.

Although international education is becoming more accessible to students from all socio-economic backgrounds through programs, such as the EU's Erasmus programs and widespread availability of scholarships, it is important to still recognize the ongoing inequalities associated with accessing international education. Pure finances might not be as much of an inhibitor but being from an upper class still has a significant advantage when it comes to language skills, exposure to culture, and international networks (Munk 2009). Gaining knowledge capital from international education is mediated by other factors beyond class such as age, ethnicity, urban/rural, and gender. Overall, while class and economic inequality in the access to international education is not within the primary scope of this research, it should not be dismissed as a factor in shaping the landscape of international education and the connect to innovation.

\subsection{International Student Mobility Knowledge Gaps}

There is substantive literature on international education, despite being a relatively new field of study. However, it only focuses on a few themes; country specific, economic value, and 'push-pull' theory of why students move. The earliest theories relating to international education focused on the 'push and pull factors' of why students chose to study aboard (Li et al 1996; Mazzarol and Soutar 2002). University reputation, reduced tuition fees, career opportunities, international experience, and even love were considered 
pull factors as they enticed students towards certain regions (Cubillo et al 2006; Li \& Bray 2007; Eder et al 2010; Arthur and Flynn 2011). Push factors are those that motivate students to leave their home country such as conflict, social or economic inequality, lack of job opportunities, or absence of certain educational programs (Mpinganjira 2012; Lee 2014). While this theory in migration is less common now, it still is important in highlighting what factors students consider during their decision-making process.

Furthermore, research has focused predominantly on students coming from Asia, primarily China (To et al 2010; Jiani 2017; Ghazarian 2016; Lee 2014), and Africa (Mpinganjira 2012; Usman et al 2015; Ahmad \& Hussain 2017) typically to the EU or an English-speaking country (Valentin 2012). This supports the original notion of the global north as a 'host' and the global south as 'sending'. As mentioned and will be highlighted, this is changing. Common in academia and government policy is constructing international education solely as an economic benefit to the host state (Li 1996; Geddie 2015; Brooks et al 2012; Scott et al 2015; Tange \& Jensen 2012; Munk 2009; Bergerhoff et al 2013). The 'dollar value' of international students has been much of the focus rather than the intercultural and innovation skills which are now emerging in the narrative. More recently, the field of return migration, specifically focusing on international students a few years following their graduation, is becoming increasingly relevant (Wadhwa 2009; Bhandari and Blumenthal 2011). This has been incredibly relevant to China as more and more Chinese students are returning to mainland China (Hao and Welch 2012).

While there has been limited data collection on migration of international students, when available it is typically country based rather than global in nature. However, 'Project Atlas', created by the United States' Institute for International Education, is a: "global research initiative that disseminates comparable student mobility data, conducts studies on academic migration and the internationalization 
of higher education, and provides customized workshops and research to strengthen the collection of mobility data around the world" (IIE 2018).

While an international record of student mobility statistics and information is significant, it is up to countries to report information. Therefore, most of the data is still from majority English-speaking countries, with a few exceptions such as Chile, Malaysia, or Thailand. Unfortunately, Denmark does not have any information through Project Atlas.

Admittedly, there is limited data on what students are studying abroad. Nonetheless, Project Atlas predicted that engineering, math and computer science, and natural and physical sciences are largest areas international students studying in (IIE 2018). This information is for the United States, but similar trends are coming out of other countries. Furthermore, international students represent half of the number of doctoral graduates in the U.S. within STEM fields (Bhandari and Blumenthal 12). The Migration Data Portal stated that research on future career plans is the most underdeveloped aspect in research relating to international students (2018). The factors that students consider when deciding on their graduation plans are crucial insights for stakeholders in their ability to recruit those international students, yet there is little data, either state-based or international that discussed what students do after graduation.

There is not significant literature on international students by gender, and what exists mostly focuses on why female students might go abroad (Salisbury et al 2010; Holloway et al 2012; Martin 2014; Weisser 2016). Weisser briefly makes note that potential distance from home, the risk factors involved, and the gendered dynamics of a country's labour market are factors for female student mobility (23). However, this field is still underdeveloped. Sohndi and King (2017) discuss the gendering of international student mobility by focusing on Indian international students. This is one of the first to address the gendered implication in international migration and how reasons for studying 
aboard and returning could be different for students based on their gender. Furthermore, there is a lack of information on why students based on their gender may have different reasons to stay after graduation, or the influence of a perceived gender equal society has on students being attracted to that state or staying after graduation. While intersectional analysis of international students is under developed, there is more regional based literature that better takes into account power dynamics associated with race and country of origin.

\subsection{Students' Rationale for Studying Abroad}

There has been initial research on the motivations of international students to study and remain abroad, and the factors influencing these processes (Gao and Liu 1998; Pang and Appleton 2004; Alberts and Hazen 2005; Arthur and Flynn 2011). The main factors that affect students' decisions are highly influenced by historical, geographic, linguistic, and cultural links (Bhandari and Blumenthal 9; Weisser 16). In other words, students' decision to study abroad and where are deeply influenced by the institutions that surround them, which includes government policies, colonial history, international educational partnerships, language, education systems, and family.

A central reason why students study internationally is for language acquisition, which is in part why the English-speaking states have been dominating the international education market for decades (Lasnowski 195). English is perceived as the 'global' language with more people speaking English as a first or second language than any other (Lasnowski 195). Although there has been some decline in English's dominance, with the rise of Mandarin and Spanish speakers. For universities to attract international talent though, the courses are taught in English. However, the language of a country whether that be French, English, German or Spanish can play a significant factor in recruitment of 
international students wanting to improve their language skills. Language skills, just like skills of internationalization, are crucial in international mobility. Lasnowki predicts that language policy is going to be one of the strongest influences over mobility in the future (207).

Arthur and Flynn (2011) found the main reason students study abroad is to increase career opportunities in the host country therefore students were often keen to stay or at least not return home after graduation (227). Future career prospects are often a strong contributor to why students choose to study abroad on the assumption that it might either make them a more attractive candidate or provide more opportunities in another country. In an increasingly competitive international market, skills of internationalization are increasingly becoming invaluable ( $\mathrm{U}$ of $\mathrm{T}$ and $\mathrm{U}$ of $\mathrm{O}$ 2018). Intercultural skills are difficult for AI technology to compete with, strengthening human capital.

Studying abroad can simply be out of necessity too, if a home country does not have the program or capacity to support student's needs or interests. In certain states, such as India, the number of post-graduate programs are simply not sufficient to support the demand therefore students go abroad (Bhandari and Blumenthal 2). This is also the case when countries have niche and specialized programs, which attract students from outside their borders. Reputation and prestige of certain programs or states, such as the UK's Oxford University or the US's Harvard University, can also be an influence (Munk 7). Additionally, PhD programs in North America are often five years in length, while some programs in the EU are three years. The length of program could influence where students choose to go.

With the increased interest in international education, universities and governments have taken advantage of social media to influence students' decisions to study abroad and 
where to go (Galan et al 2015). Universities are able to market their programs and the advantages of study at that specific school. Galan et al (2015) notes one of the main benefits of social media is it enables open communication that allows for quick responses, which better engages students and provides necessary information, making the potential of studying abroad less intimidating or risky (296). It can also facilitate communities where past and prospective students can engage in a dialogue where post student experiences can act as a free marketing tool (Galan et al 298). Students world-wide are having greater access to information making the process of studying aboard simpler therefore enabling more students to partake.

Lastly, students are influenced to study abroad through encouragement of government policies which aim to foster an early interest and skills of internationalization. Two examples of this are: China and the EU. While, the United Kingdom had one of the earliest coordinated international student recruitment strategies, China was one of the first countries to encourage their own citizens to study abroad (Bhandari and Blumenthal 10). Furthermore, China as the largest sender of students, provides an important example in this regard. For the past forty years, the Chinese government has strongly supported students studying abroad (Xinyu 26). While a lot of the focus has been on sending Chinese students abroad, there has been increased efforts to attract students to China, through university partnerships, such as the Sino-Danish Institute or most recently the Schwartzman scholarship $^{8}$. This aims to foster stronger international ties. The focus China has on international student mobility can also be exemplified with the number of international high schools which prepares Chinese students for post-secondary education abroad. For example, the British Columbia government has thirty-eight offshore schools in China

\footnotetext{
${ }^{8}$ The Schwartzman scholarship is modelled after the Rhodes scholarship to bring talented international students to complete their Masters in China.
} 
where students are taught the $\mathrm{BC}$ curriculum and receive the $\mathrm{BC}$ Dogwood (High school diploma) which supports credit recognition when applying to BC, Canadian or even American universities. It also helps students improve their English language skills early on.

The EU is also actively encouraging their citizens to go abroad and is participating in long-term strategies to encourage students to come to the EU. The European Commission has repeatedly noted the importance of strengthening the knowledge triangle which includes education, research, and innovation, and international education has been recognized as one of the most crucial factors for innovation and making the EU more competitive on the basis of expanded research and development (R\&D) (European Commission 2016b; Volante and Ritzen 989). The Bologna Process, created under the Lisbon Agreement, strengthen educational qualification recognition to better strengthen European wide higher education (European Commission 2018). Furthermore, the EU has identified the importance of student mobility by setting a target for $20 \%$ of EU member state graduates to have studied outside the EU by the year 2020 (European Commission 2016b). In 2016, the EU hosted 1.6 million international students, the majority non-EU students came from Asia (Eurostat 2018). An EU strategy is to offer generous funding and scholarships to their own citizens and citizens abroad to foster education mobility early on (Shachar 75). Since the late 1980s, the Erasmus program has supported over 6 million, mostly European, students study abroad at EU universities (Erasmus 2019). Additionally, the EU offers funding through Jean Monnet Centre of Excellence to universities in Canada and elsewhere, to "creat[e] transatlantic connections between EU researchers in Canada and Europe and promot[e] research by emerging scholars", which not only supports 
Canadian students' engagement in EU research, Model EU participation, EU study tours, but can encourage later on migration, short or long term, to the EU (Carleton University).

\subsection{Conclusion: Supporting International Student Mobility}

Despite international student mobility becoming more accessible, gaining knowledge capital from international education is still mediated by other factors beyond class such as age, ethnicity, urban/rural, and gender. However, international student mobility is critical in supporting the ongoing global competition for talent, particularly when connected to innovation and migration. Some related literature exists (Ziguras \& Law 2009; Hunt et al 2010; Bergerhoff et al 2013; Wilken and Ginnerkov Dhalberg 2017) however, there is significant room for exploration. Specifically, there are pronounced knowledge gaps on how countries can effectively recruit and retain international students for innovation and growth, and how their education and immigration programs can be designed to actively encourage and assist industry recruitment and retention. Furthermore, there is almost no information on how the private sector stakeholders - businesses, organizations, and civil society - are benefiting from international education or how stronger coordinated plans between public and private institutions could foster increased internationalization.

As the UN Migration Data noted, comprehensive information on what attracts international students to remain when they graduate is seemingly absent (Migration Data Portal 2018). How many international students are staying in their host country upon graduation? Do they pursue permanent residency or continue their international education journey? What are the best ways for host countries to incentivize these bright students to stay? Furthermore, there is limited literature supporting a feminist analysis of international students and the different challenges students may face based on the home and host states' 
level of gender equity. There is even less information how the challenges international students face intersect with race, class, or sexual orientation.

\subsection{Bridging Migration, Innovation, and International Student Mobility}

The correlation between migration and innovation is crucial in a knowledge-based economy increasingly relying on high skilled labour. However, this research supports that migration fosters innovation, and both areas require significant research to develop this further, as the academic connection between migration and innovation are still developing (Porter 1998; Shachar 2013; Czaika and Parsons 2016). Innovation theory currently does not recognize the importance of recent graduates from around the world in promoting and increasing innovation. Additionally, migration, while there is substantial research, does not take into account its role in supporting or hindering innovation through immigration and integration policies. Furthermore, the current immigration institutions - in Denmark and abroad - are ill fitted to deal with changing migration patterns as migrants no longer fit into rigid designated categories, including international students (Mosneaga 15). Specifically, literature on high skilled migration misses the important connection to increasing innovation and knowledge transfer. International student mobility focuses strongly on the individual benefits students can acquire rather than speaking to the benefits companies or countries can receive, or how certain degrees such as in STEM, can be crucial to innovation. This is especially true in the STEM fields, as the skills are more flexible, adaptable, and have a lesser reliance on language proficiency.

Additionally, innovation, migration, and international student mobility theory and literature overly focuses on the economic benefits rather than the additional invaluable benefits. Innovation theory describes the main goal of innovation as producing something 
that contributes to economic development, whether that be through tangible goods with a profit or a policy that increases growth. Although the economy does fuel innovation, innovation is beginning to be less about the final economic goal, but rather the contributions it can make to society through overcoming of a 'problem'. Likewise, with international student mobility, economics was originally driving country-based support. However, countries are beginning to view international students as fostering greater interculturalization and even their potential contributions to innovation. Migration theory has a slightly different approach, but is still embedded in economic discourses, whether that is of the individual's reasons for migrating, economic reasons forcing migration, or states' need for labour migration. Too much focus on economics overlooks the additional benefits and can lead to a lack of conducive policies.

All these concepts start at a very state centric perspective, where states' institutions are the key innovators, beneficiaries of international student mobility, and authority over migration. While, this is not inaccurate, there has simply been a shift in this narrative to include the agency of stakeholders. Stakeholders are increasingly supporting innovation through funding university projects, developing co-working spaces, and hiring international students. Furthermore, innovation is not restricted to one specific state border, it can span across spaces through remote working and the rise of telecommunications that connections employees and ideas across the world. Migration theory remains mostly state centric due to the inherent connection between border control and the sovereignty of a state. However, the migration of people whether international students or refugees actively seeks to challenge these borders. When migration policies are created to support innovation, they are often to meet state level labour needs, without the understanding of what stakeholders actually require. As an example of this, the Danish 
Pay Limit Scheme, which offers fast tracked work permits if individuals make over a certain amount of money, is too high for start-ups to pay, yet start-ups are in great need for innovative talent. International student mobility literature is not as deeply embedded in the state centric perspective because the individual preferences were central in the theories; however, the ongoing state control over international student mobility through visas, work permits, permanent residency, and citizenship is crucial and often under researched. To encapsulate, if the state is the focus, the views and needs of stakeholders such as local businesses, companies, and universities can be overlooked, leading to a less competitive economy, stifling innovation. 


\section{Chapter Two: Intersectional Feminist and Actor-Centred Institutionalism Perspective on International Student Mobility}

Fostering innovation through migration is strongly dependent on institutions and the actors within to develop and support effective policies and initiatives. Rapidly increasing international student mobility is involving more institutions and actors, such as small businesses, universities, and large companies. International students, especially those in science and technology, are viewed as attractive migrants to retain and foster domestic innovation. The STEM fields greatly underrepresent women, and international student mobility is imbedded with racial, cultural, and classes power dynamics, therefore, a theoretical framework that analyzes institutions and actors from an intersectional perspective is necessary. Using an intersectional feminist and actor-centered institutionalist approach aims to express the agency of international students and stakeholders imbedded in institutions of migration and innovation.

Feminist institutionalism challenges the inherent power dynamics and biases entrenched within and perpetuated through institutions (Krook and Mackay 6). Institutions can include universities, government, businesses, or informal networks and norms. Feminist institutionalism and intersectional feminist methodology more broadly, are crucial for highlighting how initiatives, policies, and laws develop through institutions and can perpetuate biases existing in the institutions. These initiatives, policies, and laws influence how international students consider various factors when deciding their plans after graduation. Furthermore, initiatives, policies, and laws guide the parameters and strategies stakeholders have when recruiting and retaining international talent. Feminist institutionalism offers an inclusive approach to overcoming current challenges of recruitment and retention. Coupling feminist institutionalism with actor-centered 
institutionalism allows for analysis of institutions with consideration for the actors within

and navigating through such institutions. Actor-centered institutionalism focuses on how actors are able to navigate and influence institutions (Scharpf 1997). It highlights the agency actors have within an institution. The actors relevant for the research are international students and stakeholders. Feminist institutionalism and actor-centered institutionalism are highly compatible. While they have differences, they ultimately are interconnected, providing a more comprehensive analysis. The specific Danish institutions relevant for this research will be discussed in Section Four.

\subsection{Significance of Intersectional and Feminist Methodology}

Intersectional feminism is not a new concept, as it was introduced in the 1960s, yet is only recently gaining prominence in research methodology (Schrover and Moloney 13). Intersectionality is about understanding how identities such as gender, race, ethnicity, sexual orientation, or class, intersect, and how they cannot be studied in isolation of each other (McCall 2005; McNutt 2012; Siim 2013). Siim points out how there is "no meaning for the notion of 'women', which is not ethnocided and classed" therefore, while this research tends to focus more on gender inequalities, it cannot be studied in the absence of other intersectional oppressions (618). In other words, an international students' experiences are shaped not only by their gender, but the intersection of their race, class, and sexuality, as well. These are not isolated experiences and there is no "unitary or homogenous" category of women (McCall 1776). It is about the power relations that work to include and exclude people and how these can intersect (Schrover and Moloney 14). Highlighting intersectional perspectives "offers the greatest flexibility and analytic capacity to address complex discriminations and to promote equality in all its multiple 
dimensions" (McNutt 139). However, as McCall (2005) points out, there are complexities "arise when the subject of analysis expands to include multiple dimensions of social life and categories of analysis" (1772). Therefore, throughout this research intersectionality and the intersection of oppressions and identities that individuals occupy will be incorporated, while acknowledging the great complexity of adequately implementing intersectionality. Intersectional methodology always has capacity for future development.

Harding's 1988 Feminism and Methodology explains that there is no specific method of feminist research and does not require an overall focus on women, but rather a shift in perspective (Harding 1988). It is about understanding how power and oppression have been formalized and perpetuated through various political, economic, and social institutions. This should also be expanded to race, sexuality, and class. Furthermore, feminist theory does not say women have different experiences because of their sex (biological reproductive system), but because of their gender (socially and culturally constructed roles), women's social, economic, and political experiences and perspectives have been shaped differently than that of men's. Franceschet and Piscopo (2008) argue that women can share a female perspective independent of and not reliant on any essential female identity (96). In any discussion on policy it is crucial to be able to critically analyze the systems that influences the outcomes of policy as historically policies around the world take a 'gender blind' approach assuming that policies and practices will affect all individuals' identity in the same way, irrespective of gender identity.

Feminist theory has long focused on the role institutions play in reinforcing the patriarchy and intersecting oppressions (Krook and Mackay 3; Franceschet 58). Therefore, much of feminist research concentrations on representation of women and minorities in various institutions, often national parliaments, CEOs of companies, or in institutions 
traditionally dominated by men, such as military, law enforcement, and science and technology (Pitkin 1967; Childs and Krook 2009; Chaney 2012; Hayes and Hibbings 2017). However, some argue that it is not enough to change the institutional environment by simply having more women, it matters more who those women are (Inglehart \& Norris 2001; Franceschet \& Piscopo 2008; Wangnerud 2009; Feltham-King \& Macleod 2015; Plumb 2016). One of the most important debates in feminist theory relating to institutions, is that of representation and what is more effective: substantive or descriptive representation.

Descriptive representation, which has been studied for far longer than substantive representation, is primarily concerned with who, based on their identity, is represented in an institution, with the aim of increasing the numerical representation (Hayes and Hibbing 34). It says as long as there are equal numbers of women in an institution then gender equality will increase as women will inherently make decisions that support greater gender equality. Having women inside institutions has been successful in challenging the existing structures and, at times, is a central goal in the women's movement (Franceschet and Piscopo 63). Conversely, substantive representation aims to address the underlying factors, biases, and inequality that exists in institutions that are hindering women's participation (Vickers 24). It is also about understanding how institutions can better represent and understand the way social, economic, and political issues could affect people differently bases on their gender identity (Plumb 28). Substantive representation goes beyond 'adding women and stir' methodology to focusing on an inclusive environment within institutions. In other words, equal numbers of women alone cannot change the deeply rooted biases nature of institutions, it takes systemic changes by actors, even just a few. 
To highlight this, the case of Mexico and Iceland provide a strong example. Mexico, after the recent 2018 election, has $48.2 \%$ women represented and has had above $40 \%$ representation for the last few elections, however according to the Global Gender Gap Report, Mexico ranks $66^{\text {th }}$ in the world for gender equality (IPU September 2018; WeForum 2016). While Iceland, the top country in the Global Gender Gap Report, ranks $21^{\text {st }}$ for representation of women in parliament with 38.4\% (IPU September 2018; WeForum 2016). In other words, high numbers of women in a field does not necessarily mean greater gender equality, thus focusing beyond purely numbers but rather overarching supports for women in science and technology is more essential to overall increasing gender equality within sciences.

While representation is important in institutions, it is also vital to have a critical approach to these institutions. The discussion around substantive and descriptive representation is relevant for understanding the important role institutions have in supporting and hindering gender equality and other intersecting oppressions. It is also relevant to reiterate how the ongoing under-representation of women in science and technology inherently affects who and why certain innovative products, solutions, and advances are aimed at. Since there are $26 \%$ women globally in STEM, that means that $74 \%$ of STEM workers are male, who are influencing the direction of this incredibly important sector, often described as "chilly environment... filled with culture, hobbies, and behaviours often associated with men" (Wynn and Corell 151). However, 50\% women in STEM does not mean it will be equal as the institutions surrounding this field have been developed on inherent masculine from the beginning. This is also to say, that the science and technology industry could be more equitable for women if there is only $40 \%$ women represented if there are institutional changes. An institutional environment conducive of 
innovation must include diverse perspectives and opinions, which is strengthened with having people from different countries, backgrounds, classes, and genders.

\subsection{Actor-Centered Institutionalism}

There are many sources and strands of institutionalism (Greenwood and Hinings 1996; Diermeier and Krehbiel 2003; Immergut and Anderson 2008; Fioretos 2011; Abrutyn and Turner 2011). However, Scharpf's 1997 Games Real Actors Play: ActorCentered Institutionalism in Policy Research provides one of the more instrumental and comprehensive understandings of actor-centered institutionalism. This is relevant to understanding international students and stakeholders as actors influencing and being influenced by institutions. Institutionalism, while the author grapples with many definitions, refers to a system of rules that structure the courses of actions that a set of actors may choose (Scharpf 38). More specifically, different institutions will consist of distinct norms, rules, and systems of rules that organize and regulate social, political, and economic behaviour based on the historical context they developed out of (Lovenduski viii; Scharpf 40). These rules help understand policy and decision-making outcomes as they limit the number of possible potential behaviours or paths taken by any such actor (Scharpf 39). In other words, institutions through their base of normalized rules provides a greater understanding of why certain policy options were taken and predict what direction future policy may take.

The primary function of actor-centered institutionalism is to explain past policy choices and to produce systemic knowledge that may be useful for developing politically feasible policy recommendations (Scharpf 43). Actors are characterized by specific capabilities, preferences, and perceptions (43). There are three actors in Scharpf's model collective, corporate, and individual. Individual actors have the greatest autonomous ability 
for preferences as they interact with and shaped by institutions on an individual basis (Scharpf 54). The collective, broadly, is individualized members coming together to act as a collective unit (Scharpf 54). Unlike individual or corporate actors, collective actors are not autonomous and have the influences of the entire group. Corporate actors are more often hierarchal organizations that have a clear 'head', therefore giving members less influence than members of collective actors (Scharpf 56). This form of institutionalism is relevant to the research, as the individual actor (students), collective actor (government stakeholders), and the corporate actor (stakeholders) are central to understanding the current policies around student mobility supporting or hindering migration driven innovation. Actor-centered institutionalism puts emphasis on individuals' perspectives and how they navigate through institutions. It further highlights how the actor (international student or stakeholder) is influenced by the institutions that surround them and how institutions are also influence by the actor. Focusing attention on the actors is incredibly important when analyzing the factors international students consider in their decisions to remain in Denmark and pursue post-graduate work or not.

However, institutionalism like most other theories, assumes that the institutions originate in a neutral environment where they are not influenced by forms of power and oppressions. Furthermore, actor-center institutionalism, while it does focus on the perspectives and preferences of the actors, it does not develop any understanding of how these preferences could be different due to the construction of gender. Scharpf, overall does not critically engage with institutional biases and how actors can reproduce this through policies and practices. Scharpf, also overlooks how the intersection of institutional biases can impact actors differently. However, one of the commonalities between institutionalism and feminist theory is the understanding that institutions that seem 'neutral' are influenced 
by practices, discourses and norms and thus operate in a wider context (Krook and Mackay 13). In other words, "the norm of neutrality is profoundly gendered" yet previous forms of institutionalism did not critically engage with what perspectives are influential (Minot and Mergeart 208). Both theories are also concerned with explanations of change and outcomes and therefore the combination of intersectional feminist institutionalism and actor-centered institutionalism are aptly sufficient for the theoretical framework of this thesis.

\subsection{Feminist Institutionalism}

Feminist institutionalism understands that institutions are not homogenous, as they are historical products of the "mobilization of a male bias which produces and reproduces patriarchal power relations" (Krook and Mackay 3). Institutions affect the identities, selfimages, and preferences of the actors involved (Franceschet 63). Feminism analyzes how these preferences influence the actions or inactions taken by actors within the institutions (Franceschet 64). Recognizing how an institution can be gendered is through understanding how constructions of masculinity and femininity are imbedded into the norms, perspectives, discourses, and culture of all institutions (Krook and Mackay 6). This is also true of racial, class and sexuality biases. In other words, each institution "has a gender regime composed of a gender division of labour, a power, structure, and as gendered pattern of motions" (Vickers 130). This also extends to the informal institutions of socially shared rules - usually unwritten - which are enforced outside official institutions.

Since the 2000s, feminist institutionalism has increased in prominence (Mackay and Waylen 2009; Waylen 2009; Adams and Smerk 2018; Minot and Mergeart 2018; Thomson 2018). In 2009, the academic journal Politics and Gender published an entire compellation on feminist institutionalism, providing an invaluable focus on the vital connection between institutionalism and feminist theory. Out of this came Waylen's (2009) 
formative article on what historical institutionalism can offer to the field of feminist institutionalism. This was followed by Krook and Mackay's Gender, Politics, and Institutions: Towards a Feminist Institutionalism (2011) as an instrumental work in challenging the underpinnings of institutionalism, to move towards an understanding that institutions are inherently gendered regimes. They grapple with what feminist institutionalism could look like, while authors after them fully adopt feminist institutionalism and widely cite Krook and Mackay’s influential work.

Feminist institutionalism has strong origins in historical institutionalism as institutions are historical creations embodying the values present at the time of development (Franceschet 65). This often leads to the reproduction over time of these values. Krook and Mackay further develop the relationship between feminist theory and various branches of new institutionalism. Throughout their theory, there is a general agreement that historical institutionalism is the most well adapted to feminist theory, however, they do not discount other strands of institutionalism. Beyeler and Annesley (2011) argue that feminist institutionalism is aptly qualified to understand the gendered dynamics of a welfare state (80). This is a lot in part to the existing notion of high gender equality in welfare states' institutions.

Thomson (2018) recently described the significant contributions that feminist institutionalism makes to the broader institutionalism by providing a greater understanding of gender; of the informal institutions, rules, and norms; of how increased change can be brought about through institutions; and a comprehensive understanding of power dynamics (180). Overall, while feminist institutionalism will be the theoretical framework for this research, this does not mean that the focus is on women or 'women's issues'. As stated prior, feminism is not solely about women but rather how dynamics of oppressions and 
power intersect. Every international student and stakeholder will experience the intersection of gender, race, class, and other identities very differently. Furthermore, feminist institutionalism does not mean empirical results are only discusses in terms of gendered dynamics or that there will always be a connection to gender, but rather that critical engagement regarding power dynamics, social structures, and inherent biases throughout the analysis will be taken into consideration. Intersectional feminist institutionalism and actor-centered institutionalism, not only enhances and deepens the analysis, but offers more effective responses and future policy recommendations. Using the two theories in tandem provides a stronger intersectional approach, as feminist institutionalism highlights the biases imbedded in each institution and actor-centered institutionalism emphasized the role actors (international students and stakeholders) have on shaping institutions. Overall, these two approaches will lead to more critical and inclusive analysis.

\subsection{Research Objectives}

Based on the current literature there are a few predictions which regarding the findings that may arise throughout the field research and interviews. As previously stated to the guiding research questions are:

- Are international students, in science and technology, transitioning into postgraduate work in Denmark?

- What methods and initiatives do stakeholders have to recruit and retain international students and talent more broadly? Are strategies inclusive? 
- What are the current hurdles or challenges - policy or otherwise - that stakeholders and international students are encountering in transitioning into post-graduate work?

There is a lack of literature offering rationales for why students choose to remain in a country. Shachar (2013) suggests that high skilled workers go abroad to pursue citizenship, therefore international students may choose to remain in a country due to immigration goals. However, there is no additional literature to support this claim. Initial suggestions of length of time being a factor, is likely to influence a student's decisions to remain, as they will have a longer time to integrate into society. Therefore, students who have been in Denmark longer should be more inclined to stay. Job prospects, also, should be one of the more significant factors in where students will go after graduation, as most immigration policies, in Denmark and elsewhere, revolve around having a job offer. It is also predicted that Denmark's welfare state policies will be a significant draw for international students to, not only come to Denmark, but to remain in Denmark after graduation. The draw of free tuition for EU students and SU grants will be a strong incentive for students. Furthermore, the scholarships and funding that all $\mathrm{PhD}$ students in Denmark receive should be an appeal. While international student mobility, as the literature suggested, was originally restricted to those of financial means, Denmark seems to have found ways to increase the accessibility of education, this could increase the diversity of students. Additionally, these welfare policies, of child care, work life balance, and work place equity could be a strong incentive for female international students to either choose Denmark to study in. Danish welfare policies could increase female international student's transition into the labour force. Feminist theory suggests when institutions are inclusive of diverse perspectives and needs, that women's participation will increase. 
Through an intersectional lens, it is clear that the intersection of various oppressions could make immigration and transition to the labour market more challenging for women, visible minorities, students from a lower socio-economic background, or even students from certain countries, particularly outside the EU. The immigration process is predicted to be a significant hurdle for all international students, even those from inside the EU. With Denmark's increasing restrictive immigration systems and the rise of the DPP, all international students' immigration statuses are expected to be affected, however to varying degrees. It is also anticipated the most influential Danish institution and stakeholder in process of recruiting and retaining international students is the government, more specifically the Ministry of Higher Education and Science and the Ministry of Integration and Immigration. Due to the state centric nature of immigration policies, the government should be the most relevant stakeholder. Yet, it would be encouraging if private institutions such as businesses and organizations, were actively coordinating recruitment and retention methods.

And although, there is limited specific literature on how stakeholders are able to recruit and retain international talent, and even less relating to international students, it is predicted that stakeholders are seeking to retain international students upon graduation. This is primarily based on the need for high skilled labour to make up domestic labour market gaps, and even through stakeholder will face bureaucratic and immigration challenges hiring international students, it should be significantly less in comparative to hiring someone without Danish credentials. Immigration policies are one of the most crucial aspect to facilitating migration and are often the central aspect in discussions of migration. However, there are other aspects that the literature suggests as important, such as universities' ability to market their programs and region. The universities actually play 
a significant role in attracting students from all over the world to a region. Furthermore, universities can have a significant role in developing networks with industry for students to find jobs, however, there was less literature on this (Hemsley-Brown and Oplatka 2006). It is also predicted that a lot of recruitment and retention efforts are the responsibility of each individual stakeholder on their own to develop initiatives and strategies.

Overall the main factors predicted to influence international students' decisions to remain in Denmark are:

- Appeal of the welfare state policies and culture of acceptance.

- English language programs and work opportunities.

- Financial supports of the welfare state.

- Opportunities to study and work in a leading innovative environment.

Some of the factors predicted to deter international students from pursuing post-graduate work are:

- Desire to return home due to family commitments.

- Protracted and difficult immigration processes.

Interviews with stakeholders and international students aims to develop initial insights into why international students want to remain in Denmark, what stakeholders are doing to facilitate this, and the current hurdles that remain. There are noteworthy gaps in the current literature in all three of these areas. 


\section{Chapter Three: Qualitative Research Methodology}

This research develops initial insights on how to best recruit and retain international students. As there is currently limited literature regarding how to recruit and retain international students after graduation, supporting broad, flexible, and diverse research methods are crucial. Literature and developing the institutional context is not sufficient to gain comprehensive insights, therefore elite stakeholder interviews and international student interviews were employed. In order to understand institutions and actors it is not enough to simply recognize the policies but also the social realties encountered and experienced by actors. The lack of existing data relating to international student mobility makes qualitative research methods more useful at this stage of research. Qualitative methodology allows for the perspectives, opinions, and stories of individuals and stakeholders to provide context for a broader analysis (Gerring 19). For this reason, interviews are the most widely used methodology in qualitative research (Bryman 165). Additionally, the majority of previous literature in the fields of innovation, migration, and international student mobility relies on qualitative methods.

The research ${ }^{9}$ was conducted in Fall 2018 over a twelve-week period in Denmark. There was a total of thirty-one interviews - fourteen stakeholder interviews and seventeen international student interviews, which have all been anonymized (see annex 1). There was the broad focus on Denmark, however, due to Copenhagen's position as the capital, a lot of the research was conducted in the Copenhagen region. The specific position Copenhagen has in relation to innovation, in particular, will be elaborated in Section Four.

\footnotetext{
9 This project received Ethics Clearance (CUREB-A Clearance \#109401) from Carleton University September 2018. All interviewees signed a consent form, which explained the security procedures of the research, allowed for audio recording and clearly outlined the process if the interviewee wanted to opt out or withdraw consent up until January 2019. All interviews were recorded and transcribed in a secure method, including anonymize interviewees.
} 


\subsection{Elite Interviews with Stakeholders}

\subsection{Requirements of Interviewees}

A stakeholder was intended to include any organization, business, start-up, government agency, or university employee associated with the science and technology sector. This included the public and private institutions, to gain the most comprehensive and diverse insights on how to develop cooperative cross-sector recommendations on the recruitment and retention of international talent, particularly international students. Therefore, as long as the stakeholder had something to do with science and technology or talent recruitment, and was located, either head office or satellite, in Denmark, then they met the requirements. The interviews were considered 'elite', because the stakeholders interviewed had specialized knowledge, professionally competent, holding a strategic position, and are able to exude a certain amount of influence within their network (Harvey 433; Flick 2002). The majority of the stakeholders were directors, partners, CEOs, or senior administration, as they could best speak to the direction and challenges the organizations were facing. In total, stakeholders fell into four main categories, some being under two. These included: federal and local government agencies, recruitment organizations, sciencetech companies, or university employees. Furthermore, the individuals interviewed represented their organization, not themselves personally, and therefore no demographic information was collected, the focus was solely on the organization.

\subsection{Recruitment of Interviewees}

Prior to departing for Denmark, a contact list of potential stakeholders was compiled. Emails detailing the project, which included a more descriptive attachment, were sent to the potential stakeholders. However, it proved difficult to connect with stakeholders 
utilizing emailing alone. After not hearing back from any stakeholders within the first few weeks, different strategies were employed. On the recommendation of a local Danish educator, it was suggested to follow up with stakeholders via Facebook. This was very useful and successful advice. Another recruitment method employed was joining local online forums relating to science, technology, and start-ups in Denmark and local regions. While posts asking for volunteers proved unsuccessful, a local event on talent recruitment was listed, containing the contact information of the organizations involved. The four participants were contacted, and all agreed to be interviewed. This was the one of the most important recruitment opportunities received, as two of the stakeholders passed along contact information from their networks and provided invaluable introductions for future interviews. Specifically, the snowball method (Atkinson and Flint 1044) was crucial to finding other elite interviews and was responsible for about $35 \%$ of interviews.

\subsection{Interview Style}

An interview guide (see annex 2) was developed with initial research (Boeri et al 2012; Cerna 2014; Bosetti et al 2015; Mosneaga 2015) in international talent recruitment and Danish immigration and innovation policy. The questions were broad to allow the stakeholder to speak to any aspect they chose. Questions included; to what extent the organization relies on international talent, how does the organization attract international students, what are the most attractive aspects of Denmark, where are the main challenges in recruitment, and what would be the biggest policy change needed to improve recruitment. Since there was a wider variety in stakeholders, many questions were tailored specifically for each stakeholder, based on additional research about the stakeholder. Most 
stakeholders, once acquainted with the project, spoke at length about their organization and typically answered the majority of the questions on their own.

While face-to-face interviews were proposed at the offices of the organization, most stakeholders opted for a phone interview instead. Telephone interviews have the advantage of bridging large distances and being more time efficient for the interviewee (Brickmann 29). In the end, just under half of the interviews were conducted over the phone. As some stakeholders were quite busy, often only a fifteen-minute time slot could be committed, however, most interviews lasted closer to thirty minutes, with some being forty minutes long. All interviews with stakeholders were conducted in English, and there were no challenges with language.

\subsection{Interviews with International Students}

\subsection{Requirements of Interviewees}

The initial requirements for participation in this study was focused on international students at the PhD or Master's level ${ }^{10}$, as they were predicted to more likely be pursuing career options after and have a higher likelihood of staying in Denmark. However, throughout the recruitment process, it was expanded to undergraduate students. This was done for two reasons: the first is that Master's students were difficult to get in touch with, and; secondly, undergraduate students' perspectives offer increased understanding of recruitment and retention methods for different demographics. In the end, there were eleven PhD students, two Master's students, and four undergraduate students interviewed.

\footnotetext{
${ }^{10} \mathrm{It}$ is also important to note that $\mathrm{PhD}$ programs in Denmark are structured differently than in Canada and the US. A Danish PhD program, similar to other European programs, is typically three years in length. Students apply to a project over a school year, and they receive a salary, as it is considered more a professional research position, and includes vacation pay. Students at the $\mathrm{PhD}$ level receive the same benefits regardless of them being from inside or outside the EU. The undergraduate and the Master's students were all from within the EU, entitling them to free tuition and potential student grant payments.
} 
Research conducted prior to interviews supported that degrees in science and technology were more flexible and adaptable, which led to increased mobility and innovation (Liversage 2009). Therefore, an intentional decision was made to only interview students studying in this field. The students interviewed represented a broad base of educational backgrounds including physics, chemistry, math, and biology. There were no students from engineering.

Lastly, there was specific intentionality to have students from a diverse background, which predominately focused on gender and country of origin, as other identity factors such as sexuality or class would have been more difficult to account for. There was a total of six male students and eleven female students. It was also important to have a diverse representation of countries. Although there were still eleven EU or EEA students, they were from numerous countries such as Romania, Hungary, Spain, Italy, UK, Poland, and Norway $^{11}$. The seven students from outside the EU were from Iran, Pakistan, Canada, and Australia.

\subsection{Recruitment of Interviewees}

Students were recruited through several ways. Students were primarily contacted through publicly available email addresses for professors within STEM departments. The vast majority of professors were happy to pass along the information of potentially interested international students. Students were also recruited through online student forums such as 'International Students at Roskilde University' or 'Internationals in Aarhus'. Here, a post was made explaining the project, the requirements of students, and

\footnotetext{
${ }^{11}$ Norway is not a member of the EU, however since students from Norway are part of the Schengen Zone and the EEA and do recieve many mobility benefits from the EU, including free tuition, they are best classified with other EU students.
} 
the researcher's contact information if students would be interested in participating. Roughly a fifth of the students interviewed were recruited this way. Lastly, international students were recruited through the 'snowball method', where an initial research subject identifies other potential subjects typically based on their own network (Atkinson and Flint 1044). After a few interviews, the interviewee would suggest other students who might be interested in participating in the project. Furthermore, in two interviews, the international students brought another interested international student with them. Overall, students' recruitment was relatively easy as professors and students were more willing and interested in participating in interviews than stakeholders.

\subsection{Interview Style}

International students were interviewed individually, face-to-face in a semistructured manner, following an interview guide (see annex 3) (Flick 2002; Brinkmann 2013). Semi-structured interviews have the purpose of obtaining descriptions of "the life world of the interviewees in order to interpret the meaning of the described phenomena" (Brinkmann 2013, 21). Interviews were conducted in English, and this proved to not be a barrier as all students were studying in English.

The interview guide was designed off of initial research on international student mobility broadly and in specific relation to Denmark (Flick 2002; Salisbury et al 2010; Arthur and Flynn 2011; Mosneaga 2015; Wilken and Ginnerkov Dhalberg 2017). It consisted of nine descriptive questions aimed to understand; student's level of Danish innovation prior to studying, why they decided to study in Denmark, what reasons students have to stay in Denmark after graduation; what reasons they have to leave; what have been the major challenges with migration, and; what their plan was after graduation. Students 
were mostly asked the same questions, however some variation occurred if the student was from inside or outside the EU, as there were different migration constraints. Students were also given a one-page questionnaire and asked to rank the significance of each factor relating to why they studied abroad and the reasons for them leaving after graduation. It was prepared with the influence of Arthur and Flynn's 2011 study (annex 4), and while it

offers some insights, the questions are quite broad and potentially overlook some highly influential reason, that were only made apparent part way through the interview process.

Interviews took place most often on the campus of the university the students were studying at. Only a quarter of the interviews were done at local coffee shops, and one interview was conducted at the house of an international student who was on maternity leave. The interviews were audio recorded, with the consent of students, and additional handwritten notes were taken. The interviews lasted between fifteen and thirty minutes, though most were around twenty minutes.

\subsection{Conclusion: Challenges in Field Research}

A twelve-week period to conduct thirty-one interviews proved to be a sufficient amount of time to overcome some initial challenges with interview recruitment. Even though the initial process of finding students took a bit of time, once more information about the Danish education system was gathered, the process became simpler. Students and professors, on the whole, were very enthusiastic to participate, possibly due to their current involvement and understanding of the research process. There was capacity to have expanded the number of student interviews, if there was more time or less challenges with stakeholder recruitment. 
Overall, interview recruitment of stakeholders was more challenging than that of international students. It required significant follow up effort, and a diversity of approaches. In total, about a quarter of the stakeholders contacted were available for an interview. Most stakeholders simply did not respond or said they did not have time for an interview. Additionally, finding relevant stakeholders from the onset was a daunting task, as without any previous Danish industry networks, it is difficult to know where to start. However, the process provided significant insights into Danish businesses, such as the more relaxed and casual approach Denmark has to professional relationships, and the importance of the snowball method. Additionally, the stakeholders interviewed were incredibly keen on participating and showed great interest in the research.

There were also gaps in what countries and regions students were from. Most notably, there was no students from Asia, particularly China. This is significant as China supplies the largest population of international students world-wide, yet there were no responses from Chinese students. Furthermore, there were no students from South America or Africa - however, the number of international students from these regions studying in Denmark is far smaller than Chinese students. Stakeholder demographics were more balanced relative to the sample size, yet there were many perspectives missing in this research. Having insights from smaller tech companies and larger Danish companies such as Mærsk, International Service Systems or Carlsberg Brewing would be beneficial in developing recruitment and retention strategies based on company size. While recruitment and retention strategies need to be developed for different student and talent demographics, this is also true of stakeholders. Challenges and strategies that work for one stakeholder may not work for another. Both of these challenges could be addressed in future research. 
Furthermore, having unpredicted themes emerge later on in the research with limited ability to go back and ask students and stakeholders, was a challenge. Therefore, questions to students and stakeholder vary from the beginning to the end. A few key stakeholders were asked for follow up questions, however, they were unavailable another interview. If the field research was longer, more extensive follow up could have been developed. This would have led to increased number of comparable and quantifiable data results.

Lastly, being a white Canadian women, not in STEM, could have impacted the way in which students and stakeholders answered the questions during the interviews. Acker (2001) acknowledges the position (background, demographics, citizenship, race, gender) of the researcher can influence the responses provided and it is important to be reflexive in analyzing the themes. Being female potentially may have been a reason why female students responded more to participation requests, and even allowed me to interview in their home. However, this could have altered the way stakeholders responded, although with Denmark's general high gender equality, this was probably minimal. Students did mention issues of integration in Denmark, however, there was limited discussion on race or discrimination. My race most likely was a reason why issues of overt and subtle racism or discrimination in Denmark was not brought up.

My Canadian citizenship clearly impacted my research. One stakeholder specifically noted that they responded to my email because I was Canadian. Almost $30 \%$ of the stakeholder participants had either worked or been educated in Canada, while many others spoke highly of Canada. Being Canadian over American could have been why students felt comfortable bringing up political tensions in the US as a reason for not going to the US "I don't think I am going to try again [applying in the US], at least with this 
current administration but I am thinking about Canada" (SA Nov 7). Students were also very keen to mention their future interest in going to Canada, as 35\% of students mentioned this. While, this is not to give an extensive analysis into positionality of the researcher, it is about bringing awareness that international students and stakeholders responses may have been framed by my positionality.

There is overall difficulty in making wide generalizations or predicting trends with students as the sample size is fairly small and does not allow itself to be overly generalized. There is potential for significant expansion of this research. The following research simply offers some insights and identifies some themes important when understanding how to best recruit and retain international students, including identifying some institutional barriers. 


\section{Section Four: Context - Denmark's Institutional Environment}

Denmark provides an ideal case study for understanding the recruitment and retention of international students. This is because they receive relatively high levels of international students for their size and are considered an EU Innovation Leader. However, it is the juxtaposition between welfare state equality and restrictive immigration pathways that makes Denmark an impeccable example. Denmark institutional environment will be contextualized to explore the relevant institutions, policies, and initiatives. Three broad institutional categories that will be addressed are: institutional relationships, labour market, and immigration schemes. Specifically, Denmark's relationship with the EU and social welfare culture will be developed as Denmark's membership in the EU adds an additional layer of actors and institutions influencing how Danish stakeholders are able to recruit and retain talent. Furthermore, membership in the EU allows for increased mobility of international students into Denmark. Next, Denmark's labour market and innovative sector will be outlined to highlight where Denmark is achieving economic growth and where there are current labour gaps. Lastly, Denmark's different immigration schemes offer insights into the pathways migrants utilize when immigrating to Denmark. While this is only a brief contextual understanding of the various institutions in Denmark, if offers some initial insights into the factors that influence the ability - positive and negative - of Danish stakeholders to recruit and retain international talent. This context will also provide background for some of the motives international students consider when contemplating to leave or remain upon graduation. The contextualization of the institutional environment is supported by a combination of primary documents from the EU, OECD, and the Danish 
Government. It is supplemented by secondary academic sources, especially when describing historical origins of institutions.

\subsection{Institutional Relationships (EU, Culture, and International Students)}

The EU's institutions are highly influential in Denmark's policy outcomes, especially in regard to migration, such as the free movement of EU citizens, which includes students. Denmark entered the EU in 1973 with the United Kingdom and Ireland, whereas Sweden and Finland did not join until 1995, and Norway and Iceland still have not. Denmark's path to EU membership was intrinsically tied to that of the UK's, as Denmark originally applied with the UK and removed their application once France vetoed the UK's membership (Rasmussen and Soerensen 5). Although this has given Denmark longer time in the Union, Denmark's relationship with the EU has been shaped by referendums, numerous opt outs, and a rising Euroscepticism. This includes in 1992, when Danish citizens voted no to ratifying the Maastricht Treaty (Kruke 340). The Maastricht Treaty is a founding treaty of the EU and most notably brought in the Euro. The Foreign Affairs Office released a statement after the rejection of the Maastricht Treaty saying:

“The Danish 'no' to European Union on 2 June 1992 reflected the fact that the majority of the Danes do not wish a United States of Europe. It was not, however, a 'no' to the EC membership or European cooperation" (Foreign Affairs Office 1992).

Voting against the Maastricht Treaty highlighted that, while, Denmark is supportive of an economic union, they were more hesitant to social and political integration (Krunke 341). This is still true today. Agreement and ratification of the Maastricht Treaty was eventually reached in 1993, upon a second Danish referendum. The referendum included the provision of a 'national compromise' of the following opt-outs from the Eurozone, Common Security and Defense Policy, Justice, and Home Affairs (Rasmussen and Soerensen 5; Krunke 344). 
These opt outs are codified in the Edinburgh Agreement (European Parliament 1992). The mid 1990s saw an increase of functional spillover from the Economic and Monetary Union to the social dimension of EU integration (de la Porte and Heins 10). This marked a progression towards EU policy and integration extending to the social development and social security of all citizens. Generally, the Nordic countries are more supportive of the economic integration of the EU, however, they are sceptical of the EU's potential impact, through social dimensions of integration, to the Nordic welfare model.

Euroscepticism ${ }^{12}$ is based on the reluctance or disbelief in the European integration process but does not always entail a full rejection of integration rather a haste and caution to the type and method of integration (Szczenbiak and Taggart 2; Hooghe and Marks 120). The euroscepticism in Denmark originated out of the left-wing perspective of protecting the welfare model, local economy and national identity, however, the Danish People's Party - DPP (Dansk Folkparti) ${ }^{13}$ a right-wing populist party, is currently the driving force of euroscepticism throughout the country. The DPP was founded in 1995 as a more radical right-wing party but in the early 2000s moved more to the center to increase their voter base (Topaloff 177). Currently, the DPP has 21\% representation in the Danish Parliament (Folketing). The DPP is an active critique of the EU especially around issues of migration and has played an influential role in the recent Danish immigration restrictions.

Briefly, when understanding what institutional level - EU, member state, regional - policies should arise out of the principle of subsidiarity is utilized. The principle of subsidiarity is the "idea that action should be taken at the level of government which is best

\footnotetext{
12 According to the Oxford English Dictionary, the term Euroscepticism first surfaced in a 1992 Economist article as a way to describe the current rising anti- EU sentiments in Germany (Hooghe and Marks 120).

13 The DPP formed in 1995, after it broke off its predecessor, the Progress Party, and made euroscepticism central to their identity. The DPP does not regularly advocate for the complete withdraw of the EU but rather focuses their rhetoric on Schengen, immigration, crime regulation and border control (Topaloff 176). Conversely, DPP does support free trade, the single market, and the intergovernmental approach of the Council of Ministers, however takes issue with defense and monetary integrations, which are consistent with the Danish opt outs (Topaloff 178).
} 
able to achieve policy goals but as close to the citizens as possible" (Bomberg et al 27). It guides the EU and member states in deciding where policies should arise out of. Therefore, when the EU and member states wanted to develop policies to strengthen higher education credit recognition, the EU and European region level was the ideal choice.

To facilitate and strengthen education throughout the European region, there has been numerous policies, often arising out of the EU, to support degree recognition making studying abroad more accessible. The initial progress towards common academic recognition was the Convention on the Recognition of Qualifications Concerning Higher Education in the European Region adopted in April 1997 (Council of Europe 2018). Since then, there have been various proceedings to integrate academic recognition, such as the Bologna Process ${ }^{14}$, the Bucharest Communiqué ${ }^{15}$, and the Reykjavik Declaration ${ }^{16}$. This standard of recognition goes beyond the Lisbon Recognition Convention with aims that institutions - education and other wise - will strengthen the mutual recognition of the educational credentials of students and those entering the labour market.

Post-secondary education responsibilities in Denmark are under the purview of the Ministry of Higher Education and Science. The institution's responsibilities include; education research, credential recognition, policy development, and international education engagement (Ministry of Higher Education and Science 2018). The Ministry additionally oversees scientific research, innovation, and the space agency (Ministry of Higher Education and Science 2018). Furthermore, the Ministry is responsible for the changes to international student enrollment in Danish universities, which, as mentioned,

\footnotetext{
14 The Bologna Process was a series of meetings in 1999, intended to ensure the mutual standard and quality of higher education credentials (European Commission 2018).

15 In 2012, 47 members of the European Higher Education Area released a joint statement regarding their mutual support increased higher education quality assurances, including degree recognition (Bucharest Communiqué 2012). ${ }^{16}$ Signed by members of the Nordic Region (Denmark, Sweden, Iceland, Finland, Norway) in 2004. This declaration supports mutual degree recognition for students who attend post-secondary institutions in member countries (Reykjavik Declaration 2004).
} 
will result in a reduction of 1,000 students in Fall 2019. Denmark hosts upward of 22,000 international students annually, proportionately higher than the OECD and EU average. In recent years changes to tuition and student grants for EU citizens has led to significant enrollment increases. In a five-year period (2007-2012) Denmark's international student numbers doubled, which is well beyond the international growth rate. This highlights when Denmark, despite high living costs, made education more affordable, Denmark, in turn, education more accessible. Over $80 \%$ of international students in Denmark are from the EU, with around 5\% total from Africa, North America, and South America, and just under 10\% from Asia (Eurostat 2018).

\begin{tabular}{|l|c|}
\hline Country & \% of non- EU/EAA International Students \\
\hline United States & $25 \%$ \\
\hline Philippines & $10.7 \%$ \\
\hline China & $9.9 \%$ \\
\hline Nepal & $7.3 \%$ \\
\hline Ukraine & $6.5 \%$ \\
\hline Australia & $3.7 \%$ \\
\hline Canada & $3.4 \%$ \\
\hline
\end{tabular}

Table 1: Non-EU International Students by Country of Origin, 2015. Source: The Danish Immigration Service, 2015, Statistical Overview.

The vast majority of EU international students are from other Nordic countries and the newer EU states such as Bulgaria, Romania, and Poland (Wilken and Ginnerkov Dhalberg 1349). Most Danish students who study abroad go to another Nordic country, France, the UK or the US (Munk 10). Although Denmark is incredibly attractive to international students, the need to protect the welfare state has influences the decision to reduce the number of international students (Gadd 2018b). This emphasises Denmark's 
juxtaposing balance between social welfare and equality, with immigration and resource consumption.

Denmark's institutions are deeply influenced by maintaining strong and insular cultural connections and the Nordic ${ }^{17}$ social welfare model. The Nordic welfare system typically includes; a larger public service, dual bread winner model, and free and equal access to services such as education and health care (Jensen et al 2017; Copenhagen Capacity 2019). As Epsing-Anderson describes, the Nordic states all fall under the social democratic welfare model premised on high decommodification, strong universalism, and increased role of government (1990). While the Nordic states do have higher taxes and state supports, the welfare state should still be understood within the context of market capitalism (Siim 622). The former Prime Minister of Denmark, Helle Thorning-Schmidt highlighted the benefits of the welfare model:

"It is a very interesting model for the ordinary person, because what we have created here is that a kid from a divorced background from the south of Copenhagen like myself can actually, without any money from home or anything, take a degree, go to good schools, and become prime minister" (Financial Times, Milne, 2014).

Denmark is regarded as an older culturally homogenous nation-state that supports freedom, egalitarianism and regards themselves as tolerant and fair (Gudrun et al 52). Society is premised on high social trust or each other and institutions such as government, police, and hospitals (Jensen et al 2017; Denmark.dk 2019). Denmark values the concept of 'hygge', although difficult to define, is about the atmosphere and experiences of being happy, cozy, with family, and enjoying moment (Wiking 6). Gender equality is one of the main tenets of the Danish welfare society culture and often used as a marker of integration

\footnotetext{
17 The Nordic welfare system refers to Norway, Sweden, Denmark, Finland and Iceland, whereas Scandinavia would only refer to Norway, Sweden, and Denmark. Although each country approaches the model differently the similarities are numerous, and they are distinct from other regions around the world.
} 
(Rolandson and Sata 2013; Meret and Siim 2013) Strong work ethic is respected throughout the state but so is family, personal relationships, and enjoying moments. This impacts Denmark's attractiveness two-fold, support for work-life balance and close networks is an appealing characteristic, but it can lead to insular networks, difficult for migrants to integrate into. This can be exacerbated by cultural, racial, and religious differences. While Denmark might be the 'happiest people on earth', there are perceptions of Danes as not friendly or approachable when it comes to casual and random connections with strangers (Wiking 216). It can be difficult to make connections with Danes as an 'outsider' and almost everyone who grew up outside of Denmark, despite citizenship, falls within this category. Denmark has attempted, similar to Norway and Sweden, to develop integration initiatives to ease new immigrants' transition into society (Guiliherme Fernande 247). Sweden was the first to launch this type of initiative in 1991, with Denmark in 1999 and Norway in 2004 (Guiliherme Fernande 247). It is currently still mandatory under the Integration Act ${ }^{18}$ to obtain permanent residency in Denmark (Ministry of Immigration and Integration 2013). The aim of integration programs is to transform the individual rather than institutions into what the preconceived notions of a good Danish citizen is. Denmark's system is regarded as stricter than Norway or Sweden as it aims at changing values and norms of individuals (Guiliherme Fernande 253). This is a strong example of how Danish institutions are attempting to construct, influence, and alter the norms of individual actors.

\subsection{Labour Market}

Denmark is a modern industrial country with an economy relying on traditional sectors such as shipping and brewing, as well as engineering, pharmaceutical, and

\footnotetext{
18 Integration Act is only in Danish. However, an overview of the most recent amendments are translated into English on the European Commission's website (https:/ec.europa.eu/migrant-integration/librarydoc/integration-act-asamended-october-2017).
} 
agricultural machinery industries (OECD 2004). Out of all Danish industries, 35\% are considered high-technology industries, such as Information and Communication Technology (ICT), green technologies, and biotechnology, which have some of the highest rates of innovation (Statistics Denmark; Danish Agency for Science, Technology, and Innovation 2014). These are also industries overwhelmingly dominated by men (The World Bank 2017; Rilley et al 2017). In 2016, the employment rate in Denmark was $77.4 \%$, compared to the EU average of 71\% (Skills Panorama 2015). Women on average were employed about 5\% less than men (The World Bank 2017). There were no aggerated statistics by other factors such as income, race, or age. The EU Skills Panorama, which "turns labour market data into accurate and timely intelligence to offer new insights into the skills needed in the EU', predicts the sectors with the largest employment growth between 2015-2025 will be: finance and insurance (50.1\%), professional services (23.1\%), and ICT services (14\%) (Skills Panorama 2015).

However, due to the rising developments in these industries there is an increasing shortage of skilled employees, causing the Danish government to focus on education of domestic and international students in this area. In 2018, Denmark's Agency for Labour Market and Recruitment published their strategy Building Tomorrow's Labour Market Together, where the focus was on strengthening the labour market through policies that support businesses receiving the labour they need and citizens' participating in meaningful employment (2018). There was no mention of labour recruitment from outside Denmark. Specifically, there are over 1.7 million Danes with tertiary education relating to or employed in the STEM field (European Commission 2017b). However, this is not sufficient to meet the projected gaps nor increase innovation, therefore Denmark is increasingly relying on high skilled international talent, despite no concrete strategy. In 
March 2018, the Danish Employment Minister, Troels Lund Poulsen noted the record high employment rates and that:

"in order to keep up the momentum of the economic upturn, it is vital that companies are able to obtain the labour that they need. Otherwise, we run the risk that a labour shortage could end up acting as a brake on growth" (Gadd 2018a).

Denmark has an opportunity to develop inclusive and substantive recruitment and retention practices, which is crucial for supporting increased innovation.

The current economic situation in Denmark is one of leading innovation, which extensively relies on the movement of people and increasing internationalization. Danish innovation goes beyond the development of LEGO - arguably one of the most conducive and popular childhood toys for sparking innovation. In 2014, the Danish Agency for Science, Technology, and Innovation published Research and Innovation Indicators, which outlined the ways in which Denmark is leading innovation - from patents to $\mathrm{PhD}$ graduates to funding for research in the public and private sector (2014). This is the government's most recently published initiative. Denmark is the $12^{\text {th }}$ most competitive country internationally on the $2016 / 2017$ Global Competitiveness Index, which is based on twelve pillars of competitiveness (World Economic Forum 2018). According to the European Innovation Scoreboard, Denmark, along with Finland, Sweden, Germany, and the Netherlands rank as Innovation Leaders with innovation, well above the EU average (World Economic Forum 2018). This makes the entire region attractive for international talent and students.

Denmark's particular innovation strength lies in their ability to finance and support Research and Development (R\&D) - one of the most crucial aspects in supporting and strengthening innovation (European Commission 2015). The Danish government set a R\&D intensity target of a $3 \%$ increase by 2020 , which they surpassed in 2014 , making 
Denmark the first country in the EU to have met their target (EU Publications 2017; Danish Agency for Science, Technology, and Innovation 2014). Additionally, Denmark is excelling in innovation due to their support of entrepreneurship, and currently ranks among the top 10 entrepreneurial countries internationally, along with the US (Woodside et al 137). Denmark's perceived political and economic transparency, in addition to limited economic inequality, has produced conditions suitable for entrepreneurship (Woodside et al 138). Training and education have been key in promoting entrepreneurship throughout Denmark, as $60.3 \%$ of men and $51.7 \%$ of women stated they currently have and had access to training on how to start a business (OECD 2013). Having internationally recognized strengths in R\&D and entrepreneurship makes Denmark an attractive destination for high skilled migrates and international students, all of which are critical to increased innovation.

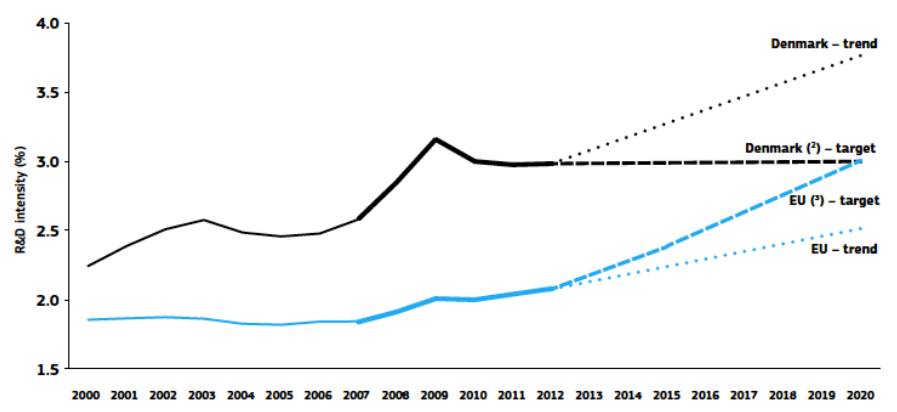

Table 2: R\&D projections 2000-2020. Denmark Compared to EU Trends and Targets.

Source: European Commission 2014, Research and Innovation Performance in Denmark.

In 2016, the Danish government launched the 'Strategy for Denmark's Cluster and Network Policy' to strengthen growth and knowledge-based development throughout the country and its various regions (Ministry of Higher Education and Science 2016). This strategy sets out clear objectives for public policy coordination, support, and evaluation of clusters' growth in innovation (Ministry of Higher Education and Science 2016). Out of 
the 5.7 million people living in Denmark, 1.2 million live in Copenhagen, which forms part of the important Greater Copenhagen region innovation and technology cluster and NUTS2 region (World Population Review). Within Denmark, this cluster is the most densely populated and has the highest per capita GDP (European Commission 2017a). Further, according to the European Regional Innovation Scoreboard the Greater Copenhagen region is also the second most innovative region in Europe (European Commission 2017a). The region is home to specialized clusters, such as the Copenhagen Healthtech Cluster - which connects business together to develop and implement digital health care solutions (Copenhagen Healthtech Cluster 2018). In comparison to the EU and other clusters in Denmark, Copenhagen's strengths lie in public-private collaboration, and in life-long learning, while certain weaknesses exist in the marketing of new innovation and comparatively low non-R\&D innovation expenditure.

\subsection{Immigration Schemes}

Denmark's population born outside of Denmark is roughly $11.5 \%$, with the largest international migrant populations coming from Sweden, Norway, Finland, Germany, Poland, Syria, and Turkey (Eurostat 2015; Migration Data Portal 2018; The Ministry of Immigration and Integration 2017). The Danish government's definition of an immigration is:

"An immigrant is defined as a person born abroad whose parents are both (or one of them if there is no available information on the other parent) foreign citizens or were both born abroad. If there is no available information on either of the parents and the person was born abroad, the person is also defined as an immigrant" (The Ministry of Immigration and Integration 2017). 
Denmark receives on average about 60,000 new immigrants per year, with most - $19 \%$ settling ${ }^{19}$ in the Copenhagen region (The Ministry of Immigration and Integration 2017). While Denmark over the past twenty years has roughly had equal migration between men and women, the last five years have seen significantly more men than women - about 5,000 more men a year (The Ministry of Immigration and Integration 2017). Yet, there are difficulties in recruiting, retaining, and utilizing high-skilled labour from around the world (OECD 2004; OECD 2014). Denmark does not have a nation-wide strategy for attracting high skilled immigrants.

Although Denmark is part of the Schengen Zone and the European Economic Area (EEA), it along with other Nordic welfare states, shares a more restrictive stance on immigration that has failed to adequately integrate migrants into the labour market. Established in 2001, the new Ministry for Refugees, Immigration and Integration was responsible for both asylum policies, mainly through the Aliens $A c t^{20}$ that regulates entry to Denmark and temporary or permanent residence permits, and integration policies, such as the Integration Act that lays out the rights and obligations of those living legally in the country (Jensen et al 60; Ministry of Immigration and Integration 2013). The Ministry was renamed in 2011 to the Ministry of Immigration and Integration ${ }^{21}$. Starting in the early 2000s, with the rise of the DPP, immigration policies have become increasingly restrictive. Access to Denmark through family reunification, and the transition to permanent residency and citizenship have become more difficult, (Ugland 147). In 2011, the now Danish Prime Minister Lars Løkke Rasmussen said:

\footnotetext{
${ }^{19}$ New immigrants, specifically refugees, are distributed throughout each municipality, where social services are tied to continued residency in the area (The Ministry of Immigration and Integration 2017).

20 The Aliens Act is translated into English - Consolidation Act No. 608 of 17 July 2002 of the Danish Ministry of Refugee, Immigration and Integration Affairs

21 The Danish government website on the Ministry of Immigration and Integration is primarily in Danish, while other Ministries such as Foreign Affairs are in Danish and English. There are a few sections in English, such as on Brexit.
} 
"We want to get a grip on the immigration policy so that the influx of asylum seekers and people coming here through family reunification is brought under control" (World Economic Forum 2011).

According to the United Nations Migration Data Portal's migration control index, Denmark receives a 0.8 rating, with 0 being less restrictive and 1 being most restrictive, and in regard to the percentage of policies in the past twenty years that have led to lessen migration restrictions, $44 \%$ of Danish migration policies made it easier to migrate to the country (2018). Comparatively, 52\% of Norwegian policies, $66 \%$ of Finnish policies, and $71 \%$ of Swedish policies supported a more liberalized immigration system (Migration Data Portal 2018). The most recent policy changes include new rules regarding religious workers, which aim to:

"prevent extremist speakers with views and values that are in conflict with fundamental Danish values, who constitute a threat to public order to enter the country... In order to obtain a residence permit as a religious worker, a sworn declaration stating that one will not engage in any activity that poses a threat to public safety, law and order, health, decency or the rights and duties of others must be signed" (The Ministry of Immigration and Integration 2017).

Other policy changes are border controls with Germany, changes to the Refugee Board, an "emergency brake" to permit rejection of asylum seekers at the border, collection of biometric information, new rules at unaccompanied minor centers which permit the "use of force", and that Denmark will not accept any more "quota refugees" (The Ministry of Immigration and Integration 2017). The restrictive and protracted nature of immigration pathways weighs negatively on the recruitment and retention efforts, and in turn the innovativeness and competitiveness of Denmark and Danish industries.

Denmark's international labour recruitment strategies begin to take into account the dependency and need of Danish employers on international labour (Ostling ${ }^{22} 2013$ ).

\footnotetext{
${ }^{22}$ Ostling's study was co-financed and published by the European Union.
} 
Adaptability as a key concept and requirement weighs strongly in the process of immigration selection. It is constituted by a set of factors including "educational background, economic self-sufficiency, language proficiency, and lasting labour activity" (Ostling 2013). Ultimately, Denmark strives to ensure that immigrants provide positive economic and social contributions to the labour force if they intend to stay long-term, and that immigrants are only admitted and allowed to stay in the country if they are likely to meet the requirement of 'adaptability'. Currently, Denmark's immigration policy for high skilled workers includes mandatory labour market tests and shortage lists. Supportive labour migration policies are crucial for Danish immigration as about $80 \%$ of migrants residing in Denmark are of working age (Migration Data Portal 2018). There are numerous initiatives and schemes for immigration from outside the EU and the European Economic Area (EEA) into Denmark. However, only those relevant to this research will be expanded on. These schemes are: Positive List, Start-Up Denmark, Pay Limit, and Establishment Card (see table 3).

However, first it is important to briefly touch on how international students, from outside the EU, are able to migrate to Denmark. The ability to study in Denmark is set out in Executive Order 1550 on the Issue of Residence and Work Permits for Students from 2014 (The Ministry of Immigration and Integration 2017). All applications are submitted to the Ministry of Immigration and Integration and take anywhere from one to two months to process and costs $1,900 \mathrm{kr}$ ( $\$ 380$ Canadian) (New to Denmark 2018 ${ }^{23}$ ). The conditions to apply for a student residence permit are: an official offer from a Danish university; proficiency of the instruction language; and proof of $6,166 \mathrm{kr}$ ( $\$ 1,255$ Canadian) for each month studying in Denmark (New to Denmark 2018). Students are also required to have

${ }^{23}$ Immigration documents online are solely in Danish. The New to Denmark website, is the main government portal for information on immigration pathways. 
their biometric information collected (fingerprints, eye scans, and signature) digitally recorded in a Danish database to receive a residency permit (Study in Denmark 2018c). Students from within the EU or the EEA are able to study at a Danish university with only a residency certificate, which allows them to receive a CPR (person number) and health insurance.

The Positive List scheme is a list compiled on the basis of the demands in specific industry sectors. The minimum qualifications and requirements in each field are outlined, and the list often provides one of the easiest pathways into the Danish labour market. A written job offer is required, and applicants also have to meet certain educational requirements, typically holding a Master's degree (The Ministry of Immigration and Integration 2017; New to Denmark 2018). A wide scope of positions are included on this list, such as engineers, IT positions, health care professionals, and program developers.

In 2015, Denmark created the Start-Up Denmark scheme to attract international entrepreneurs to establish and run a company and to contribute to innovation and growth in Denmark (New to Denmark 2018; The Ministry of Immigration and Integration 2017). The program targets entrepreneurs in life science, ICT, design and clean-tech, and sustainable energy. Applicants are required to submit a business proposal and proposals are reviewed and require the approval of experts appointed by the Danish Business Authority. There is an annual cap of maximum 50 permits issued a year (The Ministry of Immigration and Integration 2017; New to Denmark 2018). This immigration scheme is directly aimed at growing innovation, however, the scope of permits issued is relatively small to meet labour demands and compete in global innovation.

The Pay Limit scheme allows immigrants to enter into the labour market by having a job offer that pays more than DKK 417,000 (about $\$ 88,000$ Canadian) (The Ministry of 
Immigration and Integration 2017; New to Denmark 2018). Currently, there is political discussions on potentially lowering the wage requirements to meet demands in labour shortages. This is the broadest category only requiring a certain salary. The Pay Limit scheme does not take into account the intersectional aspects that make that wage unattainable for certain individuals.

Establishment Card scheme is only for Master's and $\mathrm{PhD}$ graduates who apply within 6 months of graduating, and if the student can prove they currently have sufficient funds to support themselves for the next year, which is over 88,000 Danish Kroner (kr) roughly $\$ 17,000$ Canadian (The Ministry of Immigration and Integration 2017; New to Denmark 2018). The sufficient funds amount increases if you have family to support (New to Denmark 2018). This is the only scheme directly intended for international students and remains unattainable for most students, due to the immense financial component, further privileging certain socio-economic status of migrants.

It is lastly important to highlight the EU Blue Card, which:

"is a work permit issued by 25 out of 28 EU Member States to highlyqualified non-EU citizens. Introduced in 2007 by the European Commission, the Proposal became officially known and implemented in 2009 as the EU Blue Card Directive with intentions to stimulate economic development by making Europe a desirable destination for qualified workers to practice professional knowledge and skills as well as allowing free movement within the European Union for non-EU citizens" (EU Blue Card 2015).

Most notably, Denmark, the UK, and Ireland opted out of this scheme (EU Blue Card 2015). This restricts the avenues for high skilled migration wanting to enter Denmark to just the aforementioned schemes, which can make Denmark less competitive in comparison to other EU member states with the Blue Card. 


\begin{tabular}{|l|l|}
\hline Program & Percentage \\
\hline The Pay Limit Scheme & $28 \%$ \\
\hline Green Card and Establishment Card & $13 \%$ \\
\hline Fast-Track Scheme & $6 \%$ \\
\hline Researcher and Guest Researcher & $5 \%$ \\
\hline $\begin{array}{l}\text { The Start Up Denmark Scheme and Self } \\
\text { Employment }\end{array}$ & $<1 \%$ \\
\hline Other & $48 \%$ \\
\hline
\end{tabular}

\section{Table 3: Access for STEM Talent and Other High-Skilled Workers to Denmark. Work Permits Issued in 2015 Under Different Programs. \\ Source: The Danish Immigration Service, 2015, Statistical Overview.}

There is limited information on who is entering Denmark under which scheme. Better statistics would allow for inclusive strategies to reduce the perpetuation of certain biases inherent in each scheme, often premised on high socio-economic backgrounds. The labour market, along with the policies creating these schemes, is gender, racialized, and classed, therefore talented innovative people are being overlooked because they do not meet the narrow criteria of what a high skilled migrant should be.

To meet the requirements set out by the Danish government for permanent residence status in Denmark, the applicant must (The Ministry of Immigration and Integration 2017):

- Meet the continuous requirements of the temporary residence permit

- Have legally resided in Denmark for 8 years and in exceptional circumstances 4 years

- Have not been convicted of certain crimes

- Not have any overdue public debt

- Have not received any form of social benefits in the last four years 
- Make a declaration of integration into Danish society ${ }^{24}$

- Pass a language test

- Have been employed for three and a half years in the last four years, and have current employment

- Have not worked against the establishment of their identity

In addition to meeting the above requirements, the applicant must also meet two of four supplementary requirements (increase language proficiency, employed for last four years, pass active citizenship exam, and a certain average income). After this process, it is possible to gain citizenship, yet very challenging as Denmark often only grants citizenship through Danish heritage.

\subsection{Conclusion: Regional Recruitment Initiatives}

Denmark's high level of innovation attracts international talent to participate in an innovative business environment. Denmark is excelling in areas of entrepreneurship, lifelong learning, and funding of R\&D. The Danish government's attention to the importance of innovation clusters is a strength within their policies and initiatives. Furthermore, the Greater Copenhagen region is leading the country in innovation and providing an exemplary model to other regions within Denmark and the EU. However, overall Denmark is not overly well known in regard to innovation and tech, therefore companies are utilizing the strengths of recruitment agencies, and local governments are developing initiatives to connect more high skilled international talent with innovative companies. An example of this is civil society organizations like Copenhagen Capacity. Copenhagen Capacity is

\footnotetext{
${ }^{24}$ In 2010, the Integration Act was changed so acquisition of permanent residency is based on 'successful integration' and responsibility to integrate (Jensen et al 62).
} 
providing universities, large and small businesses, research institutions, and other organizations with free tools to market Denmark as part of the recruiting top global talent process (Copenhagen Capacity 2018). Copenhagen Capacity additionally supports international business and companies in setting up new offices in the Greater Copenhagen region. Overall, Copenhagen Capacity is the main and largest organization focusing on talent recruitment in the area and has also begun to support other Danish regions in setting up their own versions. Additionally, Copenhagen developed The Capital Region of Denmark: Regional Growth and Development Strategy with the aim to create a green and innovative metropolis area to attract people from around the world (Greater Copenhagen 2015). The two goals are to achieve (1) efficient and sustainable mobility, and (2) a highly skilled workforce and internationalization (Greater Copenhagen 2015). In addition, the strategy aims to create more opportunities for international talent to gain access to employment. By 2025, the region hopes to be in the top five of the most attractive places worldwide to live and work (Greater Copenhagen 2015). These are all regional initiates and do not integrate national public and private institution cooperation. Furthermore, there is no national level initiative to recruit international talent. The Danish Agency of Labour Market and Recruitment only supports increasing the number of Danish citizens into the labour market, not immigrants. There is limited overall coordination between Danish institutions and actors. 


\section{Section Five: Stakeholder and International Student Interview Findings}

\subsection{Stakeholder Perspectives and Insights: "Why We Do This? Because We Are an Unknown Part of The Talent Ecosystem"}

The stakeholders interviewed were members of federal and local governments $\left(\mathrm{DG}^{25}\right)$, talent recruitment agencies $\left(\mathrm{RA}^{26}\right)$, companies (start-ups, gaming, finance) $\left(\mathrm{DC}^{27}\right)$, and universities $\left(\mathrm{UP}^{28}\right)$. Each stakeholder had a varying degree of internationalization; some had numerous employees from abroad, while others had mostly Danes with their own international experiences.

\subsection{Existing Recruitment Strategies by Danish Stakeholders}

Four stakeholders broadly worked in talent recruitment and were highly attune to the current institutional landscape of recruitment and retention of international talent. These stakeholders, and others, all identified the urgent need for high skilled international talent. One of the reasons for specific talent recruitment agencies is that:

"[Copenhagen is] an unknown part of the talent ecosystem, we are not top of line, when you ask a software developer, they would not say Copenhagen they would think Berlin, Amsterdam, Silicon Valley... We are just unknown, so no one would notice us unless we are out there making them aware" (RA1 October 2018).

Copenhagen is simply not as well-known enough, increasing the need for targeted and cooperative recruitment strategies. Additionally, many smaller companies are now using "local head hunters and recruiters to help...with all the recruitment" (DC1 November 2018). Other companies simply do not have any recruitment departments and at times need

${ }^{25}$ Danish Government (DG)

${ }^{26}$ Recruitment Agency (RA)

${ }^{27}$ Danish Companies (DC)

${ }^{28}$ University Professors (UP) 
to scale up quickly, therefore expertise to guide this process is required. Furthermore, it is "too hard to recruit talent, and requires too much manpower", thus a start-up decided to develop a digital talent recruitment agency to bridge this gap (RA2 October 2018). Stakeholders noted that Denmark is beginning to take more coordinated steps to acquire top talent, with significant emphasis on international talent.

Additionally, the reason companies are increasingly requiring assistance in requirement is because:

"all recruitment up until a couple of years ago has been based on the company as king... We have seen a turnaround in the fundamental process, the company now has to ask the candidate to the company... so now as the company you have to be the attractive part, you have to convince the candidate to work for you" (RA2 October 2018).

This is why so many companies advertise the additional 'perks' of their work space, as the entire work culture becomes part of the job's attractiveness. One stakeholder's acknowledgement of this shift is "we cannot tell someone you need to move here. We cannot set up the rules, we follow what the candidate wants" (DC5 November 2018). In an era where talent has more negotiating power, companies need increased resources, such as recruitment strategies, to stay competitive. When stakeholders were asked if there were any national strategies or policies regarding any overarching national strategies dedicated to innovation and international talent recruitment, they all said they did not know of any. However, a representative from Copenhagen Capacity was interviewed, who, as mentioned before, main objective is to attract and support international talent and businesses to the Copenhagen region. In their words:

"We are the official investment promotion agency in the capital Copenhagen region, ... When it comes to talent attraction, the initiative is six years old, it started after the financial crisis, there were a few companies that were growing and screaming loudly, especially Microsoft, as they were considering on opening up a financial center in the Nordics, and they reached out to us and said if we are to establish a center in Copenhagen we need to make sure we are 
able to hire the people we need to be a success, this initiated a big project with a larger number of stakeholder, universities, municipalities, regions... Over the years we have developed from dealing primarily with broad marketing and making noise about career opportunities here, we still do that but very concretely it was a number of portals to expose the clean tech industry, life science and the IT tech sector, so we still do that marketing but we have also developed over the six years, we have built a career portal, e-marketing tool_we sell jobs-, it is a way of putting hooks in people and putting messages about the region and why they should come, we also put hooks through tracking IP address with targeted ads, banner ads, so we keep this momentum." (RA1 October 2018).

\subsection{Recruitment of Women in an Underrepresented Field}

Stakeholders mentioned an overall lack of female international talent in science and technology, yet none cited any specific initiatives to recruit women or any other underrepresented group. One stakeholder noted that the biggest challenge in recruiting more women is:

"that there is a lack of female talent... [companies] are screaming for it because diversity is very high on the list in terms of gender, background, education background, also from different parts of the world" (RA3 October 2018).

Another stakeholder said she has never even interviewed a female Danish programmer, and herself and another woman are the only female programmers in her company (DC1 November 2018). A crucial aspect in science and technology that is often overlooked, as one stakeholder pointed out, is investment. The investment scene is highly male dominated, and it is hard to find business angels that are women, which leads to businesses perpetuating and institutionalizing the needs and perspectives from a masculine stance. While Danish institutions can be perceived as fairly appealing to women, due to its high rates of gender equality and family friendly work policies, this has not translated into inclusive and deliberate recruitment practices. Stakeholders were only asked about women and they did not bring up any other challenges for individuals in other underrepresented areas. 


\subsection{International Student Recruitment and Retention}

Stakeholders were asked if they had or knew of any larger coordinated initiatives to recruit international students into the labour force upon graduation. None of the stakeholders cited or were aware of any national initiatives or strategies. They further did not mention how policies or laws at the national level were hindering the process of retaining international students. However, one stakeholder had a partnership with a government agency, which invites international students to an event with businesses and companies to foster networks and connections (RA1 October 2018; DG2 November 2018).

Prior to the event, the International House works with selected international students, often from sciences and engineering:

"to prepare them for jobs, like $C V$, how to prepare a cover letter, how to approach the companies, we do different exercises to prepare them for the job interview, we do different presentation techniques, we teach them about phone calls, we try to practice how to call up a company... Then we have information about Danish citizen culture, entrepreneurship, how to set up own company. And after all this they have a mentor" (DG2 November 2018).

One stakeholder did mention their own recruitment of international students is through internships and career fairs, as they are keen on hiring students (DC 4 October 2018). However, they also did not say how often they hire students though. Internships were the most common method of recruiting international students, according to the stakeholders interviewed.

The most relevant stakeholder, in regards to retention of international students, is the federal government who said:

"the minister wants to gather the universities, business sector and student organizations and the local authorities to have them sit together to discuss how to retain more students" (DG1 December 2018). 
The government even mentioned a recent initiative to foster international student recruitment when the:

"Southern Denmark University ... faced some challenges in recruiting qualified IT employees. They have done a project where universities and businesses have offered internships to international students. That is an example that has been working well" (DG1 December 2018).

This is a positive step to greater recruitment coordination initiatives. Conversely, there is limited information regarding where recruitment efforts should be targeted, despite the fact that students in the "more the technical programs were retained... In general, within the humanities, there was more that left the country" (DG1 December 2018). While there are some contradicting strategies of the Danish government, such as the reduction international student enrollment, it is clear that the focus is on retention strategies and not recruitment of new students.

\subsection{High Quality Living and Work Culture}

The work culture and lifestyle afforded in Denmark, according to stakeholders, is the number one reason people come to Denmark, particularly Copenhagen, and the best asset the Danish government and businesses have to attract international students and talent. As one stakeholder said it is about "thinking of the whole not just work or life" (RA3 October 2018). Most of the stakeholders' observations regarding lifestyle and culture was in relation to international talent more generally - rather than a specific focus on international students. There was less differentiation of recruitment and retention strategies between international student and international talent. Stakeholders made comments such as:

"in Denmark there is a big focus on you needing to be able to live outside your job" (RA2 October 2018), and; 
"the work life balance in Denmark is also attractive and the [Copenhagen] is branded as very high-quality living city that gives us an advantage when recruiting" (DC4 October 2018).

High skilled individuals looking to have a successful career in an innovative science and technology field, while also raising a family, perceive Denmark as an incredibly attractive place to live and work in. This is exemplified by the city of Copenhagen through comments such as:

"the whole buzz around Copenhagen really helps us with recruitment ... the city is branded as very high-quality living city" (DC4 October 2018), and;

"in general I think Copenhagen is a really nice city in terms of quality of living, it is a really comfortable city to live in, ... it is not a huge metropolitan but it has it has a certain international vibe but you can bicycling around, swim in the harbour, it is clean nice" (DC6 November 2018).

There are also significant initiatives in talent recruitment and international student retention that arose out of the city, that other cities, like Aarhus, are only just beginning to develop.

Half of the stakeholders noted the extensive welfare benefits employees receive in Denmark. New parents receive at least one year of parental leave, where both fathers and mothers are expected to take time off, which is very important in strengthening gender balance in the workplace. One stakeholder, working for a gaming company, said:

"It is not just the moms that go early to pick up their kids, the dads do it too. It means that you do not feel different because you are a mom" (DC1 November 2018).

Stakeholders also want to make it clear that "family friendly is not an opposite to doing business", that businesses can support their employees lives beyond work but still be an internationally competitive company (DC6 November 2018). Some stakeholders did mention that this aspect of the culture could be less attractive for millennials and recruitment strategies should take into account different generational needs. 
Besides work culture, stakeholders noted that one of the most significant ways to retain international talent is through love and relationships:

"we have found the best way to make [international students] stay is to fall in love with a Danish citizen. That is what makes people stay. If you find your soul mate you will stay" (DG3 November 2018).

An under rated aspect in retention of internationals is their relationships with Danes, which can be significantly fostered through supportive integration methods, although stakeholders did not propose any methods. A number of international stakeholders interviewed noted their reason for coming to Denmark was love and a relationship they had with a Dane. This is also an important aspect for international student retention, as they have already been in Denmark for at least a few years, therefore with greater potential to foster relationships. Some international students did note relationships as being a reason to stay, while other students noted their relationships as an influencer to migrate elsewhere.

\subsection{Language Preferences in the Workplace}

Challenges with working languages were brought up in $70 \%$ of the interviews. Most of the organizations that speak English are Fintech, small start-ups, or large international companies, while the medium size companies tended to speak Danish. The companies that had English as the working language, were more successful in having a stronger internationalized focus. Two stakeholders, connected to larger co-working spaces, noted that those spaces have English specific parameters to support the idea that everyone is able to communicate with each other (RA3 October 2018; DC6 November 2018). Moreover, within science and technology, the language barriers at least seem to be minimized:

"when people hire coders from different countries, then they are usually open for individuals not having Danish, Danish is not a requirement, but when they hire for more businesses type of positions then you need at least one Nordic language" (DC5 November 2018). 
Specifically, programming, a common area of work in science and technology is solely in English due to coding language, making jobs in this field more accessible to international students and talent.

Another stakeholder noted that she was passed over for many jobs because she did not speak Danish, until this firm recognized her skills and understood that the language could come later, as:

"open minded firms [focus on] talent and competency over learning the language because you will learn eventually so that should not stop someone from being hired" (DC4 October 2018).

This was a similar situation for a few stakeholders. Even at the universities, where classes are officially taught in English, professors mentioned a strong push to speak Danish in classes and that the universities are not as 'international' in comparison to other countries they have worked in (UP1 November 2018). Many stakeholders, individually, are using English as the primary working language to focus internationally, however, there is no widespread government initiative to address language hurdles, as "we don't have a global mentality in Denmark" (DC6 November 2018).

\subsection{Juxtaposition of Immigration and Bureaucracy}

Challenges of immigration and bureaucracy were more significant for stakeholders than for international students. Nonetheless, stakeholders discussed immigration processes less than predicted, despite every stakeholder being asked about immigration and policies challenges. However, there were still specific visa challenges, and a number of bureaucratic processes that made migration difficult. For example, one stakeholder noted their recent challenges with an American employee being denied a visa because those skills and career were not "in demand" and there was sufficient domestic talent in that field (DC5 November 
2018). Furthermore, stakeholders seeking to attract tech talent or recent graduates said the Pay Limit scheme, often used for high skilled international talent, is especially limiting because companies cannot offer the high wage required for the visa (RA1 October 2018). If the Pay Limit scheme's minimum salary were to be lowered, stakeholders said it would allow for more junior highly skilled workers to be recruited (RA1 October 2018; DG3 November 2018). This could include international students. To support international student retention the government developed the Establishment Card to allow students to stay and search for a job, however, students then have:

"to prove that they can support themselves, which is tough because they just did two years of study and then they have to be able to show that they still have money to stay here for the year" (DG2 November 2018).

Stakeholders mentioned specific schemes that international students did not know about.

Stakeholders discussed the smaller bureaucratic hurdles more often than the specific immigration schemes or pathways. To capture this, one stakeholder said:

"[the visa application process] should be the biggest concern, not can I get a CPR number, tax number or bank account. The whole process behind it is incredibly bureaucratic, most companies, especially the young ones do not know how to handle the process" (RA2 October 2018).

Stakeholders estimate that it takes at least one month to get bureaucratically set up in Denmark (banks, CPR, taxes), a sentiment echoed by international students. Furthermore, only recently are there organizations to assist with this process. International House, located in Copenhagen is the main organization, supported by the government, which aims "to provide international citizens with the best possible start to life in Copenhagen by giving them the comfort of a one-point entry" (International House, 2018).

An additional problem was the 'perceived' closed off and restrictive immigration system. A stakeholder noted the challenge is getting over the perception that Denmark is closed off, and to better highlight how they are a welcoming society (DG3 November 
2018). So even, if the actual immigration processes are not a hinderance to the high skilled international talents, the perception is important. Especially, when Denmark is reducing the number of international students permitted. While, this policy decision might be for economic reasons, the perception of closing borders could significantly hurt future migration of students and talent, and, in turn, innovation and growth. All interviews were conducted prior to the government policy announcing the reduction in the number of international students. Therefore, no questions were asked specifically in relation to this new immigration decision.

5.17 Conclusion: "Everyone would come here and get the good life, but that is not sustainable”

In the end, one stakeholder's quote sufficiently sums up Denmark's current international talent recruitment situation:

"Most people will go back unfortunately but most people, at least the students I work with, enjoy living here very very much, they see of course some challenges, it is tough to get residency and to get a bank account can take months. It is very bureaucratic and that can take a toll on some people and that can keep some people from being here. Some will say the taxes are too high, or I can make more money at home or I miss my family. So I think most people will stay for a while so at least people who will build a family they sometimes stay here because it is a pretty neat country to build a family and have a job as well" (RA3 October 2018).

Denmark has significant strengthens that have and should be used in recruitment efforts, however coordinated recruitment and retention efforts by government and the private sector are only just emerging. Most recruitment and retention strategies are left up to the individual companies who at times lacks the skill and knowledge to effectively recruit and retain international talent. Furthermore, stakeholders are not utilizing the current international talent already present in Denmark, international students. Very limited efforts are made to directly recruit students, international or not, into the labour force. 
5.2 International Students: "It is a Pretty Good Country to Live in, Expect for The Whole Danish Language Thing”

\begin{tabular}{|l|l|l|l|l|}
\hline Field of Study & Degree Level & EU and EEA & \multicolumn{1}{|c|}{$\begin{array}{c}\text { Non- EU or } \\
\text { EEA }\end{array}$} & \multicolumn{1}{|c|}{ Gender } \\
\hline Biology (3) & Bachelors (4) & Italy & Australia & Male (6) \\
\hline Physics (3) & Masters (2) & Germany & Canada & Female (11) \\
\hline Math & PhD (11) & Spain (2) & Pakistan & \\
\hline Science (4) & & UK (2) & Iran (3) & \\
\hline $\begin{array}{l}\text { Physics-Math } \\
(3)\end{array}$ & & Hungary & & \\
\hline & & Romania (2) & & \\
\hline Chemistry (2) & & Poland & & \\
\hline Other (1) & Norway & & \\
\hline
\end{tabular}

Table 4: Overview of Student Backgrounds

5.21 Why International Students are Choosing Denmark? "I Came Here with My Eyes Completely Open”

International students were initially asked why they choose to come to Denmark.

This was to highlight potential links to their rationale for remaining in Denmark upon graduation, and to emphasizes what aspects of Denmark are working to attract international students. An important initial finding is that international students within the EU or EEA mentioned no challenges with the immigration processes to Denmark. Most students spoke how it only took days and was simple a bureaucratic manner in relocating to Denmark:

"It was very easy, I think I spent a day, no more than if I had just moved into a Norwegian city" (PhD EU4 October 2018).

"If you come as a student you do not have any problems, you just have to go do your paper work" (BA EU3 November 2018).

This is understandable given the free movement within the EEA and institutional structure of the EU. However, even students from outside the EU did not mention any protracted challenges with Danish immigration system, just that it was an exhaustive process.

"The only thing is you have to get your biometric information, fingerprints and eye scans like for Nexus, but you have to get it done within 14 days of 
them submitting this thing, so I had to go to one of three centers in Canada to have it done" (PhD non-EU2 October 2018).

"The last year it was really easy, when I applied with the visa it only took nine days, but this year something changed" (PhD non EU3 November 2018).

Overall, students did not cite any significant issues when migrating to Denmark as a student, even if they were from outside the EU or the EEA.

In a short survey presented to sixteen out of the seventeen students, students were asked to rank the significance in their decision to study abroad. It was not specifically framed in regard to Denmark but to international education in general and merely provides a short overview of why students chose to study abroad. The specific reasons students chose to study abroad will be explored below.

\begin{tabular}{|l|l|l|l|l|}
\hline Question & $\begin{array}{c}\text { Very } \\
\text { Significant }\end{array}$ & Significant & $\begin{array}{c}\text { Not at all } \\
\text { Significant }\end{array}$ & N/A \\
\hline To improve English Language Skills & 2 & 3 & 10 & 1 \\
\hline $\begin{array}{l}\text { To experience and learn about a new } \\
\text { culture while gaining intercultural } \\
\text { skills }\end{array}$ & 5 & 4 & 6 & 1 \\
\hline $\begin{array}{l}\text { To increase career prospects and } \\
\text { strengthen future job competitiveness }\end{array}$ & 8 & 5 & 2 & 1 \\
\hline $\begin{array}{l}\text { Because you were encouraged by } \\
\text { family, friends or professors }\end{array}$ & 5 & 6 & 4 & 1 \\
\hline
\end{tabular}

Table 5: Questionnaire: Factors for Studying Abroad ${ }^{29}$

\subsection{Attractive Research and Funding}

Denmark is known for their high-quality education and free tuition, especially throughout the EU. While most students did not know much about Denmark's research or innovation prior to coming to Denmark, $47 \%$ cited that the project, research, and funding were one of the main reasons they chose Denmark. One student had "only read that there

\footnotetext{
${ }^{29}$ It is a total of 16 student responses as one student's responses were not recorded.
} 
is a good level of life and the funding of research is higher than Spain, so it is a good place to be" (PhD EU2 October 2018). Supporting and working on innovative projects and getting "first hand access to people who are doing front line research, ... was a big attraction" (MA EU1 November 2018). Nonetheless, students noted that Denmark and Europe as a whole, were leading in research as "the US does not attract [them], and the other continents are not really for research, work, and living" (PhD EU3 November 201). Denmark has a strong intersection of high-quality research, interesting and relevant work, and supportive funding, making the environment highly appealing to study in.

Innovative scholarships, such as Marie Skłodoskwa-Curie Scholarship, also drew $\mathrm{PhD}$ students to Denmark. For a student unsure of where to study, "it [was] the project itself that pulled me here...The Marie Curie scholarship, so it is a very prestigious scholarship" ( $\mathrm{PhD}$ non-EU1 October 2018). Furthermore, "Marie Curie, is a great program for individuals to obtain funding and to be independent", said another student (PhD non-EU2 October 2018). The two students who received Marie Skłodoskwa-Curie Scholarships were from outside of the EU, although students in Denmark, at the PhD level, all receive the same access to funding and scholarships regardless of citizenship.

The four undergraduate students, all from the EU, noted free tuition in Denmark as one of the most important factors in their decision. The funding Denmark provides for EU undergraduate and Master's students is unparalleled by most other EU states, especially when coupled with the high numbers of English language programs. This makes education institutions in Denmark more attractive and accessible to more students. For PhD students the length of program, the salary, and no tuition - regardless of citizenship - were highly appealing. Three students stayed in Denmark for their PhD after their Master's, due to 
funding and research opportunities. These students tended to have stronger connections and a more positive outlook on Denmark, such as relationships with Danes.

\subsection{English Language Programs}

Having programs in English was a huge draw for many students, especially at the undergraduate level. While many European countries will have Master's and $\mathrm{PhD}$ programs in English, it is far more rare for undergraduate programs to be in English, which is often the reason there are more international students at higher degree levels. Students also mentioned that natural sciences at the undergraduate level were challenging to find in English. One undergraduate said:

"it is mostly because of the English courses they provide. Denmark was the second choice. The reason I chose Denmark was it was cheaper than England" (BA EU3 November 2018).

In other words, English programs were necessary, but finances were the deciding factor.

Dissemination and information in English was also crucial for student recruitment. One student noted that Denmark does not test English language skills if you have completed your previous education in English, which eased the immigration process and ruled out other countries, such as Canada, for a few students. Another student mentioned that since Denmark's university webpages were in English, while Germany's were not, it influenced his decision to study in Denmark: "the Copenhagen [website] was bilingual and I already spoke a bit of Danish so I thought that seemed a good place to apply" (PhD EU1 October 2018). While English language programs were a reason to study in Denmark, it was not necessarily to improve language skills, as often associated with international student mobility. In the short questionnaire provided only two students said improving their English language skills was 'very significant', while almost $60 \%$ of students said improving their English skills was not a significant factor in coming to Denmark. 


\subsection{Deciding Between the United Kingdom and the United States}

The United Kingdom and the United States were the most common other countries students considered. EU students typically decided between Denmark and the UK, while students from outside the EU looked also to the US. For students in the EU, the UK was often out of their price range: "I didn't choose Denmark because it was the best, just because England you have to pay", as one student clearly explained (BA EU2 November 2018). "When I graduated high school, I was thinking of going to the UK or the US, in an actual English speaking country", however, again, finances influenced their decision to come to Denmark (BA EU4 November 2018). The two students from the UK did mention Brexit as potentially changing their current status, particularly around the cost of education:

"the biggest issue for me at the moment is Brexit. Nobody can tell them anything about it. [Brexit] is obviously going to have a big impact on what I do" (MA EU1 November 2018).

However, no other students mentioned any implications of Brexit.

The US, as a potential destination, was mentioned a few times, particularly by the three students from Iran. One student noted that he:

"applied for two universities in the United States but after the travel ban issues, I just quit, I don't think I am going to try again, at least with this current administration" (PhD non-EU5 November 2018).

Another student mentioned that she did not want to go to the US anymore because of American system of single entry visas. Additionally, Europe is closer to the Middle East than North America is. One quote sufficiently sums up how a student chose Denmark over the US:

"I liked Europe, I thought life was calm and average and nice, people are not rushing and it is not crowded and busy. So I consulted with [my uncle] to come to Denmark or the States. It is everybody's dream to go to the land of the free. He told me if I want to have a big jump in my life and be very successful and accomplish a lot of things and are not looking for an average life then you should go to the States. But if you 
want an average life and a good balance then you should come to Europe, then based on that I came here to see for myself and try looking for a job and if I did not like it I could go to the States" (PhD non-EU4 November 2018).

\subsection{Welfare State Lifestyle of the Happiest People on Earth}

When students were describing the rationale for coming to Denmark, no student mentioned Denmark as a 'welfare' state being an incentive, nor did students mention the work-life balance as a reason to study in Denmark. One student did mention they knew Denmark was a "good life" (PhD EU2 October 2018). Despite this, two female EU students did mention the political institutions and the current politics in their Eastern European countries as an influence, not only to leave, but in choosing Denmark. One noted that the situation for women in her country, especially in sciences, is becoming "increasingly sexist" and that she has not felt this in Denmark (BA EU1 October 2018). The other noted that the "Nordic countries are well developed with respect" (BA EU2 November 2018). Although only two students mentioned this, it emphasizes that political institutions in a state can influence students' decisions where to study.

\subsection{International Student's Plans After Graduation: To Stay or Not to Stay}

Denmark is an incredibly attractive country to study in, based on the extensive benefits the state offers to students, however do students want to stay? Do they want to start a career in Denmark? What are the institutions that are influencing or hindering their decisions? What are students most looking for in a future career or lifestyle? Can Denmark meet these requirements? Where is the Danish government and industry failing to connect international students to employment opportunities? The following is an overview of what international students consider when they grapple with the perplexing challenges of post- 
graduate life. Some of the themes that attracted students to Denmark are also a strong influencer into why international students consider remaining in Denmark.

Below is a brief snapshot of how significant students rated certain factors in regards to their future plans. While it does not offer nearly the insights as the interviews do, it does highlight career motivations being one of the strongest reasons for students to stay in Denmark.

\begin{tabular}{|l|l|l|l|l|}
\hline Question & $\begin{array}{l}\text { Very } \\
\text { Significant }\end{array}$ & Significant & $\begin{array}{l}\text { Not at all } \\
\text { Significant }\end{array}$ & N/A \\
\hline $\begin{array}{l}\text { Staying in Denmark due to culture, } \\
\text { community, social network }\end{array}$ & 5 & 7 & 4 & 0 \\
\hline $\begin{array}{l}\text { Staying in Denmark due to positive or } \\
\text { increased job prospects }\end{array}$ & 5 & 9 & 2 & 0 \\
\hline $\begin{array}{l}\text { Returning home due to family } \\
\text { commitments }\end{array}$ & 3 & 3 & 8 & 1 \\
\hline $\begin{array}{l}\text { Returning home due to lack of job } \\
\text { prospects }\end{array}$ & 1 & 1 & 11 & 3 \\
\hline $\begin{array}{l}\text { Returning home due to difficulty in the } \\
\text { immigration system }\end{array}$ & 0 & 4 & 10 & 2 \\
\hline
\end{tabular}

Table 6: Questionnaire - Students' Plans after Graduation

\subsection{Research and Career Opportunities}

Research was equally a reason to remain in Denmark, as it was to migrate. One student mentioned "I think the top reason would be research... The university is amazing, and the research center is a great set up and the projects, funding, and landscape are amazing" (PhD non-EU1 October 2018). Even if students displayed more hesitation in remaining in Denmark after graduation, they still acknowledged the strengths of the country's research:

"the opportunities in terms of grants, infrastructure, projects, collaboration, and that they have a lot of collaboration with industry... In that sense yes, staying in Denmark or coming back to Denmark is because there are many big projects and good researchers" (PhD EU5 November 2018). 
Another student noted that while his country was currently not as competitive in the research field, he does want to go back hoping the situation will be better or that he can support greater research there (PhD EU2 October 2018). Even if students desire to stay in Denmark, having a job is the most important aspect as "everything depends on having a job", especially immigration and social services (PhD non-EU4 November 2018). Students who said that they plan on leaving Denmark after graduation, still noted that it is all dependent on job opportunities.

Students, while acknowledging the innovative research field in Denmark, noted some shortcomings with the Danish research environment. One student's worry is "that some of the companies in Denmark are possibly stagnant and would not be the best for [his] career" (PhD EU1 October 2018). Another student, who spent considerable time in Denmark, showed hesitation into pursuing a career in Denmark, as it is a "pretty small country so the job market is not necessary big, so it really depends on my job opportunities after university" (BA EU4 November 2018). One of the stakeholders actually mentioned the perception of Denmark as less competitive due to their focus on overall balance as potentially harmful in recruiting top talent. A recent international student graduate, now working for a Danish company said:

"I did apply for a lot of jobs, and was not even called for an interview even though I have experiences from Malta as a business developer, and in Malaysia and I have education and everything, yet my profile was not attractive mostly because I do not speak Danish ... So this is a big obstacle for international students" (DC5 November 2018).

While the research and jobs could be a significant reason why international students choose to stay, it is also a reason that drives students to seek out other opportunities abroad. Ultimately, the vast majority of international students did not plan on returning to their home countries because of better job prospects. 


\subsection{Language Challenges in Work and Social Settings}

Although language can be perceived as a barrier in most countries' recruitment strategies, the theme of language barriers came up in $82 \%$ of the interviews when asked about challenges to staying in Denmark. As one of the more proficient Danish speakers said, "it is a pretty good country to live in, expect for the whole Danish language thing" (BA EU4 November 2018). The difficulties in learning Danish and the extensive requirement to know Danish for employment, was a substantive factor in why international students considered leaving Denmark. Most students, who had already learned English as a second language and usually know additional languages, were not keen on the idea of learning another language that would not be vastly useful outside of Denmark. Less than half of the students were taking or had taken Danish classes. Only three out of the seventeen students interviewed could be considered proficient in Danish, and that is purely because two had Danish relatives and had been in the country for longer than 3 years, and the other was Norwegian ${ }^{30}$. Even when students did complete language classes, they noted ongoing difficulties: "I started but the classes were not sufficient. The language is tough to learn" (PhD non-EU5 November 2018), or "[He] is going to give up because the class is not organized well and they changed the teacher 6 times", one student said about her colleague (PhD non EU3 November 2018). Another student studied Danish for a year and a half but then the government "changed the system and now you have to pay and [they] felt [they were] not getting as much out of it" (PhD EU1 October 2018). A former international student, now stakeholder, said her biggest challenge to finding employment was that she did not speak Danish, despite taking classes. She currently works for a small start-up that

\footnotetext{
${ }^{30}$ Norwegian is very similar to Danish and allow for each other to read and speak without great difficulty.
} 
primarily speaks English, which was the reason the company was able to retain her after her internship.

Furthermore, the language barrier can be an incredibly isolating situation for internationals, especially considering how reserved Danes can be. The connection between language and isolation came up in about a quarter of the interviews. A student, with the highest Danish proficiency, noted that if she had to work in Danish it:

"would [be] a barrier to making friends with my colleagues, because I am not as comfortable with making jokes and interacting on the social level" (BA EU4 November 2018).

Another student, who ended up citing social reasons as the biggest influencer to wanting to leave Denmark, said "it is hard to get in the circle unless you know the language" $(\mathrm{PhD}$ non-EU1 October 2018). Overall, international students typically thought of Denmark as a stop in a larger mobility trajectory, which often ended in a native English-speaking country, therefore the time and effort put into Danish language did not always have the pay off.

\subsection{Cultural Benefits and Integration Hurdles}

Culture is an incredibly valuable part of the recruitment and retention equation.

First, Danish culture can be used as a huge attraction, from paid PhD programs, to family support, or a relaxed lifestyle full of hygge. As some students noted, this approach to life is what they value about Denmark:

"it is an easy life here, you get a job, you have a reasonable amount of working hours, you have a good salary, and everyone is seems quite relaxed here, even the working people" (BA EU3 November 2018);

"there is just general trust and happiness" (PhD non-EU2 October 2018); and

"people here are really really nice" (BA EU2 November 2018). 
However, Danish culture can also be a deterrent for many people, especially those wanting to settle down long term, if they cannot feel integrated.

It is hard to quantify a 'feeling' of inclusivity, however $70 \%$ of students mentioned the Danish culture as causing hesitations in staying. To one student, "Denmark is not home a hundred percent because I cannot integrate fully here" (BA EU3 November 2018). Only four students (23\%) noting strong personal connections or only positive experiences with Danish culture and people. No questions were asked about whether students felt included in society, or their opinions of Danish culture; simply if they had any hesitations to staying in Denmark. Student responses included;

"I thought before coming here that people were super polite but then it is not" (PhD EU2 October 2018);

"culturally Danes are quite isolated and only have a few close friends then just people that they know, and you can feel that there is ... you can't sort of sit down and just have a conversation with someone" (MA non-EU1 November 2018);

"I have not had communication with Danish people and do not have Danish friends" (PhD non EU3 November 2018); and

"I hear from my friends studying in US, the American people are more warm... the other international people, here it is a little hard to go through with other Danish people. Maybe it is my fault" (PhD non EU3 November 2018).

Another student, while really liking Denmark and noting strong connections with Copenhagen, acknowledged the lack of diasporic communities in Denmark, making it less attractive for various nationalities to stay long term. It is "challenging to integrate into the culture, and language" and students noted this sentiment over and over (PhD EU1 October 2018). "I prefer to go another place where they included internationals into their society, this is my decision right now", articulated another student (PhD non EU3 November 2018). 
Overall, the culture of Denmark was noted more often as a deterrent rather than a reason to remain.

\subsection{Immigration Schemes and Challenges of Bureaucracy}

With Denmark's increasingly restrictive immigration systems, international students' access to Danish education could be further constrained in the future. However, the vast majority of international students did not note the immigration system as a hurdle for entering post-graduate work in Denmark. A student did note that "I would like to stay in Europe, but I don't know about Denmark, it is becoming more strict, especially if you are not from the EU' (PhD non-EU4 November 2018). While international students did not mention their universities' assistance with finding work, one student mentioned her

university was incredibly helpful with navigating bureaucratic side of immigration to Denmark.

The bureaucracy of moving, regardless of being an EU citizen or not, was difficult for international students. Students noted they were mostly on their own when it comes to registering for a CPR (person number), finding accommodation, and setting up banking. A student highlighted this extensive process:

"There are many systems in Denmark that are not set up or designed for people moving to the country. You register for your CPR or getting bank accounts which could be smoother. It ends up with people not getting paid for the month or two while trying to get this set up all this bureaucracy. Especially if they are coming from outside of the EU and have to get visas. It always works out in the end, but it is more of a pain than it needs to be. You often get a feeling that they have not thought through the systems out for someone who wasn't born and raised in Denmark" (PhD EU1 October 2018).

\subsection{Recruitment Strategies - Universities and Public Sector}

Students were also asked about their own knowledge of the Danish work force to better gauge where initiatives could be developed. Most students noted an overall lack of 
recruitment: "I am always looking for work. but it is not easy and there is not a lot of an attempt with recruitment" (MA EU1 November 2018). One student, who is doing an Industrial $\mathrm{PhD}$, which means it is partly funded by a private institution, said that while there are partnerships between industry and universities, it is usually only when there is pre-existing networks and connections (PhD EU3 November 2018). In other words, it is highly ad hoc, with no broad framework. One student noted that his program was a "conveyer belt... of PhD and post-docs that have ended up in one of three companies, which are these programming companies" (PhD EU1 October 2018). However, no other students mentioned this type of connection between industry and graduate programs. Three students noted that their university did not really have any such 'work experience' program but they heard that Copenhagen University (KU) did, as their "university [is] a little further out so there is a little less direct representation of companies coming in" (MA EU1 November 2018). However, students from KU did not know of any work experience programs. There was overall not a single program, resource, or initiative that students could point to which would assist with their transition to post-graduate work.

\subsection{Conclusion: "I think it is useful to any researcher to move around"}

Only one student could definitively say she was staying in Denmark, and she was married with three children. However, four other students - two male and two female students - said that they would like to remain as long as they can get jobs once they graduate. The vast majority of students remarked that they liked Denmark but wanted to explore and experience other cities and countries, with three specifically noting they would like to go to an English-speaking country. Lastly, only two students said they did not want to stay in Denmark as they wanted to go back to their home countries. Overall, the main reasons students would be enticed to remain in Denmark is relaxed work-life balance, 
career and research opportunities, and existing connections. One of the most prominent reasons students planned to leave Denmark, was to continue their international experiences through working or studying in another country, followed by challenges with integration, lack of knowledge about future careers, and Danish language requirements. Danish weather was even cited as a reason to leave by a few students typically from warmer regions. While some initial patterns emerged, ultimately, there was no significant differences in response of students based on region, gender, country of origin, or academic level. With a larger sample size more concrete correlations could be made. 


\section{Section Six: Analysis of Interviews and Four Main Themes}

Feminist methodology has long focused on the role institutions, such as national parliaments, businesses, or the judiciary, have in perpetuating biases (Krook and Mackay 3; Franceschet 58). Institutions consist of distinct norms, policies, and systems of rules that organize and regulate social, political, and economic behaviour based on the historical context they developed out of (Lovenduski viii; Scharpf 40). Feminist institutionalism and actor centered institutionalism focus on how the institutions and the actors within institutions are imbedded with and perpetuate biases (Krook and Mackay 2011; Scharpf 1997). They are both intrinsically connected and supplementary to each other - as feminist institutionalism highlights the biases imbedded in each institution and actor-centered institutionalism emphasized the role actors - international students and stakeholders - have in shaping institutions. Analyzing the institutional environment and how actors are influenced by and can influence institutions allows for more comprehensive understandings of how policies and decisions are made.

Within this research institutions include; the European Union, the Danish government (bureaucratic and political), the immigration regime, and education structure including universities. Institutions are inherently imbedded with biases, whether that be racial, gender, class, or religious. Feminist institutionalism sheds light on how, due to these biases, these institutions' recruitment initiatives may only be suited to certain international students. Furthermore, institutions effect and shape the identities and preferences of the actors involved (Franceschet 63). The actors within this research included the individual (international students), the individual actors within the corporate (non-government stakeholders), and collective (government stakeholders). Institutions and actors are ultimately affected by the intersection of their own gender, race, class, sexuality, and 
background, among others (Schrover and Moloney 14). Therefore, the policies, initiatives, and approaches Denmark has previously taken and should develop in the future cannot be devoid of an intersectional analysis. This will best support innovation.

This research intended to answer three overarching questions:

- Are international students, in science and technology, transitioning into postgraduate work in Denmark?

- What methods and initiatives do stakeholders have to recruit and retain international students and talent, more broadly? Are strategies inclusive?

- What are the current hurdles or challenges - policy or otherwise - that stakeholders and international students are encountering in transitioning into post-graduate work?

Through an intersectional feminist and actor-centered institutional framework, the research has attempted to provide initial insights into these three questions. To reiterate, out of the international students interviewed, only one student could definitively say they were remaining in Denmark and pursuing post-graduate work. This student had significant connections - married with children - in Denmark and was from a Nordic country, making migration and integration simpler than any other student. Four other students mentioned their desire to stay in Denmark, if employment opportunities were to arise.

The various methods stakeholders utilize to recruit and retain international students and talent have been explored. The prominence of recruitment agencies was unpredicted but understandable in the context of the lesser known, Copenhagen. While stakeholders all expressed a desire to recruit more international students, there were limited methods instituted, and an overall lack of coordination between public and private institutions. Government, through their recent reduction of international students permitted to Danish 
universities, is moving away from recruitment to additional emphasis on retention of international students. Although government has not developed any international student retention plans, beyond the work of International House.

Lastly, the hurdles and challenges that stakeholders and international students encounter when transitioning international students into the workforce tended to fall into four main themes, which will be developed in the latter half of this section. Answering these research questions provides initial insights into the underdeveloped literature area of international student mobility. This research begins to understand why international students choose to remain in their host country after graduation. It also offers insights into what recruitment strategies are being taken up by stakeholders and where there is room for development. Ultimately, this research emphasizes how international student and high skilled mobility has essential benefits for supporting economic growth and innovation in a country.

While there is extensive literature discussing a diverse range of important migration issues, there is limited information regarding the benefits of increased migration and mobility on innovation (Brinley 1954; Porter 1998; Hunt and Marjolaine 2010; Shachar 2013 Bosetti et al 2015; Geiger and Bergmann 2017). This research, while not directly focusing on migration's role in increasing innovation, aimed to highlight mobility's potential contributions to innovation. Rising innovation is fueled by the development of the knowledge-based economy. There is increasing competition for knowledge transfer crucial for the knowledge-based economy - that is fuelled by interactions with people from diverse backgrounds (Neubaurer et al 2012). In an economy and society rapidly developing technological advances, such as Artificial Intelligence (AI) and Machine Learning (ML), these interactions, networks, and exchanges are crucial. While there is only limited 
literature on how the economy and technological advances are interacting, it is sure to be an increasingly relevant topic in the future (Pasquale 2019; Huang 2019). Clusters, as Ostergaard and Park (2015) predicts, such as Copenhagen are critical to innovation and the pinnacle of the changing economy. This claim is supported through this research, as recruitment and retention strategies, and most of the innovation strategies, come out of the Copenhagen region.

Moreover, the methods and motivation of migration is expanding to match the changing knowledge-based economy. One of the most important avenues for global migration is through international education. As Knight (2011) predicted, international education and student mobility is increasing due to (1) increasing demand for skills supportive of a knowledge-based economy, (2) growing orientation to commodification of education, and (3) increased numbers of students wanting to participate in international education and potential gain international credentials (211). McHale (2011) noted similar rationales for expanding student mobility. Danish and EU reports (Statistics Denmark; Danish Agency for Science, Technology, and Innovation 2014; Skills Panorama 2015) have highlighted projected skills gaps which cannot be met by citizens, therefore initiatives such as International House and Copenhagen Capacity have been developed. Their objective is to retain certain international students, especially in science and technology, into the Danish labour force. To Knight's second point, international education literature points to the commodification of international education, as the economic benefits to the host and home country, and individuals are immense (Bhandari and Blumenthal 2011; McHale 2011; BCCIE 2015). However, international student mobility is also increasing because institutions and actors see the value beyond economics. The skills of interculturalization, language, knowledge, and networks are no longer just luxuries but 
necessary for international competition. Lastly, while more students might want to study abroad to have better career prospects, as many of the international students interviewed mentioned, but it is also that studying abroad has become more accessible. This is demonstrated through international students citing language and funding as significant reasons for studying in Denmark. Furthermore, with legislation like the Lisbon Recognition Agreement, it is significantly easier to obtain international degrees and find work.

Recruiting and retaining international students is crucial for fostering innovation, as domestic talent is no longer sufficient to meet labour market demands, nor support growing innovation competition (Shachar 2006; Geddie 2015; Docquier and Machado 2016). International students are a key group to target recruitment efforts as domestic countries have already put significant investment into their success. A government stakeholder emphasized that:

"a student should stay in Denmark for nine years before the student is an economic benefit. The expense of having the education for free and the student grant would mean the student has to stay nine years in Denmark before becoming a net gain" (DG1 December 2018).

Education in Denmark is funded by the government, therefore the taxes of Danish citizens, signifying a substantial investment that may not have economic, social, cultural, or political returns, if international students leave. However, there is limited supporting international students' transition into the workforce. The Danish economy and society are losing out on the long-term benefits of international students if there are no viable pathways for international students to pursue post-graduate work. Besides the Establishment Card, the Danish government does not have any immigration schemes directly aimed to facilitate this transition. The Establishment Card and other immigration schemes like the Pay Limit, require students to have significant existing funds or a high paying job offer - reinforcing the notion that financial privilege still is incredibly advantageous. Furthermore, initiatives 
such as International House's networking partnerships, is conducive to supporting international students' knowledge and connections of the Danish business environment, however it is currently only accessible for students in the Copenhagen region. There is also no information if this program is increasing the retention of international students. The investment in international students has already been made, therefore the government and stakeholders should do more to procure the benefits.

There are many resources the government has to potentially encourage international students to stay in Denmark, some of which will be proposed in the latter half of this section. However, in a global economy that is increasingly requiring international skills, it seems Denmark's political environment is strongly shaping their approaches. The political influence of the DPP and the Eurosceptic position Denmark currently holds in the EU, especially on matters of political and social integration, should not be underestimated in decisions, such as restricting the number of international students for 2019. Triadafilopoluos and Zaslove (2006) highlighted that there is an intrinsic connection between the right-wing parties and increasing restrictive immigration policies. The combination of intersectional feminist and actor-centered institutionalism emphasises how actors' preferences can influence the actions taken by institutions (Franceschet 64). In other words, the beliefs the DPP has regarding immigration, especially from "non-western" 31 countries, influence the approaches Danish institutions have in regards to immigration and integration. Ultimately, the institutional environment in Denmark is not overly hospitable to new immigrants, even those who have completed years of formal education at a Danish university.

\footnotetext{
${ }^{31}$ In Denmark's most recent policy update on immigration, there was the division of migration between "western" and "non-western" (Ministry of Immigration and Integration 2017).
} 


\subsection{Four Main Themes: "It Varies, On How Integrated They Become"}

The following themes emerge as the most important and crucial areas to support recruitment and retention of international students and talent, more broadly. Furthermore, these themes highlight how institutions and actors can influence future policies and initiatives to foster increased innovation. The first theme is (1) Denmark's need to focus on strengthening public and private institutional cooperation, second is (2) exclusivity of immigration and protracted bureaucracy, third is (3) balancing the appeal of Danish lifestyle and challenges with integration, and lastly (4) Denmark's ability to utilize English language skills in the work place. Although certain aspects of each theme were partially predicted, they overall were difficult to have foreseen, especially considering the lack of literature on recruitment and retention. Further, the conflicting case of Denmark made it more difficult to predict exactly how the hurdles and barriers would intersect. For example, the desirability of welfare benefits and restrictions of the immigration systems.

\section{One: Greater Public and Private Institution Coordination}

One of the greatest factors stifling the transition of international students into postgraduate work and, therefore, innovation is the absence of coordinated initiatives between the public and private institutions. International students cited both private and public institution simultaneously attracting and deterring their desire to remain in Denmark upon graduation. Currently there is no national recruitment strategy for attracting international students, or talent to Denmark - only Copenhagen has a small regional strategy. The Ministry of Labour Market and Recruitment's strategy Building Tomorrow's Labour Market Together does not mention attracting labour from outside Denmark. There is explicit language referring only to "citizens"" recruitment into the labour market (Ministry 
of Labour Market and Recruitment 2018). Supporting Denmark's domestic labour market and employees is important but there is significant literature supporting the need for international talent in Denmark (Ostling 2013; OECD 2014; Danish Agency for Science, Technology, and Innovation 2014) and across the world (Shachar 2006; Geddie 2015; Docquier and Machado 2016).

While stakeholders arguably have a better platform to influence government policies on migration or partner with universities, there did not seem to be significant effort for this. Schparf noted that actors are shaped by specific, capabilities, preferences, and perceptions (43). While, on the surface most actors supported increased internationalization, there was a lack of strategies to make this possible. One stakeholder mentioned that, Denmark is simply not as internationally focused, strengthening the perception of Denmark as insular. This perception could be due to the limited influence of stakeholders, however, it could also be a result of how the social welfare system and Danish culture has impacted stakeholders' own perceptions of who belongs. Stakeholders, even those critical of these notions, are inherently shaped by the institutions surrounding them, and intentionally or unintentionally perpetuate these biases.

Danish universities, especially Roskilde University (RUC), focused on career preparation. One student noted that the university is preparing students for the job market, not an academic career, which, in her case, was very frustrating (BA EU3 November 2018). Conversely, RUC has been hosting all their career fairs solely in Danish, causing some international students to lobby the school to include at least a few career days in English. A student mentioned that this made it nearly impossible for international students to participate and benefit from job market information (MA non-EU1 November 2018). While international students may not seemingly have as much agency to shape the 
institutions around them, this is an example of how actors can influence institutions. Additionally, when students do seek employment on their own, they are unable to find postings that are in English: "I have only seen a few job posts in English, but this is mostly programming" (MA non-EU1 November 2018). There is an absence of coordinated strategies to build pathways for international students to study in Denmark, then find meaningful employment. Strengthening cooperation of public and private institutions bridges all the themes of language, cultural integration, and immigration.

Initiatives, whether created by public or private institutions, lack cooperation, input, and insights from the broader sector. Actors and institutions rarely work together. The institutions may have different goals in recruiting international talent, such as public institutions may want to attract talent to benefit the economy as a whole, while private institutions may aim to attract international talent to specifically support the growth of their own business. However, they immensely rely on the cooperative approaches of each other. Private institutions need intuitive open immigration policies or attractive tax benefits that would encourage someone to settle in a region. Conversely, public institutions benefit from a thriving successful innovation industry with positive work culture and businesses taking on exciting research. Increased coordination would better ensure that individuals are not overlooked by filling in institutional gaps in knowledge and perspectives. Specifically, an intersectional approach would allow the flexible and analytical capacity to address complex challenges to inclusive recruitment and retention (McNutt 139). Having more actors and institutions involved in decision making processes would increase the number of perspectives considered and, in turn, more inclusive initiatives and increased innovation.

Denmark has a few indications of stronger institutional coordination. First, an aspect of recruitment that was not anticipated within the literature, is the strong role 
recruitment agencies are having in supporting businesses, organizations, and start-ups to recruit international talent - though not specifically aimed at international students. Recruitment agencies in Denmark, whether private or public organizations, are assisting in positioning Danish industries and innovation on the international map. This is also an example of how institutional coordination. Next, innovation clusters, such as Copenhagen's Healthtech cluster, strengthen the network between public and private institutions. Ostergaard and Park note the interconnected web of institutions reliant on each other strengthen knowledge spill over, economies of specialization, and labour pooling (836). International students noted the first institution they sought out for labour market information was the university. However, besides a few stakeholders, there was no mention of the role universities have in supporting innovation and clusters.

While, there was no discussion of the universities' function in clusters, universities are a crucial bridge between public and private institutions and are especially relevant in the case of international student mobility. Ronnow Lonholdt et al (2013) points to how the previous model of universities shaping the outlook of the industry's research field, is now changing (63). With rapidly changing innovation, industries are more in control of the labour markets, which is leading to greater industry influence over subject matter taught in universities (Ronnow Lonholdt et al 63). Universities, as the providers of knowledge, now need to take into account what industry requires for innovation and growth (Ronnow Lonholdt et al 74). Therefore, industry and public institutions need to collaborate more on how to train and transition students to meet the needs of the innovative knowledge-based economy.

Lastly, current initiatives are solely done at the regional level, most often out of Copenhagen, with regions such as Aarhus only just beginning to develop recruitment and 
retention strategies. There is no overarching national strategy. While strategies must include public and private cooperation, it also must be multileveled, where the large institutions from the federal governments down to small start-ups or international talents are consulted. Stakeholders, especially businesses and organizations, have the capacity to entice international students to stay with the prospects of engaging, competitive, and English-speaking employment. For this to work, though, there must be coordination between government entities, universities, and businesses to facilitate simpler transitions for students. The process of finding a job, especially through networks in Denmark can be a hinderance in retaining international student. Most international students are not equipped with the knowledge and network within Denmark to find these opportunities on their own. Public and private institutions must cooperate to facilitate international student retention. To support this, there also needs to be better knowledge sharing of best practices. Although businesses and companies at times are competing for similar talent, Copenhagen, and Denmark in general, as stakeholders mention, are not well known enough for disjointed recruitment efforts. Successful recruitment and retention strategies will support innovation within public and private institutions.

\section{Two: Immigration}

International students and stakeholders overall did not mention immigration challenges as much as predicted or as the literature regarding Denmark's increasingly restrictive immigration system may have suggested (Liversage 2009; Valentin 2012; Jensen et al 2017). International students rarely pointed to immigration as being a hurdle in their ability to stay in Denmark upon graduation. Stakeholders also did not cite Denmark's current immigration system as restricting their ability to recruit and retain international students. However, this could be for a few reasons. First, the majority of the 
international students were from the EU or the EEA, making migration significantly easier. Another reason why students or stakeholders may not have noted challenges with immigration is because there are differences between how Denmark:

"treats the highly educated people compared to others. There is big discrimination... it is all based on if you have job because as soon as you do not, you get kicked out of the country" (PhD non-EU4 November 2018).

In other words, students are considered highly skilled, therefore they often face fewer challenges through immigration pathways. Nonetheless, challenges can still arise for smaller start-ups and international students who often do not meet the thresholds for the most common immigration pathways - the Pay Limit Scheme or the Establishment Card. Lastly, the international students interviewed have not begun the process of applying to stay beyond their studies, therefore more challenges could be cited in the future and potentially be more of an influencing factor then. No student mentioned the Establishment Card, highlighting a lack of knowledge on the implications of their future immigration status. Overall, addressing restrictive immigration is crucial in retaining international students, even those from inside the EU, despite the absence of international students' and stakeholders' current attention.

Although, international students and stakeholders did not mention immigration challenges as much as expected, it does not mean there are not very tangible restrictions. A few students did say the immigration process is becoming increasingly restricted, but with no mention of exactly how that could impact them individually. The students from the UK only briefly touched on the implications of Brexit and without any political critique. This was similar to how the Iranian students approached discussing the immigration challenges they would have encountered in the US. While they did discuss their applications to the US, the specific political situation in the US, which is directly relevant 
to Iranian citizens, was not mentioned. Political critiques were entirely absent in answers regarding immigration for all students. However, international students may not have felt as comfortable discussing issues of race or cultural discrimination. Stakeholders, who were mostly Danish, either are unaware of some of the restrictions or did not want to portray a negative perception of Denmark. One stakeholder did mention, with reservations, the challenges with the politics of immigration:

"I don't want to get in the whole immigration crisis discussion, but there is a problem with the politics in Denmark right now, you see it all over the world. You have this polarized political environment that says anything coming from outside your country is dangerous, they want to take your job, they want to infiltrate your country, Denmark's case, and probably said in Canada too, the welfare is compromised, they come from the outside and take up the good things, but still we need these international talents to come join us to help the Danish companies, because the Danish companies cannot fill the international positions" (RA2 October 2018).

Triadafilopoluos and Zaslove (2006) highlight how the increasing political representation of far-right parties can lead to increased immigration restrictions. This seems to be what is happening in Denmark through the influence of the DPP and just a general shift in the political climate fueled by voter's preferences, as Razin et al's (2011) predicted. There is significant literature relating directly to Denmark's institutional immigration processes perpetuating specifically racial biases (Siim 2013; Meret and Siim 2013; Guiliherme Fernandes 2015; Jensen et al 2017). There has been the construction of racism in Denmark as highly individualized, removing the implications of this as an institutional problem (Jensen et al 57). Therefore, when racism, cultural biases, or religious intolerance is encountered it is often blamed on individuals rather than how institutions and the actors within have reproduced and perpetuated biases. However, as feminist and actor-centered institutionalism theorizes, these biases and discrimination are not developed in isolation but rather imbedded into the perspectives and actions of institutions and actors, alike. For 
example, in Denmark's most recent government report on immigration, data was aggregated into two categories: "western" and "non-western" (The Ministry of Immigration and Integration 2017). These two categories are not neutral - there is a blatant dichotomization of types of immigrants. This is an example of a more obvious institutionalized bias.

Government is the most influential actor in the institutional environment of immigration policy (Favell 2006; Pattieu 2017). The government can make it easier or harder for businesses to attract talent. This can be viewed through Denmark's recent decision to restrict the number of international students. Giugni and Passy (2006) highlighted the role government has in the regulation of immigration flows; the management of ethnic relations and integration; and antiracism and antidiscrimination policies. Furthermore, the immigration policies, arising out of biased institutions, can be highly racialized - as mentioned- while also being gendered and classed. For example, wage thresholds in immigration policies often privileges men, as on average, men make more money than women. This is true in every single country in the world. Feminist institutionalism highlights how making small changes, such as lowering the pay limit requirement or adding supplementary categories could be more inclusive and encourage more female migration. Additionally, immigration is often based on skills that appear neutral. However, it is hard to support neutrality of skills when considering how inherently feminized, racialized, and classed the low skilled work force is (Boucher 29). High skilled migration is not a neutral term but rather one developed through institutional hierarchies of privileging certain skills and labour. While Denmark has strong strains of institutional equality, it does not mean Denmark is immune to inherent biases. 
Lastly, it is important to note that the hurdle of protracted bureaucracy was consistently brought up by international students and stakeholders. Although the process of getting a CPR number, banking, and housing are seemingly more impartial than immigration, feminist institutionalism still highlights how biases exist and are perpetuated through banal bureaucracy. Through the support of government agencies such as International House, the bureaucratic process is becoming simpler and more accessible to everyone. Additionally, training for businesses and industry partners could also greatly reduce the protracted process of CPR number, banking, and housing. This would permit smoother transition for international students and talent into Danish society and the labour force. However, without actors pushing for institutional change improvements will not happen.

\section{Three: Danish Culture Contradictions}

The social welfare culture is a strong incentive for living in Denmark. With the rise of the international associate of hygge with Denmark, there is a growing understanding of Denmark as a comfortable, trusting, and equitable country. Culture is an incredibly valuable part of the recruitment and retention equation, that should not be overlooked. First, Danish culture can be used as a significant attraction; from paid $\mathrm{PhD}$ programs, to family support, to the relaxed lifestyle. A number of international students and stakeholders mention the social welfare culture and the work life balance as what drew them to Denmark. Marketing these positive aspects of Danish culture are crucial to attracting international talent who wish to work in an innovative environment and enjoy a balanced lifestyle. Furthermore, one stakeholder said: "I don't think you will have gender equality if you don't just have general equality in the work place" (DC1 November 2018). Denmark 
throughout the institutional environment aims for this equality, or at least is perceived to be equitable and inclusive. A strength of this is, that besides other Nordic countries, this model is distinctively Danish, giving them a niche competitive edge over other European countries.

A positive outlook of the Danish welfare culture was predicted, especially from female students. However, this did not actually translate into why international students chose to study in Denmark and rarely impacted their decision to remain. There was no substantive difference between the responses regarding culture or lifestyle of students by gender - female students were not more inclined to discuss the welfare state than male students, as predicted. Although, students from outside the EU encountered stronger cultural challenges with integration. The longer international students were in Denmark, the more critical responses they provided. For example, a first year undergraduate enthusiastically described how amazing Denmark is and how nice everyone was, while an undergraduate, who had been in Denmark for three years, noted the ongoing challenges she had with the system and the people, citing an overall lack of support from Danish institutions. The latter student did not plan on staying in Denmark. They were both from the same EU country. This varies from what the Danish government found in their previously mentioned 2013 study - that the longer students were in Denmark the more likely they would remain (Damvad 2013). There was the general perception that Danes and Danish society were not as accepting as students were used to or expected.

Additionally, universities are often more 'international', which can lead to a more optimistic opinion of Danish culture: "it is a comfy place to be with many possibilities, but for foreigners outside academia it can be a bit tricky" (PhD EU5 November 2018). Therefore, if students in academia are having challenges with remaining in Denmark, this 
sentiment could be further intensified for international talent coming to Denmark. If a culture, no matter how 'happy' or 'cozy' it is, does not easily allow internationals to feel included in society, retention will be difficult.

Danish culture can be a deterrent for many people, especially those wanting to settle down long-term. One stakeholder noted that retention is based on integration (DC6 November 2018). Therefore, if Denmark is able to integrate individuals into the Danish society effectively, then individuals are more likely to stay long-term. Thus, Danish culture is at the core of retention methods. For this research, integration is not about assimilation, but rather ensuring individuals feel included and accepted throughout society. It is more about breaking down societal dichotomies of who belongs. Most interviewees noted how familial relationships such as love, family, or even close friendships can be at the core of integration and support an individual's reason to stay. A stakeholder alleged the best way to get international students to stay is for them to fall in love with a Dane (DG3 November 2018). On a policy and institutional level, there is no way to encourage relationships and love with domestic citizens; however, universities and businesses can at least focus on fostering better connections between international and Danish society. Most international students noted that they had none or only one Danish friend. This is partly a product of the larger Danish culture of close exclusive relationships, but also due to a lack of events, initiatives, and programs offered in English at the universities and in the community. These soft factors matter. Feminist institutionalism seeks to understand how the power dynamics throughout Danish institutions are reinforcing these notions of inclusion. Who is being left out more? What makes internationals have an easier time integrating into society? Whose responsibility is it to integrate and whose definition and expectations of integration is valued more? While student and stakeholder interviews did not explicitly say this, research 
(Siim 2013; Boucher 2016; Jensen et al 2017) supports that formal and informal institutions' notions of inclusion are often developed long racial, religious, and cultural lines.

In such a trusting society - a society that leaves their babies outside coffee shops there seems to be a natural distrust in foreigners that will directly impact internationals desire to remain in Denmark. This distrust permeates the vast majority of institutions and actors within them. There is a reason Denmark is one of the happiest places on earth - the government actively seeks to improve livelihoods of Danes. The emphasis though is 'of Danes'. Danish society represents many positive aspects that the vast majority of individuals would like to partake in, but the key is you have to 'belong'. Denmark supports equal and political rights for immigrants, yet it is deeply premised on the understanding of cultural homogeneity (Jensen et al 55). Integration is on the responsibility of the individual migrant not Danish institutions. Recently, the laws ${ }^{32}$ and policies arising out of Danish institutions are increasingly aimed at constructing who belongs in Danish society and who does not. News articles from the last six months highlight this: "Surviving Denmark's open prisons for UnDeportables"33, "Denmark swings right on immigration - and Muslims feel besieged" 34 , or "Denmark extends border controls by six months" 35 . It is clear there is growing tensions between who is allowed to belong and benefit from the positive aspects of Danish culture and who is not. While Denmark can sometimes be resistant to critiques due to their perceived high levels of equality in areas of sexual orientation and gender identity, further research needs to be conducted in the areas of how institutionalism racism

\footnotetext{
${ }^{32}$ Most recently, in 2018, Denmark joined other EU countries with banning any face coverings in public and upholding a fine of over \$200 Canadian. It is more commonly known as a Burqa Ban.

33 (Medina, October 2018)

34 (Orange, June 2018)

35 (The Local, 2018)
} 
is hindering international student's decisions to stay or not, and how this can have a longterm effect on Danish innovation and competitiveness.

\section{Four: Working Language Challenges}

A reoccurring theme in interviews with students and stakeholders is the challenge of the Danish language - ranging from social to employment challenges. Naturally, there are going to be language challenges with a new country, however the frequency or language related issues and the contention stakeholders and students spoke with, were not foreseen. Danish, derived from Old Norse, is arguably easier to learn ${ }^{36}$, especially in relation to Finnish or Icelandic. However, it remains a challenge for most internationals who study or work in Denmark and was consistently one of the predominant barriers to entrance into the labour market. Although it is important to note, that international students who can learn Danish easier will have an advantage in transitioning into the labour market, and that learning Danish is often simpler for other Germanic language speakers, such as English, German, Swedish, Norwegian, or Dutch speakers. The challenges that students had with the language are not because they were unwilling; most international students from inside and outside the EU and at all degree levels, attempted Danish language classes. Some international students were even instituting social rules to strengthen their Danish: "we have a rule in my group of friends that is only Danish in the breaks" (MA EU1 November 2018). However, due to financial and time constraints, international students were not able to sufficiently learn Danish, which significantly impacts their ability to transition into the labour force. Undergraduate students were slightly more inclined to learn the language,

\footnotetext{
${ }^{36}$ While Danish might not be incredibly difficult for native English speakers, it can be for many others, such as people coming from Asia, the Middle East or Eastern Europe. The pronunciation to Danish words is difficult and not overly intuitive.
} 
probably as they were guaranteed to have more time in Denmark. However, international students and stakeholders were equally dismayed by Danish language challenges and the impact on future labour prospects.

To address integration and labour market challenges of new migrants, Denmark offers Danish language classes. They are provided through the local community and can range from being slower paced for international students or more intensive for new immigrants. Currently, these classes are not mandatory for those temporarily living in Denmark, such as international students. However, the classes are mandatory to meet permanent residency requirements in Denmark, as with most countries. Prior to July 2018, all classes were free to internationals, however there is now a cost of $2000 \mathrm{kr}$ ( $\$ 400$ Canadian) for a single module. A module can last anywhere between two to four months consisting of two evening classes a week, therefore it can take multiple modules to gain any level of proficiency in Danish. Additionally, a deposit of $1250 \mathrm{kr}$ ( $\$ 250$ Canadian) is required that is only returned when each test is passed ${ }^{37}$. Denmark, which already has a high cost of living, is now requiring internationals, especially students, to spend thousands of dollars to learn an uncommon language to maybe find employment. This only hinders Denmark's capabilities to compete in the global race for talent.

The dilemma with internationals coming to Denmark first then learning the language is that individuals, due to the fairly restrictive immigration process, cannot get a visa without a job offer, and immigrants cannot receive employment without knowing Danish. The exception to this redundant loop is international students. International students - whether they participate or not - are afforded the opportunity to learn Danish

\footnotetext{
37 During my 12 weeks in Denmark I took Danish classes, while the class seemed intriguing in the beginning, it was overall poorly run, changed teachers all the time so there was no consistency, and was full of miscommunications that ended up costing myself additional money and lose of classes.
} 
prior to entering the labour force. This, however, is now seriously hindered by class fees, which only strengthens economic divides and further supports students from a higher socio-economic class having greater access to economic opportunities. As Lasnowski (2011) discussed, language policy is one of the strongest influencers of mobility, therefore to alleviate some of the language barriers Denmark could: re-introduce free language classes to students and new immigrants; encourage businesses to utilize English to be more inclusive; and recognize internationals skills beyond language abilities.

However, if Denmark truly wants to immediately compete internationally for global talent by transitioning more international students into the labour force, they need to better utilize their own strengths - their ability to speak English. The English language skills of Danes is incredibly high, rivaling only other Nordic countries. The Education First English Proficiency Index (EF EPI), which measures the English proficiency of 88 countries, ranked Denmark as fifth ${ }^{38}$ best non-native English speakers, beating out Germany, Belgium, France, and China - all countries important in international student mobility (EF EPI 2018). The Education First EPI began in 2011 and Denmark has consistently ranked in the top five since, and in 2014 was number one. This is understandable when there is not a large population to sustain Danish. For example, most movies and TV programs are in English with Danish subtitles because costs are too high to dub into Danish, whereas Germany, for example, can afford to dub into German for their 88 million residence. If Denmark, through actors, such as government or individual companies, were able utilize and market their English proficiency skills it would be a significant competitive advantage, particularly over countries such as Germany or France. Stakeholders do not even need to rely on larger institutions to achieve this. Businesses have

\footnotetext{
38 The current EF EPI rankings go as follows; Sweden, Netherlands, Singapore, Norway, then Denmark.
} 
near complete autonomy to institute language policies to attract more international talent and retain international students, which cannot be said of immigration policies or cultural practices. Initial success in English language proficiency, as a recruitment method, is evident in the motivations international students cited studying in Denmark. Moreover, there is a reason large Danish companies and small start-ups use English. Large companies' growth is in part due to their ability to recruit international talent and open operations world-wide. Start-ups speak English because they strive for innovation, and innovation occurs when people from around the world can collaborate through mutual communication, most often being in English.

On the recruitment side, English as a working language is useful, but on the retention side, Danish is still the national language, making those who do not speak Danish face increased difficulty in integration. A stakeholder mentioned that they will hire those who do not speak Danish, but the working language is Danish because they want their employees to be integrated into the broader society (DC4 October 2018). Denmark's institutional environment is strongly premised on equality, real or perceived, yet there is little analysis of how supporting broader use of English could be more inclusive. Is the lack of Danish language skills affecting international students' participation in the labour market differently? How have international students' home countries' institutions impacted their own abilities to learn English or develop other language skills? What impact does socio-economic status, class, and finances have on which international students can get a job? While this research has not specifically answered exactly how Danish and English language challenges are impacting international students differently, it does highlight how acquiring language skills is highly dependent on access to opportunities. When Denmark 
is developing retention strategies for international students, they must take into consideration how language requirements includes and excludes individuals.

\section{Conclusion - Inclusive Recruitment and Retention Strategies}

Overall, this research does not offer an exhaustive analysis of where biases in Danish institutions are; it is far too small of a sample size to make specific insights and claims. This research is also not making any definitive claims on which international students might have any easier time transitioning into post-graduate work but rather highlighting some initial factors that may support or hinder international students' ability and desire to stay in Denmark. However, the research does highlight some areas in which Denmark can focus their recruitment and retention efforts to have comprehensive and specific initiatives that attract international talents and retain international students from

all backgrounds. In addressing how best to recruit top talent and retain international students, strategies must be inclusive and diverse. More is required to understand exactly how current recruitment and retention practices are influencing international students differently based on gender, race, country of origin, class or any other intersecting factor. It is not wise, nor advantageous to develop recruitment strategies that do not take into account the different perspectives and preferences of individuals.

Deconstructing who is the 'talent' or 'international student' is fundamental to developing recruitment and retention strategies better matched to individuals. It is also important to reiterate the challenges with the term high skilled migration. This research has been premised on the notion that high skilled migration, particularly in the form of internationals student mobility, can facilitate innovation. However, who is considered high skilled can be gendered, classed, and racialized. Boucher (2016) argues that society values 
certain skills as 'high skilled' and that there are certain rights and privileges attached to skills. One of which being immigration pathways. Most students and stakeholders acknowledge their relative ease with the immigration system was dependent on their position as a high skilled worker.

Furthermore, the influence of soft factors, relationships, work culture, or transportation cannot be overlooked in recruitment and retention strategies. Thinking that the job benefits and pay are the main incentive, even language skills, can disregard softer factors which potentially are more influential to a diverse range of talent. One of the challenges in recruitment stakeholder brought up is having better ways to attract millennials to Denmark. Denmark's emphasis on 'family benefits' can be less attractive to millennials:

"most young people will not come to Denmark because we have a great model for having kids and the work life balance, because that is not what all young millennials are thinking about right now" (RA3 November 2018).

Specifically, this stakeholder noted that remote working is an important avenue for millennial retention:

"[mobility] is getting more and more important to people of my generation because we have that possibility of bringing our work everywhere because it is right here in our laptops and in our phones" (RA3 November 2018).

This goes beyond generational as well. While family friendly policies have often helped attract more women in the labour market, it is essential to acknowledge that not all women, or men, want children. Although Denmark is highly attractive regarding work-life balance, this simply shows this is not everyone's priority and therefore recruitment strategies should be diverse enough to attract a variety of international students and talent. 
International students' choices are shaped by the intersection of their background, culture, gender, sexuality, age, and more. There is no one specific way to recruit or retain international students, and policies developed must not be blind to these differences. Feminist methodology is all about, as Harding states, a shift in perspective (1988). A shift that will understand the 'student' or 'talent' as inherently complex with many intersecting identities. Furthermore, it is important to understand the role actors have within institutions. Institutions are not simply a homogenous collection perpetuating historical biases and reinforcing power dynamics, but rather dynamic structures shaped by the individual, collective, or corporate actors within them. Actors can and do play a role in shaping institutions. 


\section{Conclusion}

International student mobility is significantly increasing, and Denmark is well positioned to develop recruitment and retention strategies for international students and talent, based on the four aforementioned themes: (1) increased cooperation and strategies between public and private institutions; (2) comprehensive immigration schemes and streamlined bureaucracy; (3) inclusive cultural integration; and (4) more equitable access to Danish language classes and utilization of English skills. With more countries involved in sending and hosting a greater diversity of international students, recruitment and retention strategies must go beyond a 'one-size-fits-all' to develop inclusive strategies and initiatives. In turn, innovation will be strengthened by a greater diversity of perspectives and experiences being employed. This research offers some initial insights into what the main factors international students consider when deciding on where to pursue postgraduate employment, and the current methods and strategies stakeholders employ in recruiting international students and talent, more generally. However, there are important areas of future research and exploration.

First, while the research focused predominantly on international students' transition from student to labour market employee, why students are choosing to study abroad is still a crucial area of research. Additionally, how students' decisions are influenced by the intersection of their identities could be a valuable contribution to student mobility literature. Why do female students study abroad? How does their country of origin influence this? Are male and female students more likely to choose different countries to study in? How much does economic class still influence students' interest and ability to study abroad? There is still significant research within the area of why students study abroad. 
This research concentrated on giving voices to crucial actors, however a significant area of future research is the need for an exhaustive analysis of primary documents arising out of the EU, OECD, UN, and Denmark's national and local governments. This would include extensive research into the past and current policies and laws relating to immigration, education, science and technology, innovation, and labour market trends. Primary document analysis would strengthen the institutional context and highlight where recruitment and retention efforts could best be supported. Moreover, it could lend insights into the current capacity and willingness of Denmark to achieve recruitment and retention goals. However, to assist with a primary document analysis, more aggregated data on international students in Denmark would be needed. Currently, there is no recent information on where students are coming from, what are they studying, how many male or female students choose Denmark, or where in Denmark students are choosing to study. Related, another challenge is the lack of statistics regarding the number of international students pursuing employment upon graduation, who these students are, and how long they are staying. This gap in knowledge is also absent from international data.

Furthermore, the current Danish recruitment and retention strategies are still very new and regionally based. Organizations, such as Copenhagen Capacity and International House, are in their infancy, therefore analyzing their success in the future would be crucial. It is also important to evaluate recent policy changes' impact on long term recruitment and retention of international students and talents; the two most crucial Danish policy changes being reducing the number of international students admitted to Danish universities and charging fees for Danish language classes.

A more comprehensive analysis of immigration schemes, especially the Pay Limit scheme and the Establishment Card, would also be useful, especially in understnading how 
many students utilize these schemes. Some international students' insights were missed because they had not gone through the process of transitioning into the Danish labour force, therefore future research could focus on international students who are currently working in Denmark. This would also be a way to gain further insights on the success of each immigration scheme. One stakeholder, who was in this position herself, offered significantly more insights into the process than most of the current international students were able to. While, this would not capture why international students left Denmark, it would offer substantial insights into what retention practices are currently successful.

The sample size of seventeen international students and fourteen stakeholders is too small to make broader claims, regarding, for example, patterns based on gender or country of origin. Increasing the sample size would allow for more tangible insights and concrete claims. Additionally, the sample has significant potential to be more representative. As mentioned, students from Asia, Africa, and South America are not represented. However, the absence of Chinese students in particular would enhance the analysis, due to China's crucial role in international student mobility and international education. This is a significant perspective to include as Chinese students often return to China upon graduation. The stakeholders interviewed covered a range of backgrounds, however increasing the number of stakeholders would allow for more diverse insights from larger corporations and smaller start-ups. With this information, recruit and retention strategies could be better specified for each stakeholder. Further research could also focus more on cluster and regional level comparisons and better engage with policy sharing. This could also include developing comparative research with other Nordic countries. One stakeholder mentioned the importance of marketing the entire region. While there was no evidence of an overarching coordinated strategy, there is potential for research into this. 
More students from a greater number of countries are participating in this global exchange of knowledge. The reason international student mobility is valuable is because it supports diverse perspectives, knowledge, and cultural interactions. Through this process, knowledge sharing increases and, in turn, can foster innovation. This innovation can be in the form of technological advances, as it is often associated with science and technology fields. However, innovation can also include new policies and processes. With globalization and the rapidly changing knowledge-based economy, innovative products and solutions are becoming how countries compete for international influence. This, coupled with domestic talent no longer being sufficient to support the local labour market, has fueled the global race for talent. International students are a key group in the broader international talent, as they are deemed high skilled and can navigate immigration systems more seamlessly. This has led to the expansion of international education. The skills and knowledge learned through international education will only becoming more vital.

Empirical research and interviews with international students identified initial factors that could best support international student transition into the Danish labour market. This information is useful for stakeholders to utilize their agency to influence institutions to promote increased retention of international students. The case study of Denmark offers some preliminary insights into recruiting and retaining international students through the attraction of welfare state policies and hurdles of restrictive immigration and isolating culture. Continuing research into recruitment and retention is essential to innovation, as one stakeholder said, "because mobility is important" and the skills and knowledge learned internationally are vital to supporting the ever-changing knowledge-based economy (DC 2 November 2018). 


\section{Works Cited}

Acker, Sandra. Resources for Feminist Research Toronto, vol. 28, no. 3/4, Winter/Spring 2001. pp. 153-172.

Adams, Melinda and Michal Smerk. "Making Institutions and Context Count: How Useful Is Feminist Institutionalism in Explaining Male Dominance in Politics?" Gender and Politics, vol. 14, no. 2, 2018. pp. 271-276.

Ahmad, Syed Z., and Matloub Hussain. "The Analytic Hierarchy Process of the DecisionMaking Factors of African Students in Obtaining Higher Education in the United Arab Emirates." Compare: A Journal of Comparative and International Education, vol. 47 , no. $2,2017$.

Altbach, Phillip and Jane Knight. "The Internationalization of Higher Education: Motivations and Realities." Journal of Studies in Higher Education. vol. 11, no.3/4, 2007. pp. 290-305.

Anokhin, Sergey and William Schulze. "Entrepreneurship, Innovation, and Corruption." Journal of Business Venturing vol. 24 2009. pp. 465-476.

Appleyard, Reginald. "International Migration and Development - An Unresolved Relationship." International Migration, vol. 30, no. 3-4, 1992, pp. 251-266

Arbutyn, Seth and Jonathan Turner. "The Old Institutionalism Meets New Institutionalism.” Sociological Perspectives, vol. 54, no. 3. 2011. pp. 283-306.

Arthur, Nancy and Sarah Flynn. "Career Development Influences of International Students Who Pursue Permanent Immigration in Canada." International Education Journal of Vocational Guidance vol.11, 2011. 221-237.

Atkinson, Rowland and John Flint. "Snowball Sampling." The SAGE Encyclopedia of Social Science Research Methods, edited by Michael Lewis Beck, Alan Brynman and Tim Futing Liao. Thousand Oaks: Sage Publications Inc, 2011.

Barnett, Michael and Martha Finnemore, "The Politics, Power, and Pathologies of International Organizations." International Organization, vol. 53, no. 4, 1999.

Bergerhoff, Jan, Lex Borghans, Philipp Seegers and Tom van Veen. "International Education and Economic Growth." Journal of European Labour Studies, vol. 2, no.3, 2013. pp.1-13.

Betts, Alexander and Gil Loescher, "Refugees in International Relations." Refugees in International Relations, edited by Alexander Betts and Gil Loescher. Oxford: Oxford University Press, 2011. 
Beyeler, Michelle \& Annesley, Claire. "Gendering the Institutional Reform of the Welfare State: Germany, the United Kingdom, and Switzerland." Gender, Politics and Institutions. Gender and Politics Series, edited by Mona Lena Krook and Fiona Mackay. Palgrave Macmillan: London. 2011.

Bilimoria, Diana, Linely Lord, and Melissa Marenelli. "Introduction to Women in STEM: International Perspectives on Increasing Workforce Participation, Advancement, and Leadership." Women in STEM Career: International Perspectives on Increasing Workforce Participation, Advancement and Leadership. edited by Diana Bilimoria Diana and Linely Lord. Monograph Book. 2014.

Bhandari, Rajika and Peggy Blumenthal. International Students and Global Mobility in Higher Education: National Trends and New Directions. Palgrave Macmillan. 2011.

Bomberg, Elizabeth, Peterson, John, and Corbett, Richard. The European Union How Does it Work? New York: Oxford University Press.

Boeri, Tito, Herbert Brücker, Frédérid Docquier, and Hillel Raport. Brain and Drain and Brain Gain: The Global Competition to Attract Highly Skilled Migrants. Oxford: Oxford University Press. 2012.

Bosetti, V., Cattaneo, C., and Verdolini, E. "Migration of Skilled Workers and Innovation: A European Perspective." Journal of International Economics, vol. 96, 2015. pp.311-322.

Boucher, Anna. Gender, Migration and the Global Race for Talent. Manchester University Press. 2016.

Brinkmann, Svend. Qualitative Interviewing. London: Oxford Press. 2013.

Brinley, Thomas. "Migration and Economic Growth: A Study of Great Britain and the Atlantic Economy." Economic and Social Studies vol. 12. 1954.

British Columbia Council for International Education. An Assessment of the Economic Impact of International Education in British Columbia in 2010 and 2015. January $2017 . \quad \mathrm{http}$ //bccie.bc.ca/wp-content/uploads/2017/02/RKA-Internationaleducation-Rpt-to-BCCIE-final-revised-1.pdf

Brooks, Rachel, Johanna Waters, and Helena Pimlott-Wilson. "International Education and the Employability of UK Students." British Educational Research Journal. vol. 38, no. 2, 2012. pp. 281-298.

Bucharest Communiqué. Making the Most of Our Potential: Consolidating the European Higher Education Area. 2012.

http://www.ehea.info/Upload/document/ministerial_declarations/Bucharest_Com munique_2012_610673.pdf 
Carleton University. Centre for European Studies: Jean Monnet Centre of Excellence at Carleton University. https://carleton.ca/ces/ces-projects/jean-monnet-centreexcellence-carleton-university/

Cerna, Lucie "Attracting High-Skilled Immigrants: Policies in Comparative Perspectives." International Migration. vol. 52, no. 3, 2014. pp. 69-84.

Chaney, Paul. "Critical Actor vs. Critical Mass: The Substantive Representation of Women in the Scottish Parliament" The British Journal of Politics and International Relations, vol. 14, 2012. pp. 441-457.

Cheryan, Sapna, John Oliver Siy, MarissaVichayapai, Benjamin Drury and Saenam Kim. "Do Female and Male Role Models Who Embody STEM Stereotypes Hinder Women's Anticipated Success in STEM?" Social Psychology and Personal Science, vol. 2, no. 6, 2011. pp. 656-664.

Childs, Sarah and Mona Lena Krook. "Analyzing Women's Substantive Representation: From Critical Mass to Critical Actors" Government and Opposition, vol. 44, no. 2, 2009. pp. 125-145.

Chubin, Daryl, Catherine Didion and Josephine Beoku- Betts. "Promising Programs: A Cross-National Exploration of Women in Science, Education to Workforce" Advancing Women in Science edited by Willie Pearson, Lisa Frehill, and Connie McNeal. Springer International Publishing. 2015

Copenhagen Healthtech Cluster. About. http://www.cphhealthtech.com/about

Copenhagen Capacity. About Us. 2018 http://www.copcap.com/about-us/about

Copenhagen Capacity. 2019. Living and Working http://www.copcap.com/living-andworking/a-welfare-society

Costa, Maria Conceiç o da. "Challenges of Intersectionality in Gender, Science and Technology." Cadernos PAGU. 2016

Council of Europe. Details of Treaty No 165: Convention on the Recognition of Qualifications Concerning Higher Education in the European Region. 2018. https://www.coe.int/en/web/conventions/full-list/-/conventions/treaty/165

Cubillo, J.M., Sanchez, J., and Cervin o, J. "International Students' Decision-Making Process." International Journal of Educational Management, vol. 20, no. 2, 2006. pp. 101-115.

Czaika M and Parsons C. "High-Skilled Migration in Times of Global Economic Crisis." IMI Working Paper 126. Oxford: IMI (International Migration Institute). 2016.

Danfoss 2017. Engineering Tomorrow. https://www.danfoss.com/en/aboutdanfoss/company/engineering-tomorrow/ 
Danish Agency for Science, Technology, and Innovation. Research and Innovation Indicators 2014. 2014. https://ufm.dk/en/publications/2014/files-2014-1/researchand-innovation-indicators-2014_web.pdf

Danish Parliament. The Danish Opt-Outs from EU Cooperation http://english.eu.dk/en/denmark_eu/danishoptouts

The Danish Immigration Services. Statistical Overview: Migration and Asylum. 2015.

de Hoyos, Maria, and Anne Green. "Recruitment and Retention Issues in Rural Labour Markets." Journal of Rural Studies, vol. 27, no. 2, 2011, pp. 171-180.

de la Porte, Caroline, and Elke Heins. "A New Era of European Integration? Governance of Labour Market and Social Policy Since the Sovereign Debt Crisis," Comparative European Politics vol. 13, no.1, 2015, 8-28.

Denmark.dk. Why Denmark is a Great Place to Live. 2019. https://denmark.dk/people-andculture

Diermeier, Daniel and Keith Krehbiel. "Institutionalism as a Methodology." Journal of Theoretical Politics, vol. 15, no. 2. 2003. pp.123-144.

Docquier, F. and J. Machado "Global Competition for Attracting Talents and the World Economy." The World Economy, vol. 39, no. 4, 2016. pp. 530-542.

Dodgson, Mark. "Exploring New Combinations in Innovation and Entrepreneurship: Social Networks, Schumpeter, and the Case of Josiah Wedgwood (1730-1795)" Industrial and Corporate Change, vol. 20, no. 4, 2011. pp. 1119- 1151.

Eder, Judith, Wayne W. Smith, and Robert E. Pitts. "Exploring Factors Influencing Student Study Abroad Destination Choice." Journal of Teaching in Travel \& Tourism, vol. 10 , no. 3, 2010, pp. 232-250.

Education First. English Language Proficiency Index. 2018. https://www.efdanmark.dk/epi/

Epsing-Anderson, Gøsta. The Three Worlds of Welfare Capitalism. Princeton University Press. 1990.

European Commission. Research and Innovation Performance in Denmark. 2015. https://publications.europa.eu/en/publication-detail//publication/ddd2c629-cf4a4f8a-a2bf-2398f05c5c99/language-en

European Commission. Eurostat (online data code: migr_pop3ctb). 2016a. http://ec.europa.eu/eurostat/web/productsdatasets/product?code $=$ MIGR_POP3CTB 
European Commission. Education and Training Monitor 2016: Country Analysis. $2016 \mathrm{~b}$.

European Commission. Regional Innovation Scoreboard: Denmark. 2017a. http://ec.europa.eu/DocsRoom/documents/24170

European Commission. Human Resources in Science and Technology by Sub Groups Denmark. 2017b https://rio.jrc.ec.europa.eu/en/country-analysis/Denmark/keyindicators/25564

European Commission. The Bologna Process and the European Higher Education Area. 2018. https://ec.europa.eu/education/policies/higher-education/bologna-processand-european-higher-education-area en

European Commission. Erasmas. 2019 https://ec.europa.eu/programmes/erasmusplus/node_en

European Union Publications. Denmark 2016: Boosting Innovation for Higher Productivity Growth. 2017. https://publications.europa.eu/en/publication-detail//publication/8646a065-f280-11e6-8a35-01aa75ed71a1/language-en

Eurostat. High Tech Export: Eurostat Code: tin00140. 2015.

http://ec.europa.eu/eurostat/tgm/table.do?tab=table\&init $=1 \&$ language $=$ en\&pcode $=\mathrm{t}$ in $00140 \&$ plugin $=1$

Eurostat. Share of Tertiary Education Students from Abroad by Continent. 2018. https://ec.europa.eu/eurostat/statistics-

explained/index.php/Learning_mobility_statistics

Fagerberg, Jan and Martin Srholec. "National Innovation Systems, Capabilities, and Economic Development." Research Policy, vol. 37, no. 9, 2008. 1417- 1435.

Favell, Adrian. "The Nation Centered Perspective.” Dialogues on Migration Policy edited by Marco Giugni and Florence Passy. Oxford: Lexington Books, 2006.

Feltham-King, Tracey and Catriona Macleod. "Gender, Abortion and Substantive Representation in South Africa Newsprint Media." Women's Studies International Forum vol. 51, 2015. pp. 10-18.

Fioretos, Orfeo. "Historical Institutionalism in International Relations." International Organization, vol. 65, no. 2, 2011. pp. 367-399.

Flick, Uwe. An Introduction to Qualitative Research. Thousand Oaks et al: Sage, 2009.

The Foreign Affairs Office. Introductory remarks, Memorandum given to the parliamentary European Affairs Committee. October 30, 1992.

Franeschet, Susan and Jennifer Piscopo. “Gender Quotas and Women's Substantive Representation: Lessons from Argentina" Politics and Gender vol. 4, 2008. pp. 
$393-425$.

Gadd, Stephan. "Employment levels in Denmark at record-breaking high" CPH Post. March 21, 2018a. http://cphpost.dk/news/business/employment-levels-in-denmarkat-recordbreakinghigh.html?fb comment id=1627043434016908 1627240370663881

Gadd, Stephan. "University Courses Discontinued Due to SU Cuts Reducing Foreign Student N umbers" CPH Post. November 16, $2018 \mathrm{~b}$. http://cphpost.dk/news/university-courses-discontinued-due-to-su-cuts-reducingforeign-student-numbers.html

Galan, Miranda, Meredith Lawley and Michael Clements. "Social Media's Use in Postgraduates' Decision-Making Journey: An Exploration Study." Journal of Marketing for Higher Education, vol. 25, no. 2, 2015. pp. 287-312.

Gao, M., and Liu, X. "From Student to Citizen: A Survey of Students from the People's Republic of China in Australia." International Migration Review, vol. 36, no. 1, 1998. pp. 27-48.

Geddes, Andrew and Andrew Taylor. "How EU Capacity Bargains Strengthen States: Migration and Border Security in South-East Europe." West European Politics, vol. 36, no. 1, (2013) pp. 51-70

Geddie, Kate. "Policy Mobilities in The Race for Talent: Competitive State Strategies in International Student Mobility." Transactions of the Institutes of British Geographers, vol. 40, no. 2, 2014. pp. 235-248.

Geiger, Martin and Amanda Bergmann. "How Will Canadian Technology Clusters Continue to Thrive and Remain Competitive in Managing STEM Migration for Innovation and Growth?" SSHRC Knowledge Synthesis Report. 2017. Ottawa.

Geiger, Martin and Antoine Pecoud. "International Organizations and the Politics of Migration.” Journal of Migration Studies, vol. 40, no. 6. 2014. pp. 865-887.

Ghazarian, Peter G. "Country Image and the Study Abroad Destination Choice of Students from Mainland China." Journal of International Students, vol. 6, no. 3. 2016.

Greater Copenhagen. Regional Growth and Development Strategy. 2015. https://www.regionh.dk/til-

fagfolk/erhverv/regional\%20vaekst $\% 200 \mathrm{o} \% 20 \mathrm{udvikling/Documents/Handlingspl}$ an $\% 202015-2016 /$ Greater $\% 20$ Copenhagen $\% 20$ \%20Regional\%20growth\%20and\%20development $\% 20$ strategy.pdf 
Greenwood, Royston and C. R. Hinings. "Understanding Radical Organizational Change: Bringing together the Old and the New Institutionalism." The Academy of Management Review, vol. 21, no. 4, 1996. pp. 1022-1054.

Gudrun Jensen, Tina, Kristina Weibel and Katherine Vitus. "There is No Racism Here: Public Discourse on Racism, Immigration and Integration in Denmark." Patterns of Prejudice, vol. 51, no.1, 2017. pp. 51-68.

Guiliherme Fernandes, Ariana. "(Dis) Empowering New Immigrants and refugees through their participation in introduction programs in Sweden, Denmark, and Norway." Journal of Immigrant and Refugee Studies, vol. 13, no. 3, 2015. pp. 245-264.

Guigni Marco and Florence Passey. Dialogues on Migration Policy. 2006.

Hammerstad, Anne. "Whose Security? UNHCR, Refugee Protection and State Security After The Cold War." Security Dialogue, vol. 31, no. 4, 2000.

Hannerberg, David. “Migration in Sweden: A Symposium”. Lund Studies in Geography, vol. 13. 1957.

Hansen, Holly. "Defining International Education." Internationalizing Higher Education. vol. 117. 2002. pp. 5-12.

Hao, Jie and Welch, Anthony. "A Tale of Sea Turtles: Job-Seeking Experiences of Hai Gui (High-Skilled Returnees) in China.” Higher Education Policy, vol. 25., 2012. pp. 243-260

Harding, Sandra. Feminism and Methodology. Indiana Press. 1988.

Harvey, William. "Strategies for Conducting Elite Interviews." Qualitative Research, vol. 11, no. 4, 2011. pp. 431- 441.

Hayes, Matthew and Matthew Hibbings. "The Symbolic Benefits of Descriptive Representation" Political Behavior, vol. 39. 2017. pp. 31-50.

Hemsley-Brown, J., and Oplatka, I. "Universities in a Competitive Global Marketplace: A Systematic Review of The Literature on Higher Education Marketing." International Journal of Public Sector Management. vol. 19, no. 4. 2006. pp. 316338

Holloway, S. L, S. L. O'Hara, and H. Pimlott-Wilson. "Educational Mobility and the Gendered Geography of Cultural Capital: The Case of International Student Flows Between Central Asia and the UK." Environment and Planning A, vol. 44, no. 9. 2012. pp. 2278-2294.

Hooghe, Liesbet and Gary Marks. "Sources of Euroscepticism." Acta Politica: Palgrace Macmillan. vol. 42, 2007. pp. 119-127. 
Howlett, Robert J, Bogdan Gabrys, Katarzyna Musial-Gabrys, and Roach, Jim. Innovation Through Knowledge Transfer. Springer Berlin Heidelberg. 2013

Huang, Alice. "The Era of Artificial Intelligence and Big Data Provides Knowledge Services for the Publishing Industry in China" Publishing Research Quarterly. vol. 35, no. 1. 2019. pp. 164- 171

Hunt, Jennifer, and Marjolaine Gauthier-Loiselle. "How Much does Immigration Boost Innovation?" American Economic Journal: Macroeconomics, vol. 2, no. 2, 2010. pp.31-56

The Institute of International Education. Project Atlas. 2018.

https://www.iie.org/Research-and-Insights/Project-Atlas

International House. About. 2018. https://ihcph.kk.dk/indhold/about

International Service System. History. 2017. https://www.issworld.com/about-iss/get-toknow-iss/our-strategy

Inglehart, Richard and Pippa Norris. "Cultural Obstacles to Equal Representation." Journal of Democracy. vol. 12, no. 3, 2001. pp.126-140.

Inter-Parliamentary Union. Women in National Parliament. 2018. http://archive.ipu.org/wmn-e/classif.htm

Immergut, Ellen and Karen M. Anderson. "Historical Institutionalism and West European Politics," West European Politics, vol. 31. no. 1-2, 2008. pp. 345-369.

Jiani, M.A. "Why and How International Students Choose Mainland China as a Higher Education Study Abroad Destination." Higher Education. vol. 74, no. 4, 2017. pp. 563-579.

Keohane, Robert "The Demand for International Regimes." International Organization, vol. 36, no. 2, 1982.

Kerr, W. J. "Breakthrough Inventions and Migrating Clusters of Innovation." Journal of Urban Economics, vol. 67, 2010. pp. 46-60.

Khoo, Siew-Ean. "Attracting and Retaining Globally Mobile Skilled Migrants: Policy Challenges Based on Australian Research." International Migration, vol. 52, no. 2, 2014, pp. 20-30

Kim, Junmo, and Yong-Soo Kwon. "Economic Development, the Evolution of Foreign Labor and Immigration Policy, and the Shift to Multiculturalism in South Korea." Philippine Political Science Journal, vol. 33, no. 2, 2012, pp. 178-201

Knight, Jane. "Regional Education Hubs: Mobility for Knowledge Economy" International Students and Global Mobility in Higher Education: National Trends 
and New Directions. edited by Bhandari, Rajika and Peggy Blumenthal. Palgrave Macmillan. 2011.pp. 211-231

Kofman, Elenore. "Towards a Gender Evaluation of Highly Skilled Immigration Policies in Europe." International Migration, vol. 52, no. 3, 2014. pp. 116-128.

Kosiara-Pedersen, Karina. "Denmark". European Journal of Political Research Political Data Yearbook, vol. 56, no. 1, 2017. pp. 79-84.

Krook, Mona Lena and Fiona Mackay. Gender, Politics and Institutions: Towards a Feminist Intuitionalism. Palgrave Macmillian. 2011.

Krook, Mona Lena. Quotas for Women in Politics: Gender and Candidate Selection Reform Worldwide, New York: Oxford University Press. 2009.

Krunke, Helle. "From Maastricht to Edinburgh: The Danish Solution." European Constitutional Law Review (EuConst), vol. 1, no. 3, 2005, pp. 339-356.

Kushnirovich, Nonna, and Sibylle Heilbrunn. "Innovation and Conformity: Intersection of Gender and Ethnicity in Hi-Tech Organizations." Journal of Management Development, vol. 32, no. 2, 2013, pp. 204-20.

Lasanowski, Veronica. "Can Speak, Will Travel: The Influence of Language on Global Student Mobility." International Students and Global Mobility in Higher Education: National Trends and New Directions. edited by Bhandari, Rajika and Peggy Blumenthal. Palgrave Macmillan. 2011. pp. 193-210.

Lee, Cheng-Fei. "An Investigation of Factors Determining the Study Abroad Destination Choice: A Case Study of Taiwan." Journal of Studies in International Education, vol. 18 , no. 4, 2014. pp. 362-381.

Li, F. L., Findlay, A. M., Jowett, A. J., \& Skeldon, R. "Migrating to Learn and Learning to Migrate: A Study of the Experiences and Intentions of International Student migrants." International Journal of Population Geography, vol. 2, 1996. pp. 5167.

Li, M., \& Bray, M. "Cross-Border Flows of Students for Higher Education: Push-Pull Factors and Motivations of Mainland Chinese Students in Hong Kong and Macau.” Higher Education, vol. 53, no. 6, 2007. pp. 791-818.

Liversage, Anika. "Finding a Path: Investigating the Labour Market Trajectories of HighSkilled Immigrants in Denmark." Journal of Ethnic and Migration Studies. vol. 35, no. 2, 2009. pp. 203 - 226.

Lombardo, Emanuela, and Petra Meier. "Gender Mainstreaming in the EU: Incorporating a Feminist Reading?" European Journal of Women's Studies, vol. 13, no. 2. 2006. pp. 151-66. 
Lovenduski, Joni. "Forward". Gender, Politics and Institutions: Towards a Feminist Intuitionalism, edited by Mona Lena Krook and Fiona Mackay. Palgrave Macmillian. 2011. pp. vii-xii.

Mabogunje, Akin. "Systems Approach to Theory of Urban Rural Migration." Geographical Analysis, vol. 2, no. 1, 1970. pp. 1-18

Mackay, Fiona and Georgina Waylen. "Feminist Institutionalism" Politics and Gender: Critical Perspectives on Gender and Politics vol. 5, 2009, pp. 237-280.

Mærsk. Digital Innovation. 2017. https:/www.maersk.com/explore/digital-innovation

Malkki, Liisa "National Geographic: The Rooting of People and the Territorialisation of National Identity Among Scholars and Refugees," Cultural Anthropology, vol. 7, no. $1,1992$.

Manso, Gustavo. "Motivating Innovation.” The Journal of Finance, vol. 66, no. 5, 2011. $1823-1860$.

Manthorpe, J., Hussein, S., Charles, N., Rapaport, P., Stevens, M., \& Nagendran, T. "Social Care Stakeholders' Perceptions of the Recruitment of International Practitioners in the United Kingdom - A Qualitative Study." European Journal of Social Work, vol. 13, no. 3, 2010, pp. 393-408.

Massey, Douglas, Joaquin Arango, Graeme Hugo, Ali Kouaouci, Adela Pellegrino and J. and Edward Taylor. "Theories of International Migration: A Review and Appraisal" Population and Development Review. 19(3) (1993). 431-466.

Martin, F. "The Gender of Mobility: Chinese Women Students' Self-Making Through Transnational Education." Intersections: Gender and Sexuality in Asia and Pacific, vol. 35, 2014. pp. 1-16.

Mazzarol, T., and G.N. Soutar. "Push-Pull' Factors Influencing International Student Destination Choice." The International Journal of Educational Management, vol.16, no. 2, 2002, pp. 82-90.

McCall, Leslie. "The Complexity of Intersectionality." Signs, vol. 30, no. 3, 2005, pp. $1771-1800$

McEvoy, B., and C.J. Edwards. "Human Migration: Reappraising the Viking Image." Heredity, vol. 95, 2005. pp. 111-112.

McHale, John. "Structural Incentives to Attract Foreign Students to Canada's Postsecondary Educational Systems: A Comparative Analysis." International Students and Global Mobility in Higher Education: National Trends and New Directions. edited by Bhandari, Rajika and Peggy Blumenthal. Palgrave Macmillan. 2011. pp. 167-192. 
McNutt, Kathleen. "Politics, Policy, and Participation: Contemporary Issues in Canadian Gender Equality" Canadian Political Science Review, vol. 6, no. 2-3, 2012, pp. 139141.

Medina, Alicia. "Serving Denmark's Open Prison for 'Undeportables”" News Deeply. October 1, 2018. https://www.newsdeeply.com/refugees/articles/2018/10/01/surviving-denmarksopen-prisons-for-undeportables

Meret, Susi and Birte Siim. "Gender, Populism and the Politics of Belonging: Discourses of Right-Wing Populist Parties in Denmark, Norway, and Austria." Negotiating Gender and Diversity in an Emergent European Public Sphere, edited by Birte Siim and Monika Mokre. London, UK: Palgrave Macmillian. 2013.pp 78-96.

Migration Data Portal. 2018. International Students. https://migrationdataportal.org/themes/international-students\#definition

Mihi-Ramirez, Antonio, Yolanda Garcia-Rodriguez and Eduardo Cuenca. "Innovation and International High skilled Mobility." Inzinerine Ekonomika-Engineering Economics, vol. 27, no. 4, 2016. pp. 452-461.

Milne, Richard. "Lunch with the FT: Helle Thorning Schmidt." Financial Times. February 7, 2014. https://www.ft.com/content/6a2010fa-8e51-11e3-98c6-00144feab7de

Milner, James "Introduction: Understanding Global Refugee Policy." Journal of Refugee Studies. vol. 27, no. 4, 2014.

Ministry of Higher Education and Science. Cluster Strategy 2.0 - Strategy for Denmark's Cluster and Network Policy 2016-2018. 2016. https://ufm.dk/en/publications/2016/files/danish-cluster-strategy-2-0_eng.pdf

Ministry of Higher Education and Science. Organization. 2018. https://ufm.dk/en/theministry/organisation/the-ministry

Minto, Rachel and Lut Mergert. "Gender Mainstreaming and Evaluation in the EU: Comparative Perspectives from Feminist institutionalism." International Feminist Journal of Politics. vol. 20, no. 2, 2018. pp. 204-222.

Mosneaga, Ana. "Managing International Student Migration: The Practices of Institutional Actors in Denmark." International Migration, vol. 53, no.1, 2015.

Mouritsen, Per and Tore Vincents Olsen. "Denmark Between Liberalism and Nationalism" Ethnic and Racial Studies, vol. 36, no. 4, 2011. pp. 691-710.

Mpinganjira, Mercy. "Factors Influencing African Postgraduate International Students' Choice of South Africa as a Study Destination." Educational Research and Reviews, vol. 7, no. 11, 2012. 
Munk, Martin. "Transnational Investments in Informational Capital: A Comparative Study of Denmark, France and Sweden." Acta Sociological, vol. 52, no. 1, 2009. pp. 523.

New to Denmark. You Want to Apply: Work Permits https://www.nyidanmark.dk/enGB/You-want-to-apply/Work

New to Denmark. Apply for Permanent Residence Permit. https://www.nyidanmark.dk/enGB/You-want-to-apply/Permanent-residence-permit/Permanentresidence?anchor $=$ canyouapply

Novo Nordisk. About. 2017. https://www.novonordisk.com/about-novo-nordisk.html

Nubauer, Mattias, Stefan Oppl, Christian Stary and George Weichhart. "Facilitating Knowledge Transfers in IANES - A Transactive Memory Mpproach." Innovation Through Knowledge Transfer, vol. 18. 2012. pp. 39-50.

Organisation for Economic Co-operation and Development. Innovation Cluster: Drivers of National Innovation Systems. 2001.

https://www.nist.gov/sites/default/files/documents/2017/04/28/spi-the-plasticsindustry-trade-association-attachment.pdf

Organisation for Economic Co-operation and Development. Developing High Skilled Workers: Review of Denmark. 2004. https://www.oecd.org/sti/ind/34458043.pdf

Organisation for Economic Co-operation and Development. "The Measurement of Scientific and Technological Activities: Guidelines for Collecting and Interpreting Innovation Data: Oslo Manual, Third Edition" prepared by the Working Party of National Experts on Scientific and Technology Indicators, OECD, Paris. 2005.

Organisation for Economic Co-operation and Development Data. Starting a Business. 2013. https://data.oecd.org/entrepreneur/starting-a-business.htm\#indicator-chart

Organisation for Economic Co-operation and Development Data. Permanent Immigration Inflow. 2014. https://data.oecd.org/migration/permanent-immigrant-inflows.htm

Organisation for Economic Co-operation and Development Matching Economic Migration with Labour Market Needs in Europe, OECD Publishing. 2014. https://www.oecdilibrary.org/social-issues-migration-health/matching-economic-migration-withlabour-market-needs_9789264216501-en

Organisation for Economic Co-operation and Development Data. Denmark. 2018 https://data.oecd.org/denmark.htm

Organisation for Economic Co-operation and Development. Education at a Glance 2018: OECD Indicators, OECD Publishing, Paris. 2018. 
Orange, Richard. "Denmark Swings Right on Immigration - and Muslims Feel Besieged" The Guardian. June 2018.

https://www.theguardian.com/world/2018/jun/10/denmark-swings-rightimmigration-muslims-besieged-holbaek

Ostergaard, Christian Richter and Eunkyng Park. "What Makes Clusters Decline? A Study of Disruption and Evolution on a High Tech Cluster in Denmark." Regional Studies, vol. 49, no. 5, 2015. pp. 834-849.

Ostling, Alina. "An Overview of Highly Skilled Labour Migration in Denmark with a Focus on Indian Migration." CARIM India. 2013. http://www.india-eumigration.eu/media/CARIM-India-HSM-2013-43.pdf

Pang, B. C., and N. Appleton. "Higher Education as an Immigration Path for Chinese Students and Scholars" The Qualitative Report, vol. 9, no. 3, 2004. pp. 500-527

Park, Sang-Chu. "Innovation Policy and Strategic Value for Building Cross-Border Clusters in Denmark and Sweden." AI and Soc, vol. 29, 2014. pp. 363-375

Pasquale, Frank. "Professional Judgment in an Era of Artificial Intelligence and Machine Learning." Boundary, vol. 46, no. 1, 2019. pp. 73-101.

Pattieu Sylvain. "The BUMIDOM in Paris and Its Suburbs: Contradictions in a State Migration Policy, 1960s-1970s, African and Black Diaspora" An International Journal vol. 10, no. 1, 2017. pp. 12-24.

Pemberton, Simon and Claire Stevens. "The Recruitment and Retention of Central and Eastern European Migrant Workers in the United Kingdom: A Panacea or a Problem under the New Policies of 'Managed Migration'?' Regional Studies, vol.44, no 9. 2010. pp. 1289-1300.

Pitkin, Hanna. The Concept of Representation. University of California Press. 1967.

Plumb, Alison. "The Substantive Representation of Women On 'Morality Politics' Issues in Australia And The UK: How Does The Substantive Representation Of Women Occur in Conservative Parties?” Political Science, vol. 68, no.1, 2016. pp. 22-35.

Porter, Michael E. "Clusters and the Economics of Competition." Harvard Business Review, vol. 76, no. 6. 1998. 77-90.

Ritzen, Josef M. M., and Hendrik P. van Dalen. "The Economic Consequences of Selective Immigration Policies." Migration and Economic Development. Edited by Klaus F. Zimmermann. Springer-Verlag, New York: Berlin. 1992.

Raghuram, Parvati. "Situating Women in the Brain Drain Discourse: Discursive Challenges and opportunities." Gender and Migration in $21^{\text {st }}$ Century Europe. edited by Helen Stalford, Samantha Currie and Samantha Velluti. 2009. 
Rasmussen, Maja Kluger and Catharina Sorensen. "Denmark: A Pragmatic Euroscepticism" Building Bridges Papers Series March 2016. 2016.

Reykjavik Declaration. Recognition of Qualifications in Higher Education - The "Reykjavik Declaration" 2004.

Razin, Assaf, Efrain Sadka, and Benjarong Suwankiri. Migration and the Welfare State: Political-Economy Policy Formation. Cambridge, Massachusetts: The MIT Press. 2011.

Reclus, Elisee and Ravenstein, E.G. The Earth and its Inhabitants. New York: D. Appleton. 1882.

Reilly, Erin, Kadie R. Rackley, and Germine H. Awad. "Perceptions of Male and Female STEM aptitude: The Moderating Effect of Benevolent and Hostile Sexism." Journal of Career Development, vol. 44, no. 2. 2017. pp. 159-173.

Robertson, David and Bill Breen. Brick by Brick: How LEGO Rewrote the Rules of Innovation and Conquered the Global Toy Industry. Crown Business. 2014.

Rodríguez-Pose, Andrés and Riccardo Crescenzi. "Research and Development, Spillovers, Innovation Systems, and the Genesis of Regional Growth in Europe." Regional Studies, vol. 42, no. 1, 2008. pp. 51-67

Ronnow Lonholdt, Jens, Mille Wilken Bengtsson, Lone Tolstrup Karlby, Dorthe Skovgaard Lund, Carsten Møller, Jacob Nielsen, Annette Winkel Schwara, and Kristoffer Amlani Ulbak. "Next Practicing in University Research Based Open Innovation - From Push and Pull: Case Study form Denmark." Innovation Through Knowledge Transfer, vol. 18, 2012. pp. 61-77.

Rolandsen Agustin, Lise and Robert Sata. "Gendered Identity Constructions in Political Discourse: The Cases of Denmark and Hungary." Negotiating Gender and Diversity in an Emergent European Public Sphere, edited by Birte Siim and Monika Mokre. London, UK: Palgrave Macmillian.2013. pp. 60 -77.

Rye Olsen, Gorm. "How Strong is Europeanisation, Really? The Danish Defence Administration and the Opt-Out from the European Security and Defence Policy." Perspectives on European Politics and Society, vol. 12, no. 1, 2011. pp. 13-28.

Salisbury, M. H., M. B. Paulsen, and E. T. Pascarella. "To See the World or to Stay at Home: Applying an Integrated Student Choice Model to Explore the Gender Gap in the Intent to Study Abroad." Research in Higher Education, vol. 51, no. 7, 2010. pp. 615-640.

Schover, Marlou and Dierdre Moloney. Gender, Migration and Categorisation: Making Distinctions Between Migrants in Western Countries, 1945-2010 Amsterdam University Press. 2013. 
Scott, Colin, Saba Safdar, Roopa Desai Trilokekar, and Amira El Masri. "International Students as 'Ideal Immigrants' in Canada: A Disconnect between Policy Makers' Assumptions and the Lived Experiences of International Students." Comparative and International Education, vol. 43, no. 3, 2015.

Settles, Isis H., Rachel C. O’Connor, and Stevie C. Y. Yap. "Climate Perceptions and Identity Interference among Undergraduate Women in STEM: The Protective Role of Gender Identity." Psychology of Women Quarterly, vol. 40, no. 4, 2016. pp. 488503.

Shachar, A. "The Race for Talent. Highly Skilled Migrants and Competitive Immigration Regimes." NYU Law Review, vol. 8, no. 1, 2006. pp. 148-206.

Shachar A. and Ran Hirschl. "Recruiting "Super Talents" The New world of Selective Migration Regimes.” Indiana Journal of Global Legal Studies, vol. 20, no. 1, 2013.

Siim, Birte. "Gender, Diversity, and Migration - Challenges to Nordic Welfare, Gender Politics, and Research." Equality, Diversity, and Inclusion: An International Journal, vol. 32, no. 6, 2013. pp. 615-623.

Singh, Romilia, Nadya A. Foud, Mary Fitzpatrick, Catia Figueiredo and Wen Hsin Chang. "To Stay or Leave: Factors that Differentiate Women Currently Working in Engineering from those Who Left." Women in STEM Career: International Perspectives on Increasing Workforce Participation, Advancement and Leadership, edited by Diana Bilimoria Diana and Linely Lord. Monograph Book. 2014. 39-56.

Skills Panorama. Future Employment Growth. 2015. http://skillspanorama.cedefop.europa.eu/bg/countries/denmark

Skills Panorama. Denmark: Mismatch Priority Occupations. 2016. http://skillspanorama.cedefop.europa.eu/en/analytical highlights/denmark$\underline{\text { mismatch-priority-occupations }}$

Solheim, Marte and Rune Dahl Fitjar 2016. "Foreign Workers are Associated with Innovation but Why? International Networks as Mechanism." International Regional Science Review, vol. 41, no. 3, 2016. pp. 311-334.

Sondhi, Gunjan and Russell King. "Gendering International Student Migration: an Indian Case Study." Journal of Ethnic and Migration Studies, vol. 43, no. 8, 2017. pp. 1308-1324.

Statista. 20 Biggest Companies in Denmark as of October 2017. 2018. https://www.statista.com/statistics/555296/denmark-top-20-biggest-companiesby-number-of-employees/ 
Statistics Denmark. International Students. 2018a https://www.dst.dk/en/Statistik/emner/uddannelse-ogviden/fuldtidsuddannelser/internationale-studerende

Statistics Denmark. Labour, Income, Wealth. 2018b https://www.statbank.dk/statbank5a/default.asp?w=1366

Study in Denmark. An Innovation Leader. Ministry of Higher Education and Science. 2018a.https://studyindenmark.dk/why-denmark/excellence-in-education1/creativity-and-innovation-run-deep

Study in Denmark. News on Higher Education. 2018b.

https://studyindenmark.dk/news/considerably-more-international-studentspursuing-a-full-study-programme-in-denmark

Study in Denmark. Residence Permits for non- EU/EEA citizens. 2018c. https://studyindenmark.dk/live-in-denmark/permits-visas-red-tape/residencepermits-for-non-eu-citizens

Sundbo, Jon. The Theory of Innovation: Entrepreneurs, Technology and Strategy. Cheltenham, UK: Edward Elgar. 1998.

Sweeney, Gerry. Innovation Policies: An International Perspective. London, UK: Frances Pinter Publishers Ltd. 1985.

Szczenbiak, Aleks and Paul Taggart. "Introduction: Researching Euroscepticism in European Party Systems: A Comparative and Theoretical Research Agenda" Opposing Europe? The Comparative Party Politics of Euroscepticism. edited by Aleks Szczerbiak and Paul Taggart. New York: Oxford University Press, 2008. pp. $1-27$.

Talent Attraction Denmark. Key Danish Industries. http://www.talentattractiondenmark.dk/en/?toolid=229

Tange, Hanne and Iben Jensen. "Good Teachers and Deviant Learners? The Meeting of Practices in University Level International Education." Journal of Research in International Education, vol. 11, no. 2, 2012. pp. 181-193.

The Local. "Denmark Extends Border Control by Six Months" October 2018. https://www.thelocal.dk/20181012/denmark-extends-border-control-by-sixmonths

Thomson, Jennifer. "Resisting gendered change Feminist Institutionalism and critical actors.” International Political Science Review 39(2), (2018) 178 - 191.

To, W. M., et al. "Destination Choice of Cross-Border Chinese Students: An Importance Performance Analysis." Educational Studies, vol. 40, no. 1, 2014. pp. 63-80. 
Top Talent Denmark. Your Way to Danish Higher Education Institutions and Companies. 2016. http://www.toptalentdenmark.com.cn

Topaloff, Luibomir K. Political Parties and Euroscepticism London: Palgave MacMillian. 2012.

Triadafilopoluos and Zaslove. "Influencing Migration Policy from Inside Political Parties". Dialogues on Migration Policy. edited by Marco Giugni and Florence Passy. Oxford: Lexington Books. 2006. pp. $171-192$.

Ugland, Trygve. "Canada as an Inspirational Model: Reforming Scandinavian Immigration and Integration Policies" Nordic Journal of Migration Research, vol. 4, no. 3, 2014. pp. 144-152.

Usman, Abbo, Abd R. Romle, and Mohammed M. Qader. "Examining the Relationships between Quality Assurance, Training Need and Choice of Study Destination: A Study of Nigerian Students in UUM." International Journal of Economics and Financial Issues, vol. 5, no. 1, 2015.

United Nations Education, Scientific, and Cultural Organisation. UNESCO Institute for Statistics: Women in Science. 2016.

University of Toronto and University of Ottawa. Global Education for Canadians: Equipping Young Canadians to Succeed at Home and Abroad. November 2017. http://goglobalcanada.ca

Valentin, Karen. "Caught Between Internationalisation and Immigration: The Case of Nepalese Students in Denmark." Learning and Teaching, vol. 5, no. 3, 2012. pp. 5674.

Vasiljeva, Kristine. "On the Importance of Macroeconomic Factors for The Foreign Student's Decision to Stay in The Host Country." Economics Working Papers, Aarhus University, Denmark. vol. 17, 2014.

Vickers, Jill. "Gendering Federalism: Institutions of Decentralization and Power-Sharing." Gender, Politics and Institutions: Towards a Feminist Intuitionalism. edited by Mona Lena Krook and Fiona Mackay. Palgrave Macmillian. 2011.

Volante, Louis and Jo Ritzen. "The European Union, Education Governance and International Education Surveys." Policy Futures in Education, vol. 14, no.7, 2016. pp. 988-1004.

Wadhwa, Vivek. Losing the World's Best and Brightest: America's New Immigrant Entrepreneurs. Pat V. Kansas City. MO: The Ewing Marion Kauffman Foundation. 2009.

Wangneurd, Lena. "Women in Parliaments: Descriptive and Substantive Representation" The Annual Review of Political Science, vol. 12, 2009. pp. 51-69. 
Watson, Scott "Manufacturing Threats: Asylum Seekers as Threats or Refugees", Journal of International Law and International Relations, Vol. 3, 2007.

Waylen, Georgina. "What can Historical Institutionalism Offer Feminist Institutionalists?" Politics and Gender, vol. 5, no. 2, 2009. pp. 245 - 253.

WeForum. Gender Parity. 2016. https://www.weforum.org/agenda/archive/gender-parity

Weisser, Reinhard. "Internationally Mobile Students and Their Post-Graduation Migratory Behavior: An Analysis of Determinants of Student Mobility and Retention Rates in The EU." OECD Social, Employment and Migration Working Paper 186: OECD Publishing Paris. 2016.

Wiking, Meik. The Little Book of Hygge: The Danish Way to Live Well. Penguin United Kingdom. 2016.

Wiking, Meik. The Little Book of Lykke: The Danish Search for the World's Happiest People. Penguin Canada. 2017.

Wilken, Lisanne and Mette Ginnerkov Dhalberg. "Between International Student Mobility and Work migration: Experiences of Students from EU's Newer Member States in Denmark." Journal of Ethnic and Migration Studies, vol. 43, no. 8, 2017. pp. 13471361.

Wildavsky, Ben. The Great Brain Race: How Global Universities are Reshaping the World. Princeton. NJ: Princeton University Press. 2010.

Woodside, Arch, Pedro Mir Bernal and Alicia Coduras. "The General Theory of Culture, Entrepreneurship, Innovation and Quality of Life: Comparing Nurturing Versus Thwarting Enterprise Start-Ups in BRIC, Denmark, Germany, and the United States.” Industrial Marketing Management, vol. 53, no. 1, 2016. pp.136-156.

The World Bank. The Gender Portal. 2017. http://datatopics.worldbank.org/gender/country/denmark

World Economic Forum. 11 Quotes on the Danish Election. 2011. https://www.weforum.org/agenda/2015/06/11-quotes-on-the-danish-election/

World Economic Forum. Global Competitiveness Index: Denmark. 2018. http://reports.weforum.org/global-competitiveness-report-20152016/economies/\#economy=DNK

World Population Review. Denmark. 2018. http://worldpopulationreview.com/countries/denmark-population/

Work Permit.com Denmark Green Card Scheme. http://workpermit.com/immigration/denmark/denmark-green-card-scheme 
Wynn, Alison and Shelly Correll. "Puncturing the Pipeline Do Technology Companies Alienate Women in Recruiting Session?” Social Studies of Science, vol. 48, no. 1 2018. pp. 149-164.

Xinyu, Yang. "Mobility Strategies and Trends: The Case of China." International Students and Global Mobility in Higher Education: National Trends and New Directions. edited by Rajika, Bhandari and Peggy Blumenthal. Palgrave Macmillan. 2011.

Zheng, Y. and Y. Chen. "Studies on Human Resources in Science and Technology from a Nordic-Countries-Based Analysis," 2010 International Conference on Management and Service Science, Wuhan, China. 2010. pp. 1-4.

Ziguras, C., \& Law, S. F. "Recruiting International Students as Skilled Migrants: The Global 'Skills Race' as Viewed from Australia and Malaysia." Globalization, Societies and Education, vol. 4, no.1, 2009. pp. 59-76.

Zucker, L. G., and Darby, M. R. "Movement of Star Scientists and Engineers and HighTech Firm Entry." National Bureau of Economic Research. Working Paper 12172. 2006. 


\section{Annex 1: List of Interviews}

Stakeholder Interviews:

Recruitment Agency 1, October 2018

Recruitment Agency 2, October 2018

Recruitment Agency 3, October 2018

University Professor 1, November 2018

University Professor 2, November 2018

Danish Government 1, December 2018

Danish Government 2, November 2018

Danish Government 3, November 2018

Danish Company 1, November 2018

Danish Company 2, November 2018

Danish Company 3, November 2018

Danish Company 4, October 2018

Danish Government 3, November 2018

Danish Company 5, November 2018

Danish Company 6, November 2018

International Student Interviews:

PhD EU1, October 2018

PhD EU2, October 2018

PhD EU3, November 2018

PhD EU4, October 2018

PhD EU5, November 2018

PhD EU6, October 2018

PhD non-EU1, October 2018

PhD non-EU2, October 2018

PhD non EU3, November 2018

$\mathrm{PhD}$ non-EU4, November 2018

PhD non-EU5, November 2018

MA EU1, November 2018

MA non-EU1, November 2018

BA EU1, October 2018

BA EU2, November 2018

BA EU3, November 2018

BA EU4, November 2018 


\section{Annex 2: Interview Guide - Stakeholders \\ Typical questions for industry stakeholders (technology and innovation sector, recruitment agencies)}

1. To what extent does your company rely on foreign talent? What are typical job descriptions, requirements in terms of skills and degrees? How do you evaluate the future need, and what developments/trends can you describe (last 5-10 years)?

2. Have there been any changes in terms of composition of talent flows? What are the main nationalities, countries you are recruiting and retaining talent from?

3. What initiatives does your company employ to recruit and retain international students from the local universities?

4. To what extent does your company rely on retaining international students and STEM talent already present in the country? To what extent does your company rely on new talent? Are you required to recruit abroad? What trends do you see?

5. What is your company's experience in recruiting and retaining foreign talent on the basis of existing policies and government programs? What are the main avenues, pathways your company is using and has most experience in? What have been your company's challenges in recruiting and retaining foreign talent?

6. Which previous reforms, policy changes have proved useful for your company and have facilitated the recruitment and retention of foreign talent? Which reforms or policy changes had a negative impact on your company's recruitment and retention and were making it more difficult to recruit and retain foreign talent? Why?

7. What are the policy or program changes your company would require for more easily recruiting and retaining the best talent for innovation and growth? Are there any specific policies or initiatives to attract more women into the sector?

8. Are there any issues and particular challenges and developments regarding recruitment and retention that you think we should know about, and concentrate our research on? 


\section{Typical questions for government stakeholders, at the cluster level (local administration), provincial (sub central state) and (federal) central government level}

1. To what extent does the local cluster/the province of $\mathrm{X} /$ the country of $\mathrm{X}$ rely on foreign talent? What are typical job descriptions, requirements in terms of skills and degrees? How do you evaluate the future need, and what developments/trends can you describe (last 5-10 years)?

2. What are the main origin countries and nationalities of foreign STEM talent? Have there been any changes?

3. To what extent does the (local/provincial/national) economy rely on retaining international students and STEM talent that are already present in the country? To what extent does the tech and innovation sector rely on new talent, and is it required to recruit abroad? What trends do you see?

4. Does your government entity generally agree with industry demands for more global STEM talent recruitment and retention?

5. What is your experience in how industry stakeholders recruit and retain foreign talent and are able to use existing local/federal/central state policies and government programs? What are the main avenues, pathways they are using?

6. Which previous reforms, policy changes have proved useful for companies to hire and retain foreign talent? Which reforms, policy changes were necessary to respond to labour market needs or other societal and political demands and requirements?

7. What are the policy or program changes that you think are required for spurring innovation and growth, and helping local tech and innovation sectors? How important is foreign talent now and in the future? What policies and programs are currently in pipeline? What is the state of discussion?

8. Are there any issues and particular challenges and developments regarding recruitment and retention that you think we should know about, and concentrate our research on? 


\section{Annex 3: Interview Guide - International Students}

1. What was your level of knowledge of the STEM sector in Denmark prior to choosing to study here?

2. Have you studied abroad before? If so, where?

3. Has the university provided resources regarding staying in Denmark upon your graduation for either post graduate work or permanent residence? Are there any additional services you think your campus could offer?

4. Do you know of any programs the STEM sector or Tech sector in Denmark is doing to retain international students? Are any specifically for increasing the number of women in STEM?

5. Why did you choose to study in your respect field? Did you start in a different field and switch?

6. Have you worked during your study in Denmark? Was it in the STEM sector?

7. What would be the main incentivising factor to stay in Denmark? In other words, what or who has the greatest influence in a decision for staying in Denmark?

8. What are your main hesitations for staying in Denmark upon graduation? In other words, what or who has the greatest influence in a decision returning to your home country?

9. Have you experienced any major barriers to being able to study in Denmark? Are there any major barriers to staying in Denmark post-graduation? 


\section{Annex 4: International Student Questionnaire}

Student Information - Please fill out

\begin{tabular}{|l|l|}
\hline 1.) What country are you a citizen of? & \\
\hline $\begin{array}{l}\text { 2.) What post-graduate degree are you } \\
\text { enrolled in? }\end{array}$ & \\
\hline 3.) What are you studying in Denmark? & \\
\hline
\end{tabular}

4.) Rate the significance of the following factors in your decision to study abroad

\begin{tabular}{|ll|l|l|l|l|}
\hline \multicolumn{2}{|c|}{$\begin{array}{l}\text { To improve your English Language } \\
\text { Skills }\end{array}$} & Very significant & Significant & $\begin{array}{l}\text { Not at all } \\
\text { significant }\end{array}$ & N/A \\
\hline $\begin{array}{l}\text { b. } \\
\text { To experience and learn about a new } \\
\text { culture while gaining intercultural skills }\end{array}$ & Very significant & Significant & $\begin{array}{l}\text { Not at all } \\
\text { significant }\end{array}$ & N/A \\
\hline $\begin{array}{l}\text { c. } \\
\text { To increase career prospects and } \\
\text { strengthen future job competitiveness }\end{array}$ & Very significant & Significant & $\begin{array}{l}\text { Not at all } \\
\text { significant }\end{array}$ & N/A \\
\hline $\begin{array}{l}\text { d. } \\
\text { Because you were encouraged by } \\
\text { family, friends, or academic professors }\end{array}$ & Very significant & Significant & $\begin{array}{l}\text { Not at all } \\
\text { significant }\end{array}$ & N/A \\
\hline
\end{tabular}

5.) Rate the significant of the following factors in your decision to stay in Denmark or return to your home country upon graduation

\begin{tabular}{|c|c|c|c|c|}
\hline $\begin{array}{l}\text { a. Staying in Denmark due to the } \\
\text { inclusive, safer culture and community } \\
\text { and/or strong social network }\end{array}$ & Very significant & Significant & $\begin{array}{l}\text { Not at all } \\
\text { significant }\end{array}$ & $N / A$ \\
\hline $\begin{array}{l}\text { b. Staying in Denmark due to positive or } \\
\text { increased job prospects }\end{array}$ & Very significant & Significant & $\begin{array}{l}\text { Not at all } \\
\text { significant }\end{array}$ & $N / A$ \\
\hline $\begin{array}{l}\text { c. Returning home due to family } \\
\text { commitments }\end{array}$ & Very significant & Significant & $\begin{array}{l}\text { Not at all } \\
\text { significant }\end{array}$ & $N / A$ \\
\hline $\begin{array}{l}\text { d. Returning home due to lack of job } \\
\text { prospects in Denmark }\end{array}$ & Very significant & Significant & $\begin{array}{l}\text { Not at all } \\
\text { significant }\end{array}$ & $N / A$ \\
\hline $\begin{array}{l}\text { e. Returning home due to difficulty in the } \\
\text { gaining legal status after graduation }\end{array}$ & Very significant & Significant & $\begin{array}{l}\text { Not at all } \\
\text { significant }\end{array}$ & $N / A$ \\
\hline
\end{tabular}

